\title{
Algoritmos Paralelos para o Paradigma de Pertinência Interior/Exterior
}

\author{
Marcos Machado Ottani Assis
}

\section{DISSERTAÇÃO DE MESTRADO APRESENTADA AO INSTITUTO DE MATEMÁTICA E ESTATÍSTICA \\ DA UNIVERSIDADE DE SÃO PAULO}

Curso: Mestrado em Ciência da Computação Área de Concentração: Computação Gráfica

Orientador: Prof. Dr. Antonio Elias Fabris

18 de Janeiro de 2001 


\title{
Algoritmos Paralelos para o Paradigma de Pertinência Interior/Exterior
}

\author{
Este exemplar corresponde à redação \\ final da dissertação devidamente corrigida \\ e defendida por Marcos Machado Ottani Assis \\ e aprovada pela comissão julgadora.
}

São Paulo, 18 de Janeiro de 2001.

Banca examinadora:

- Prof. Dr. Antonio Elias Fabris (orientador) (IME-USP)

- Prof. Dr. Kunio Okuda (IME-USP)

- Profa. Dra. Liria Matsumoto Sato (EP-USP) 


\begin{abstract}
The Point Containment predicate which specifies if a point is part of a mathematically welldefined object is a crucial problem in computer graphics. Point-driven algorithms can be executed for several points in parallel as there is no interdependence among the computations for different points. This work presents a variety of parallel implementations for filling and stroking operations to counteract the main disadvantage of the point-driven algorithm: its slowness on a standard uniprocessor software implementation for interactive editing and manipulation.
\end{abstract}

\title{
Resumo
}

O teste interior/exterior, que especifica se um ponto é parte de um objeto matematicamente bem definido, é um problema crucial em Computação Gráfica. Algoritmos baseados nesse teste podem ser executados para diversos pontos em paralelo, uma vez que não há dependência entre as computações para diferentes pontos. Esta dissertação apresenta uma variedade de implementações paralelas para operações de preenchimento e traçado de linhas para combater a principal desvantagem desse tipo de algoritmo: sua lentidão em uma implementação seqüencial em software para edição e manipulação interativa. 


\section{Agradecimentos}

Gostaria de agradecer, em primeiro lugar, ao meu orientador, por todo o apoio e estímulo dados em minha graduação e no mestrado, e por ter feito com que o estudo da Computação Gráfica e o meu desenvolvimento como estudante tenham sido feitos da melhor forma possível.

Também gostaria de agradecer a meus colegas, Cassio, Eduardo e Ronney, que muito me ajudaram em várias ocasiões durante todos esses anos de faculdade. E que a amizade que surgiu na faculdade se mantenha fora dela.

Não poderia esquecer de meus pais, uma vez que só foi possível atingir o objetivo de completar mais esta etapa da vida com o apoio deles.

Finalmente gostaria de agradecer à Diana, por todos esses anos em que estivemos juntos e por tudo o que fez por mim. 


\section{Sumário}

$\begin{array}{ll}\text { Lista de Figuras } & 5\end{array}$

$\begin{array}{lc}\text { Lista de Tabelas } & 8\end{array}$

1 Introdução $\quad 9$

2 Curvas Discretas 12

2.1 Curvas Discretas . . . . . . . . . . . . . . . . . . . . 12

2.2 Curvas de Bézier Discretas . . . . . . . . . . . . . . . . . . 13

2.3 Teste Interior $/$ Exterior . . . . . . . . . . . . . . . . . . 15

2.3.1 Custo de um teste interior/exterior . . . . . . . . . . . . . 18

3 Preenchimento de Regiões (Filling) 19

3.1 Versão Quadrática . . . . . . . . . . . . . . . . . . . . . . 20

3.2 Coerência com Quadtrees . . . . . . . . . . . . . . . . . . . 21

3.3 Coerência Maximal . . . . . . . . . . . . . . . . . . . . 23

3.4 Comparação Teórica entre os Algoritmos de Preenchimento Seqüenciais . . . 25

4 Traçado de Linhas (Stroking) 26

4.1 Versão Quadrática . . . . . . . . . . . . . . . . . . . . . 28

4.2 Coerência com Quadtrees . . . . . . . . . . . . . . . . . . 28

4.3 Pi-Coerência . . . . . . . . . . . . . . . . . . . . . . . . . . 29

4.4 Comparação Teórica entre os Algoritmos de Stroking Seqüenciais . . . . . . . 31

5 Paralelismo 33

5.1 Conceitos Básicos de Computação Paralela . . . . . . . . . . . . . . . . 33 
5.1.1 Memória Compartilhada x Memória Distribuída . . . . . . . . . . . 33

5.1 .2 Tipos de Máquinas Paralelas . . . . . . . . . . . . . . . . . . . 34

5.1.3 Topologias nas Conexões entre os Processadores . . . . . . . . . . . 35

5.2 Balanceamento de Carga . . . . . . . . . . . . . . . . 35

5.3 Partição do Problema . . . . . . . . . . . . . . . . . . . . . 36

5.4 Análise da Performance . . . . . . . . . . . . . . . . . . . . . 37

5.4 Análise Teórica . . . . . . . . . . . . . . . . . . . 37

5.4 .2 Análise Prática . . . . . . . . . . . . . . . . . . . 37

5.5 O Projeto Pixelflow . . . . . . . . . . . . . . . . . . . . 38

6 Preenchimento de Regiões em Paralelo 39

6.1 Versão Quadrática . . . . . . . . . . . . . . . . . . . . . . 39

6.1 .1 Memória Compartilhada . . . . . . . . . . . . . . . . . . 39

6.1.2 Memória Distribuída . . . . . . . . . . . . . . . . . 40

6.2 Coerência com Quadtrees. . . . . . . . . . . . . . . . . . . 42

6.2 .1 Memória Compartilhada . . . . . . . . . . . . . . . . . 43

6.2 .2 Memória Distribuída . . . . . . . . . . . . . . . . . 43

6.3 Coerência Maximal . . . . . . . . . . . . . . . . . . . . . 45

6.3 .1 Memória Compartilhada . . . . . . . . . . . . . 45

6.3 .2 Memória Distribuída . . . . . . . . . . . . . . . 46

6.4 Comparação Teórica entre os Algoritmos de Preenchimento Paralelos ... 48

6.4 Memória Compartilhada . . . . . . . . . . . . . . . 48

6.4 .2 Memória Distribuída . . . . . . . . . . . . . . . . 48

6.4.3 Tabela Comparativa . . . . . . . . . . . . . . . . 49

6.4.4 Fixando a curva e o tamanho da imagem . . . . . . . . . . . . . . 49

6.5 Resultados Práticos . . . . . . . . . . . . . . . . . . . 50

6.5.1 Memória Compartilhada . . . . . . . . . . . . . . . 52

6.5 .2 Memória Distribuída . . . . . . . . . . . . . . . 53

6.6 Análise dos Dados . . . . . . . . . . . . . . . . . . . . . 54

6.6.1 Memória Compartilhada . . . . . . . . . . . . . . . . 54

6.6 .2 Memória Distribuída . . . . . . . . . . . . . . . . . . . 55 
6.6 .3 Tabela Comparativa . . . . . . . . . . . . . . . . . 56

7 Traçado de Linhas em Paralelo $\quad 57$

7.1 Versão Quadrática . . . . . . . . . . . . . . . . . . 57

7.1.1 Memória Compartilhada . . . . . . . . . . . . . . . . 58

7.1 .2 Memória Distribuída . . . . . . . . . . . . . 58

7.2 Coerência com Quadtrees . . . . . . . . . . . . . . . . . . . . 59

7.2 .1 Memória Compartilhada . . . . . . . . . . . . 60

7.2 .2 Memória Distribuída . . . . . . . . . . . . . . 60

7.3 Pi-Coerência . . . . . . . . . . . . . . . . . . 62

7.3.1 Memória Compartilhada . . . . . . . . . . . . . 62

7.3 .2 Memória Distribuída . . . . . . . . . . . . . 63

7.4 Comparação Teórica entre os Algoritmos de Stroking Paralelos . . . . . . . . 64

7.4.1 Memória Compartilhada . . . . . . . . . . . . . . . . . . 64

7.4 .2 Memória Distribuída . . . . . . . . . . . . . . . . . . 64

7.4 .3 Tabela Comparativa . . . . . . . . . . . . . . . 65

7.4.4 Fixando a curva, a brush e o tamanho da imagem . . . . . . . . . 65

7.5 Resultados Práticos . . . . . . . . . . . . . . . . . . . 66

7.5.1 Memória Compartilhada . . . . . . . . . . . . . . 68

7.5.2 Memória Distribuída . . . . . . . . . . . . . . 69

7.6 Análise dos Dados . . . . . . . . . . . . . . . . . . . . . . 70

7.6 .1 Memória Compartilhada . . . . . . . . . . . . . . . 70

7.6 .2 Memória Distribuída . . . . . . . . . . . . . . . . . 71

7.6.3 Tabela Comparativa . . . . . . . . . . . . . . . 72

8 Conclusões $\quad 73$

$\begin{array}{ll}\text { Referências Bibliográficas } & 75\end{array}$ 


\section{Lista de Figuras}

2.1 Formas conexas estruturais de $\mathbb{Z}^{2}$ : 4-conexa, 6-conexa e 8-conexa . . . . . . 12

2.2 Listas conexas em $\mathbb{Z}^{2}:$ 4-conexa, 6-conexa e 8-conexa . . . . . . . . . . 13

2.3 Uma curva de Bézier de grau $3 \ldots \ldots$. . . . . . . . . . . . . . 14

2.4 Divisão da curva da Figura 2.3 . . . . . . . . . . . . . . . . . . . . 14

2.5 Segmentos da lista $L$ imersos em $\mathbb{R}^{2} \ldots \ldots \ldots \ldots \ldots$

2.6 Teste interior/exterior de $P$ com relação a $C \ldots \ldots \ldots$. . . . . . . 17

3.1 Preenchimento de uma região . . . . . . . . . . . . . . . . . . . . 19

3.2 Algoritmo quadrático para preenchimento de regiões . . . . . . . . . . . . . 20

3.3 Testes de coerência de três regiões com relação a uma curva fechada . . . . . 21

3.4 Divisão recursiva de uma imagem . . . . . . . . . . . . . . . . . . 22

3.5 Subdivisão de uma imagem em regiões não maximais . . . . . . . . . . . . 23

3.6 Propagação da cor interior a partir do ponto $Q$ vizinho de $P$. . . . . . . . 24

4.1 Traçado de uma linha. . . . . . . . . . . . . . . . . . 26

4.2 Soma de Minkowski que define a Figura $4.1 \ldots \ldots$. . . . . . . . . . 27

4.3 Teste interior/exterior utilizado na operação de stroking . . . . . . . . . . . . 27

4.4 Versão mais simples do teste interior/exterior para stroking . . . . . . . . . . 28

4.5 Apenas mais alguns teste precisam ser feitos quando a brush anda sobre a curva 30

4.6 Oito direções a serem consideradas no deslocamento da brush . . . . . . . . . 30

5.1 Memória Compartilhada X Memória Distribuída . . . . . . . . . . . . . . 34

5.2 Alguns exemplos de topologias existentes . . . . . . . . . . . . . . . 35 
6.1 Divisão de uma imagem entre quatro processadores - Algoritmo Filling Quadrático Paralelo . . ....

6.2 Divisão de uma imagem entre quatro processadores com transferência de trabalho - Algoritmo Filling com Quadtrees Paralelo . . . . . . . . . . . . . . 42

6.3 Preenchimento de uma região em paralelo utilizando memória compartilhada 45

6.4 Divisão da imagem entre quatro processadores . . . . . . . . . . . . . . . . 46

6.5 Curva da Imagem Teste $1 \ldots \ldots$. . . . . . . . . . . . . . . . . 50

6.6 Imagem Teste $1 \ldots \ldots \ldots \ldots$. . . . . . . . . . . . . . . . . . . . . . . . .

6.7 Curva da Imagem Teste $2 \ldots \ldots \ldots \ldots$. . . . . . . . . . . . . . . 51

6.8 Imagem Teste $2 \ldots \ldots \ldots \ldots \ldots \ldots$

6.9 Tempos de execução para os algoritmos paralelos de preenchimento utilizando memória compartilhada . . . . . . . . . . . . . . . . . . 52

6.10 Tempo de execução para os algoritmos paralelos de preenchimento utilizando memória distribuída . . . . . . . . . . . . . . . . . . . 53

6.11 Speed-ups para os algoritmos paralelos de preenchimento utilizando memória compartilhada . . . . . . . . . . . . . . . . . 54

6.12 Speed-ups para os algoritmos paralelos de preenchimento utilizando memória distribuída . . . . . . . . . . . . . . . . . 56

7.1 Divisão de uma imagem entre quatro processadores . . . . . . . . . . . 57

7.2 Divisão de uma imagem entre quatro processadores com transferência de trabalho . . . . . . . . . . . . . . . . . . . . 59

7.3 Traçado de uma linha em paralelo . . . . . . . . . . . . . . . . 62

7.4 Curva da Imagem Teste $3 \ldots \ldots \ldots 6$

7.5 Brush da Imagem Teste $3 \ldots \ldots$. . . . . . . . . . . . . . . . 66

7.6 Imagem Teste $3 \ldots \ldots \ldots$. . . . . . . . . . . . . . . . . . . . . . . .

7.7 Curva da Imagem Teste $4 \ldots \ldots \ldots$. . . . . . . . . . . . . . . . 67

7.8 Brush da Imagem Teste $4 \ldots \ldots \ldots$. . . . . . . . . . . . . . . 67

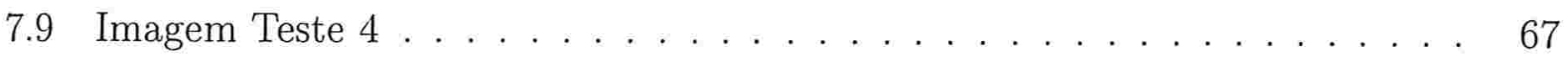

7.10 Tempo de execução para os algoritmos paralelos de stroking utilizando memória compartilhada . . . . . . . . . . . . . . . . 68

7.11 Tempo de execução para os algoritmos paralelos de stroking utilizando memória distribuída 
7.12 Speed-ups para os algoritmos paralelos de stroking utilizando memória compartilhada . . . . . . . . . . . . . . . . . .

7.13 Speed-ups para os algoritmos paralelos de stroking utilizando memória distribuída . . . . . . . . . . . . . . . . . . . . 


\section{Lista de Tabelas}

2.1 Simulação de um teste interior/exterior . . . . . . . . . . . . . . . . 18

3.1 Comparação teórica entre os algoritmos de preenchimento seqüenciais . . . . 25

4.1 Comparação teórica entre os algoritmos de stroking seqüenciais . . . . . . . . . 31

6.1 Comparação teórica entre os algoritmos de preenchimento paralelos . . . . . 49

6.2 Comparação teórica entre os algoritmos de preenchimento paralelos fixando a curva e o tamanho da imagem . . . . . . . . . . . . . . . . . 49

6.3 Comparação prática entre os algoritmos de preenchimento paralelos . . . . . 56

7.1 Comparação teórica entre os algoritmos de stroking paralelos . . . . . . . . . 65

7.2 Comparação teórica entre os algoritmos de stroking paralelos fixando a curva, a brush e o tamanho da imagem . . . . . . . . . . . . . 65

7.3 Comparação prática entre os algoritmos de stroking paralelos . . . . . . . . . 72

8.1 Comparação final entre todos os algoritmos descritos . . . . . . . . . . . . 74 


\section{Capítulo 1}

\section{Introdução}

O teste interior/exterior (Point Containment Test), que especifica se um dado ponto é parte de um objeto definido matematicamente, é um problema crucial em Computação Gráfica. Além disso, é uma ferramenta muito utilizada em diversos problemas de Computação Gráfica, por ser uma forma natural de implementação.

Nesta dissertação será tratada a construção de algoritmos paralelos, utilizando o teste interior/exterior, para preenchimento de regiões fechadas (filling) e traçado de linhas (stroking). Tais operações são as ferramentas básicas de muitos sistemas de geração de imagens por computador, como por exemplo o PostScript.

Outra classe de algoritmos muito utilizados na resolução desse tipo de problema é o scan-conversion (e.g. [Fol96]), que utiliza linhas de varredura paralelas na imagem. A principal vantagem dessa classe de algoritmos é o baixo tempo de processamento necessário, linear com relação à resolução da imagem. Entretanto, essa abordagem exige pré-processamento dos objetos, como recorte e transformação de objetos complexos em outros mais simples.

Os algoritmos baseados no teste interior/exterior requerem um número de testes quadrático com relação à resolução da imagem (veja [NewS79]). Para contornar isso, Corthout et al. apresentam em [CorJ87, CorJ88, CorP89, CorP92] um algoritmo eficiente e robusto para o teste interior/exterior (baseado em uma versão discreta do Teorema de Jordan), que foi implementado em hardware no chip Pharos, e um modo de reduzir a complexidade do número de testes para quasi-linear utilizando coerência com quadtrees. Em [FabSF97, FabSF98], Fabris et al. apresentam os algoritmos de Coerência Maximal (para preenchimento de regiões) e Pi-Coerência (para stroking), que reduzem ainda mais a complexidade do número de testes necessários.

Utilizando o fato de que testes interior/exterior para pontos diferentes da imagem são 
independentes, desenvolvemos versões paralelas dos algoritmos citados acima que diminuem consideravelmente o tempo necessário para a produção da imagem sem introduzir muita complexidade aos algoritmos.

Brooks [Bro96] citando Poulton previu que se o desenvolvimento do hardware continuar seguindo a tendência atual, o número de pixels por primitiva renderizado por hardware se aproximará da unidade e, em tais circunstâncias, os pixels poderiam ser gerados diretamente da geometria original ao invés de se aproximar a geometria por polígonos ou segmentos de reta. O uso do teste interior/exterior é um exemplo dessa estratégia, possibilitando uma implementação paralela simples e gerando pixels diretamente da curva discreta,.o que evita as dificuldades numéricas apontadas por Klassen [Kla91] e Lien [Lien87] et al para a renderização robusta de curvas.

Em nossa implementação utilizamos um número baixo de processadores, mas apresentamos indícios com base teórica de que alguns algoritmos apresentados são eficientes para um número grande de processadores, podendo até ser utilizado um processador por pixel ou grupo pequeno de pixels, como o que ocorre com as máquinas PixelFlow [EylesMP97, MolEP92], em desenvolvimento pelo grupo de Computação Gráfica da Universidade da Carolina do Norte.

O uso de paralelismo proposto neste texto é justificado pela necessidade do estudo de algoritmos paralelos simples para as operações básicas de computação gráfica, como o filling e o stroking. Com isso esses algoritmos poderão ser implementados em hardware dedicado ou em software, seguindo a tendência de evolução atual dos computadores.

O trabalho apresentado aqui também pode ser encontrado em dois artigos do mesmo autor. Em [FabAF00] foram apresentados os algoritmos paralelos de preenchimento utilizando memória distribuída e em [FabAF01] serão apresentados os algoritmos paralelos de stroking. Ambos os artigos são versões resumidas de partes do conteúdo da presente dissertação.

Os próximos capítulos estão organizados da seguinte forma:

No Capítulo 2 serão apresentados o conceito de curvas discretas e o teste interior/exterior utilizado. A partir desses conceitos serão definidas as discretizações do preenchimento de regiões e do traçado de curvas nos capítulos subseqüentes. No final do capítulo será apresentado um algoritmo para o teste interior/exterior sobre curvas discretas.

Os Capítulos 3 e 4 são referentes à descrição e análise dos algoritmos seqüenciais de preenchimento e traçado de linhas, respectivamente. Em cada caso veremos um algoritmo quadrático e duas versões para redução da complexidade do número de testes necessários.

O Capítulo 5 apresenta uma breve revisão de alguns conceitos básicos de Computação 
Paralela utilizados neste texto.

A nossa principal contribuição concentra-se nos capítulos 6 e 7, onde são apresentados os algoritmos paralelos de preenchimento e traçado de linhas, respectivamente, juntamente com a análise comparativa dos algoritmos, uma análise com resultados reais e uma análise teórica prevendo o comportamento dos algoritmos para números maiores de processadores.

Finalmente, no Capítulo 8 são apresentadas as conclusões finais do trabalho e indicações de trabalhos futuros a serem pesquisados. 


\section{Capítulo 2}

\section{Curvas Discretas}

Neste capítulo apresentaremos o conceito de curva discreta. A partir desse conceito serão definidas as discretizações do preenchimento de regiões e do traçado de curvas. No final do capítulo será apresentado um algoritmo para o teste interior/exterior sobre curvas discretas.

\subsection{Curvas Discretas}

O conceito de curvas discretas requer o conceito de conectividade em $\mathbb{Z}^{2}$. Um conjunto de pontos de $\mathbb{Z}^{2}$ é $k$-conexo se cada ponto é vizinho de $k$ pontos. Na Figura 2.1 vemos alguns exemplos de formas conexas estruturais em $\mathbb{Z}^{2}$.

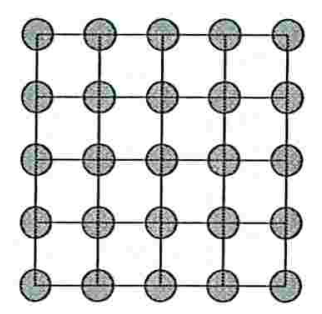

4-conexa

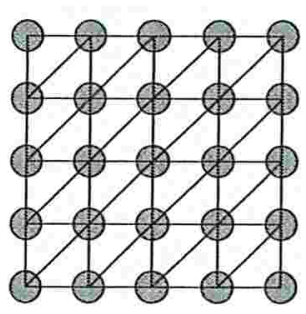

6-conexa

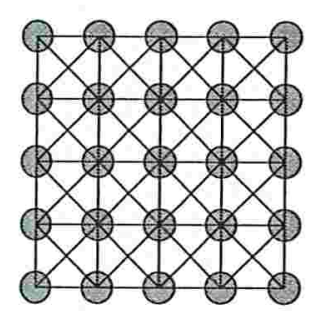

8-conexa

Figura 2.1: Formas conexas estruturais de $\mathbb{Z}^{2}$ : 4-conexa, 6-conexa e 8-conexa

A partir da definição de conectividade em $\mathbb{Z}^{2}$, podemos definir o conceito de distância entre pontos. Não utilizaremos a distância euclidiana e sim a definida contando-se o número de arestas percorridas num caminho mínimo entre dois pontos. Essa noção de distância é a mesma que é utilizada em grafos, quando os pesos de todas as arestas é o mesmo. Para uma 
definição formal veja [CorP92, Sil98].

Curvas discretas podem então ser definidas como uma seqüência ordenada de pontos com coordenadas inteiras cujas distâncias entre pontos consecutivos é menor ou igual a 1. São portanto representadas por listas conexas. A Figura 2.2 mostra exemplos de curvas discretas definidas por listas conexas.

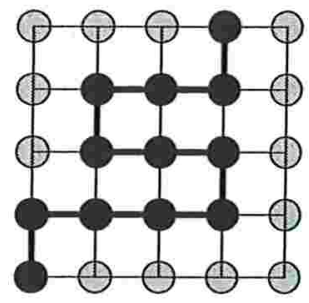

4-conexa

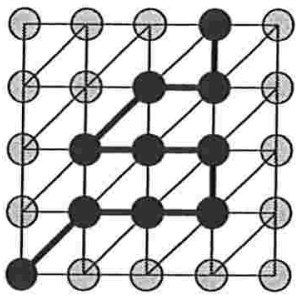

6-conexa

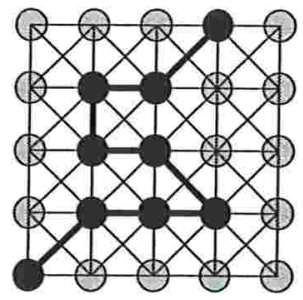

8-conexa

Figura 2.2: Listas conexas em $\mathbb{Z}^{2}$ : 4-conexa, 6-conexa e 8-conexa

É fácil notar que uma curva 4-conexa também pode ser considerada 6-conexa ou 8conexa e que uma curva 6-conexa também pode ser considerada 8-conexa. Por esse motivo consideramos todas as curvas em nossa implementação como 8-conexas, que são as mais utilizadas em Computação Gráfica.

Normalmente curvas discretas não são definidas pelo usuário em sua forma final, ou seja, como um conjunto de pontos. Na prática essas curvas são construídas a partir de pontos de controle fornecidos pelo usuário. Por exemplo: para se definir um segmento de reta bastam as coordenadas das extremidades e para se definir uma curva de Bézier basta se fornecer os pontos de controle da curva. O algoritmo poderá calcular os pontos da curva discreta apenas no momento em que forem necessários, economizando espaço em outros momentos.

\subsection{Curvas de Bézier Discretas}

O conceito de curva de Bézier discreta é semelhante ao conceito de curva de Bézier contínua. Entretanto, a teoria utilizada aqui (apresentada em [FabSF98]) é baseada inteiramente na matemática discreta.

Uma curva de Bézier de grau $n$ pode ser definida pelos seus $n+1$ pontos de controle. A Figura 2.3 mostra um exemplo de curva de Bézier de grau 3, definida pelos seus 4 pontos de controle. 


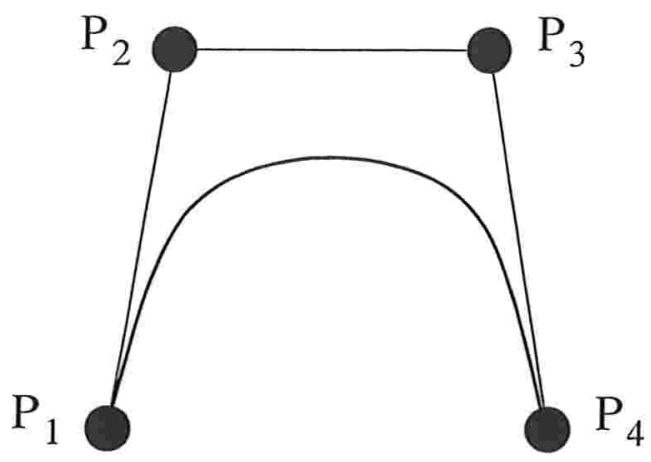

Figura 2.3: Uma curva de Bézier de grau 3

Uma operação essencial que pode ser definida sobre curvas de Bézier é a subdivisão. A subdivisão de uma curva de Bézier resulta em duas curvas de Bézier, chamadas de parte esquerda e parte direita que, concatenadas, compõe a curva original. A Figura 2.4 mostra um exemplo dessa operação.
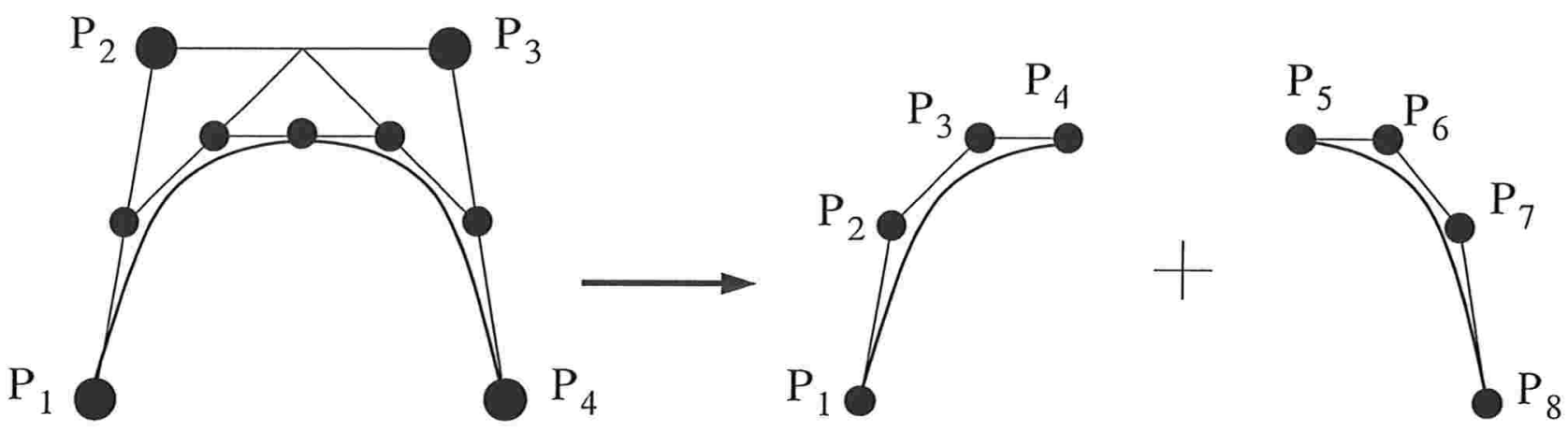

Figura 2.4: Divisão da curva da Figura 2.3

Para implementar subdivisão em um algoritmo que utiliza apenas números inteiros, deve-se mapear os pontos de controle das duas partes em $\mathbb{Z}^{2}$, usando funções de truncamento ou arredondamento.

Utilizando esses conceitos, pode-se construir um algoritmo recursivo para calcular os pontos de uma curva de Bézier com base nos pontos de controle fornecidos pelo usuário. Basta fazermos as subdivisões em duas partes recursivamente até atingir cada ponto da curva discreta, que formam a base da recursão (sabemos que um ponto da curva discreta foi atingido quando todos os pontos de controle coincidem). Os pontos da curva discreta gerados podem ser agrupados em uma lista conexa. Para uma definição mais completa veja [Far90]. 


\subsection{Teste Interior/Exterior}

O teste interior/exterior para regiões definidas por curvas discretas fechadas nãosimples utilizado aqui é baseado em uma versão discreta do Teorema de Jordan e foi inicialmente apresentado por Corthout et al. em [CorJ87, CorJ88, CorP89, CorP92] e posteriormente por Fabris et. al. em [FabF97a, FabF97b, FabSF97, FabSF98]. São algoritmos extremamente robustos, visto que decorrem de uma teoria desenvolvida tendo como base o plano discreto $\mathbb{Z}^{2}$.

Apesar de a implementação ser simples, os conceitos envolvidos na construção do algoritmo são bastante complexos. Portanto será apresentada aqui apenas uma breve descrição do funcionamento do algoritmo. Não é necessária a leitura desta seção para o entendimento dos próximos capítulos. Se o leitor desejar, basta saber o custo de um teste interior/exterior, que está indicado no final do capítulo.

O teste consiste em: dada uma lista $L$ representando uma curva fechada e um ponto $P$, descobrir se $P$ está na região interior ou exterior da curva. Para isso, a curva discreta é imersa em $\mathbb{R}^{2}$ e cada par de pontos consecutivos de $L$ passará a representar um segmento de reta, como mostra a Figura 2.5, transformando a curva discreta em um polígono contínuo. Deve-se notar que essa imersão em $\mathbb{R}^{2}$ é apenas conceitual e não precisa ocorrer na prática.

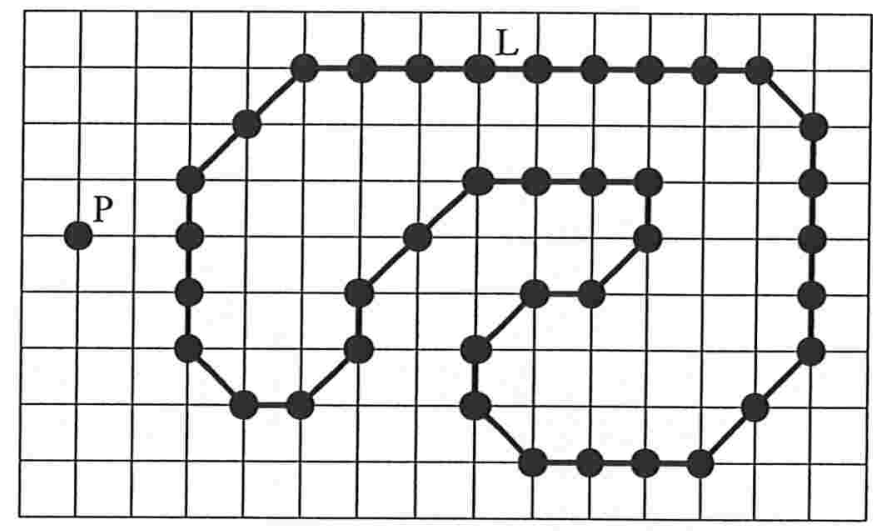

Figura 2.5: Segmentos da lista $L$ imersos em $\mathbb{R}^{2}$

Então será calculado o Número de Rotação do polígono. Para isso, deve-se calcular a contribuição de cada segmento, que é o número de cruzamentos feitos pela semi-reta partindo de $P$ em um sentido menos o número de cruzamentos no outro sentido. Se o número de rotação for igual a zero então $P$ está fora da curva. Senão $P$ está no interior da região definida pela curva.

Conforme descrito em [CorP92], um teste de contribuição de um segmento $\overline{A B}$ para o teste interior/exterior de um ponto $P$ consiste na avaliação de três regras: 
(R1) se $\left(P_{x}<\min \left\{A_{x}, B_{x}\right\}\right)$ ou $\left(P_{y} \leq \min \left\{A_{y}, B_{y}\right\}\right)$ ou $\left(P_{y}>\max \left\{A_{y}, B_{y}\right\}\right)$ então Contribuição $(A, B)_{P}=0$

(R2) se $\left(P_{x} \geq \max \left\{A_{x}, B_{x}\right\}\right)$ e $\left(P_{y}>\min \left\{A_{y}, B_{y}\right\}\right)$ e $\left(P_{y} \leq \max \left\{A_{y}, B_{y}\right\}\right)$ então Contribuição $(A, B)_{P}=\operatorname{sinal}\left(A_{y}-B_{y}\right)$

(R3) subdividida em duas condições:

- se $\overline{A B}$ for paralela ao eixo $x$ então Contribuição $(A, B)_{P}=0$

- se $\overline{A B}$ não for paralela ao eixo $x$ então seja $v$ um vetor perpendicular a $\overline{A B}$ tal que $v_{x}>0$ e $c=A \cdot v$

- se $P \cdot v \geq c$ então Contribuição $(A, B)_{P}=\operatorname{sinal}\left(A_{y}-B_{y}\right)$

- se $P \cdot v<c$ então Contribuição $(A, B)_{P}=0$

Para facilitar, podemos transladar todo o sistema, posicionando o ponto $P$ sobre a origem. Dessa forma teremos o seguinte algoritmo para o cálculo da contribuição de um segmento:

\section{Contribuição de um segmento para o número de rotação com relação à origem:}

Entrada: ponto A, ponto B

Saída: contribuição do segmento $\mathrm{AB}$

// calcula a bounding box do segmento

$\min x=\min (A \cdot x, B \cdot x)$

$\max x=\max (A \cdot x, B \cdot x)$

$\operatorname{miny}=\min (A \cdot y, B \cdot y)$

$\operatorname{maxy}=\max (A \cdot y, B \cdot y)$

// R1

se $(\min x>0)$ ou $(\min y>=0)$ ou $(\operatorname{maxy}<0)$ então retorne 0

// R2

$\mathrm{s}=\operatorname{sinal}(\mathrm{A} \cdot \mathrm{y}-\mathrm{B} \cdot \mathrm{y})$

se $(\max x<=0)$ então retorne $\mathrm{s}$

// primeira condição de R3

$\mathrm{V} \cdot \mathrm{x}=\mathrm{A} \cdot \mathrm{y}-\mathrm{B} \cdot \mathrm{y}$

$\mathrm{V} \cdot \mathrm{y}=\mathrm{B} \cdot \mathrm{x}-\mathrm{A} \cdot \mathrm{x}$

se $(V \cdot x=0)$ então retorne 0

// segunda condição de R3

se $(V \cdot x<0)$ então

$\mathrm{V} \cdot \mathrm{x}=-\mathrm{V} \cdot \mathrm{x}$

$\mathrm{V} \cdot \mathrm{y}=-\mathrm{V} \cdot \mathrm{y}$

se (produto_escalar $(A, V)>0$ ) então retorne 0

retorne $\mathrm{s}$ 
O algoritmo que faz o teste interior/exterior calculando a contribuição de cada segmento, posicionando o ponto $P$ na origem está descrito abaixo:

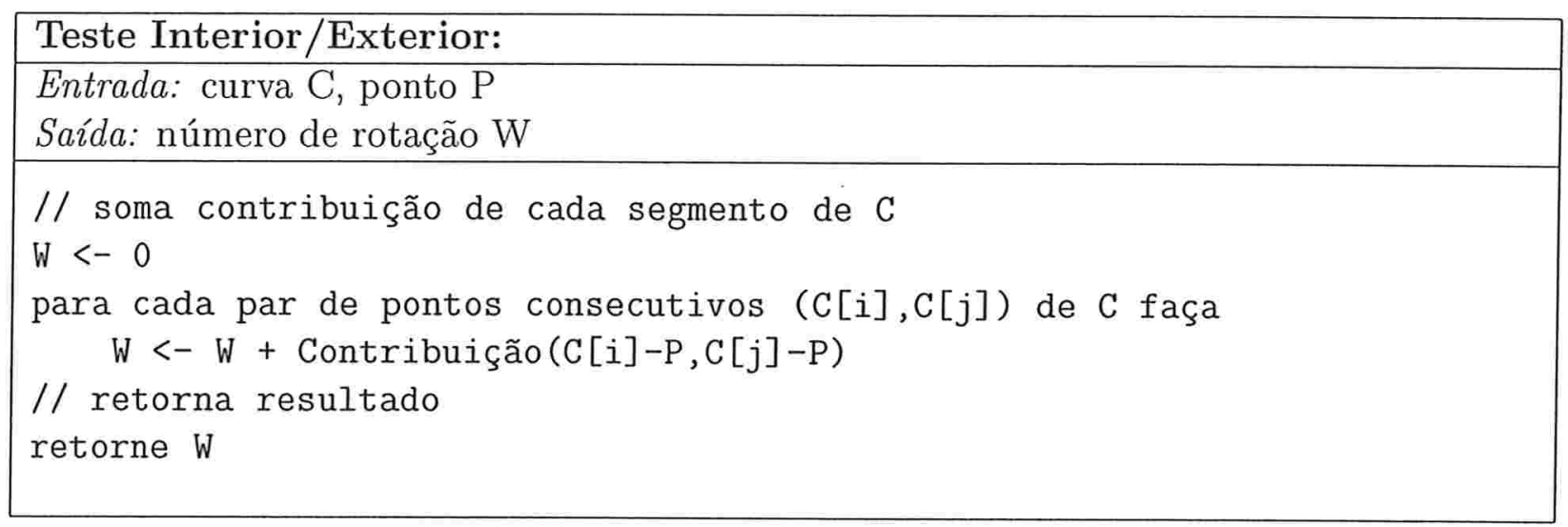

Na Figura 2.6 está indicada a simulação de um teste interior/exterior de um ponto $P$ sobre uma curva discreta $C$, ambos imersos em $\mathbb{R}^{2}$. Os valores das contribuições de cada segmento de reta $\overline{C_{i} C_{i+1}}$ estão na Tabela 2.1.

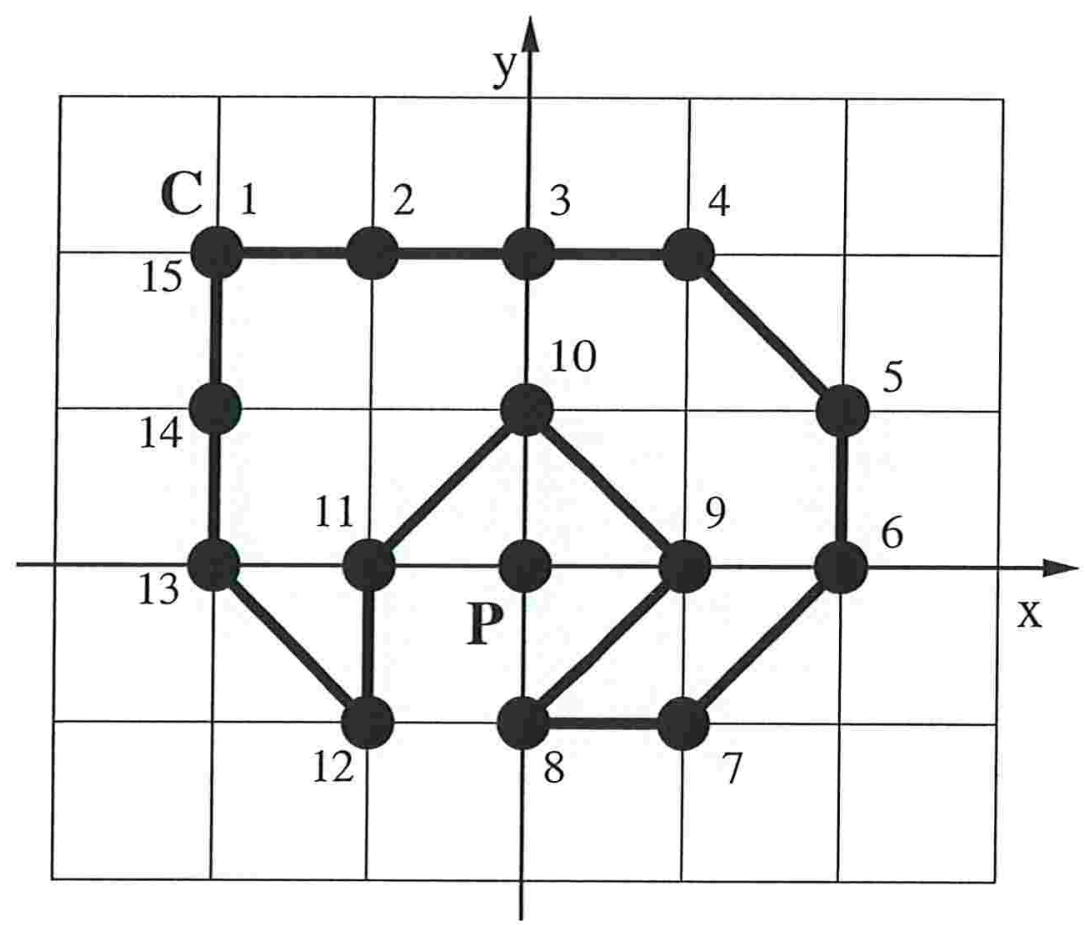

Figura 2.6: Teste interior/exterior de $P$ com relação a $C$ 


\begin{tabular}{|c|c|c|c|c|}
\hline$A$ & $B$ & Contribuição & Regra & Motivo \\
\hline 1 & 2 & 0 & $\mathrm{R} 1$ & $\min _{y} \geq 0$ \\
2 & 3 & 0 & $\mathrm{R} 1$ & $\min _{y} \geq 0$ \\
3 & 4 & 0 & $\mathrm{R} 1$ & $\min _{y} \geq 0$ \\
4 & 5 & 0 & $\mathrm{R} 1$ & $\min _{x}>0$ \\
5 & 6 & 0 & $\mathrm{R} 1$ & $\min _{x}>0$ \\
6 & 7 & 0 & $\mathrm{R} 1$ & $\min _{x}>0$ \\
7 & 8 & 0 & $\mathrm{R} 1$ & $\max _{y}<0$ \\
8 & 9 & 0 & $\mathrm{R} 3.2$ & $\mathrm{R} 1$ \\
9 & 10 & 0 & $\mathrm{R} 1$ & $\min _{y} \geq 0$ \\
10 & 11 & 0 & $\mathrm{R} 2$ & $\min _{y} \geq 0$ \\
11 & 12 & 1 & $\mathrm{R} 2$ & $\max \leq 0, A_{y}-B_{y}=1$ \\
12 & 13 & -1 & $\mathrm{R} 1$ & $\max \leq 0, A_{y}-B_{y}=-1$ \\
13 & 14 & 0 & $\min _{y} \geq 0$ \\
14 & 15 & 0 & $\mathrm{R} 1$ & $\min _{y} \geq 0$ \\
\hline
\end{tabular}

Tabela 2.1: Simulação de um teste interior/exterior

Somando as contribuições de todos os segmentos, teremos o valor total do teste interior/exterior para $P$, zero, indicando que $P$ está no exterior da região delimitada por $C$.

\subsubsection{Custo de um teste interior/exterior}

Nas análises dos algoritmos descritos nos próximos capítulos deverá ser considerado o tempo de processamento gasto em cada teste interior/exterior. Analisando o algoritmo descrito acima, podemos verificar que cada cálculo de contribuição requer um número fixo de passos e consome, portanto, tempo constante. Sendo $p$ o número de pontos (perímetro) da curva, serão feitos $p$ cálculos de contribuição, resultando em um tempo total $\mathrm{O}(p)$ para cada teste interior/exterior feito. 


\section{Capítulo 3}

\section{Preenchimento de Regiões (Filling)}

Preenchimento de regiões é a transformação de um caminho fechado em uma região, de forma que todos os pixels pertencentes a essa região sejam marcados (pintados) com a cor do objeto.
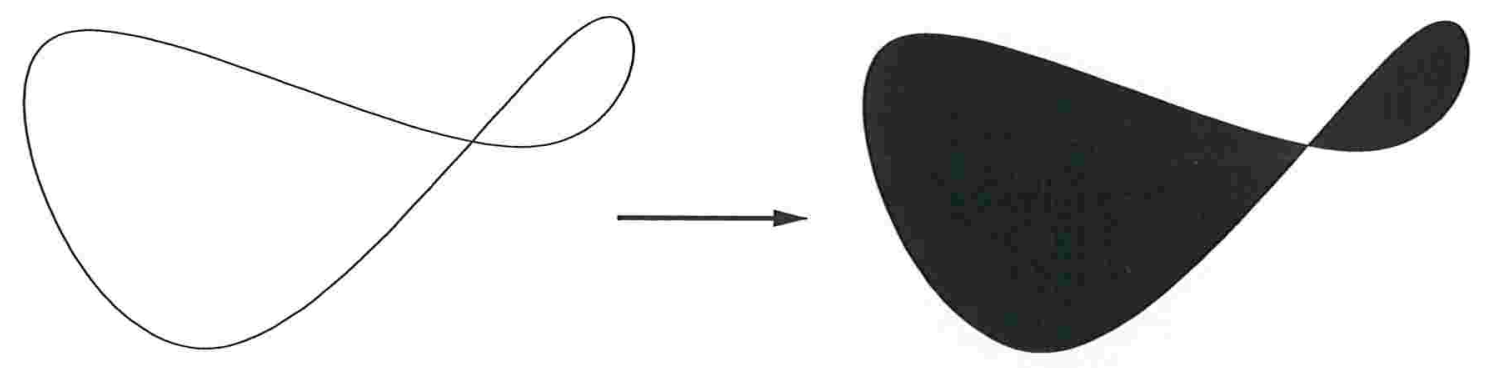

Figura 3.1: Preenchimento de uma região

Uma aplicação importante do preenchimento de regiões é na produção de caracteres. Define-se a borda que limita os caracteres (através de curvas de Bézier ou equivalentes) e preenche-se o seu interior. Desse modo o caractere pode ser ampliado ou rotacionado sem perda de qualidade, o que não ocorre em fontes definidas por bitmaps.

Conforme mencionado, a abordagem usual adotada no preenchimento de regiões é o scan-conversion, cujos algoritmos trabalham em geral com regiões poligonais simples (isto é, sem auto-interseções), sendo que outros tipos de curvas devem ser aproximadas por polígonos simples. Porém isso pode levar a inconsistências geométricas, causadas por problemas numéricos, como os descritos em [For85, For88, Fra86, Kla91].

Por outro lado, os algoritmos descritos em [FabSF97] para as operações de preenchimento de regiões são extremamente robustos, visto que decorrem de uma teoria desenvolvida tendo como base o plano discreto $\mathbb{Z}^{2}$, que resultou na obtenção do Teorema Discreto de Jor- 
dan para curvas fechadas não-simples. Nessa abordagem, a quantidade de pré-processamento diminui significativamente. Além disso, recorte explícito de objetos contra a imagem ou contra os outros objetos não é necessário, simplesmente para cada ponto da imagem, ou ele é afetado ou não.

Porém, vimos que essa abordagem em geral produz algoritmos mais lentos. Veremos, além de uma versão quadrática, dois algoritmos para redução da complexidade de tempo.

\subsection{Versão Quadrática}

Essa primeira versão simplesmente testa cada ponto da imagem contra o objeto (como mostra a Figura 3.2). Inicialmente a imagem deve ser toda preenchida com a cor de fundo.

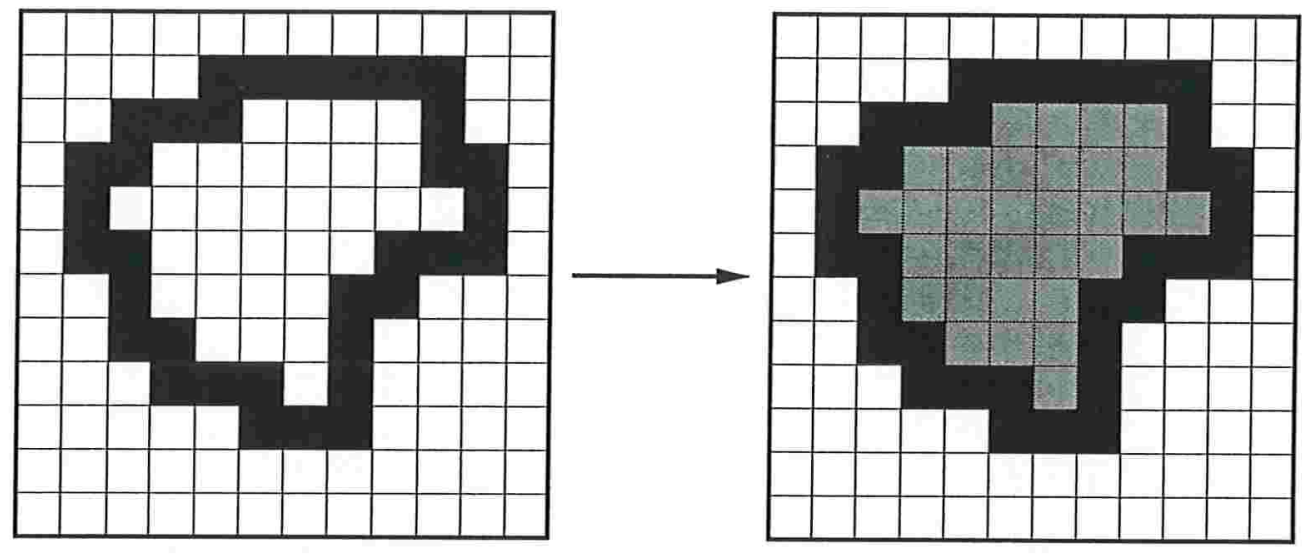

Figura 3.2: Algoritmo quadrático para preenchimento de regiões

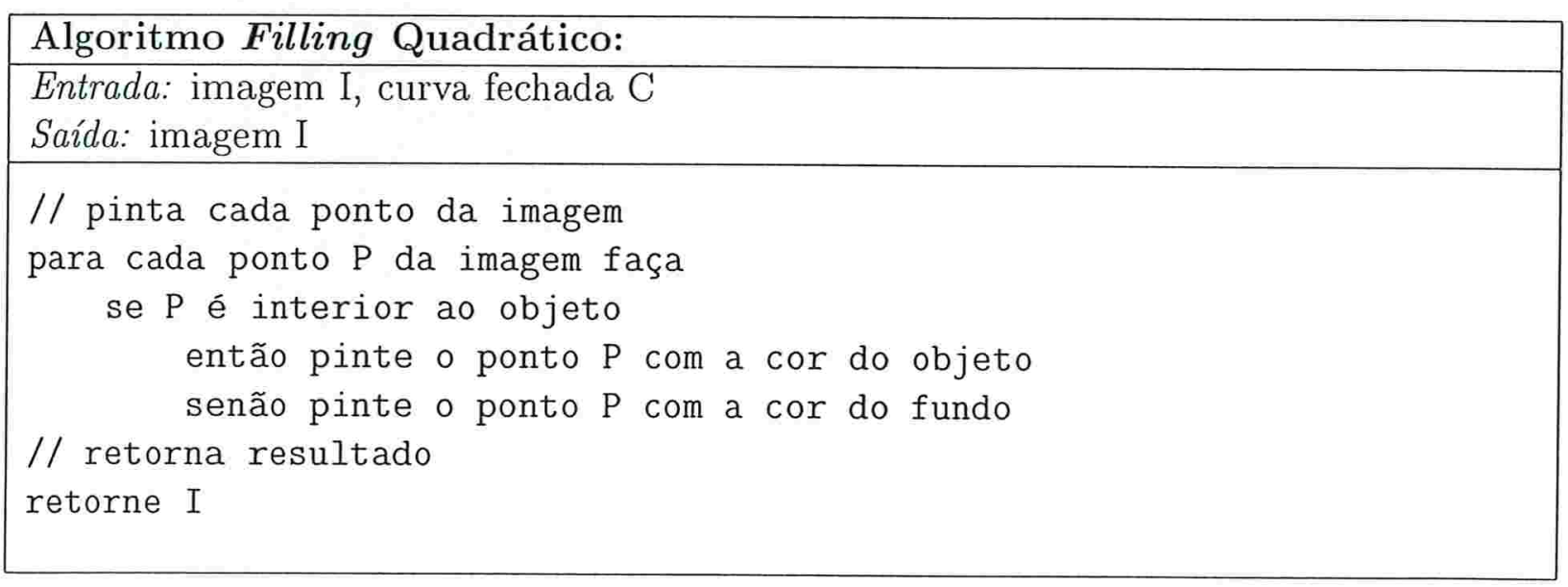


O algoritmo faz $\mathrm{O}\left(r^{2}\right)$ testes interior/exterior, cada um gastando tempo $\mathrm{O}(p)$, onde $r$ é a resolução da imagem (número de pixels em cada eixo). O número de atribuições de cor também é $\mathrm{O}\left(r^{2}\right)$, onde cada atribuição de cor é uma operação primitiva e gasta tempo constante.

O tempo total de execução do algoritmo será então $\mathrm{O}\left(r^{2} \cdot p+r^{2}\right)=\mathrm{O}\left(r^{2} \cdot p\right)$.

\subsection{Coerência com Quadtrees}

Uma região $R$ é dita coerente com relação a uma curva discreta fechada $\mathrm{C}$ se $R$ está totalmente contida no interior de $\mathrm{C}$ ou totalmente contida no exterior de C. A Figura 3.3 mostra três regiões $\left(R_{1}, R_{2}\right.$ e $\left.R_{3}\right)$ e uma curva fechada $C$. $R_{1}$ e $R_{2}$ são coerentes com relação a $C$, mas $R_{3}$ não, pois contém um trecho de $C$.

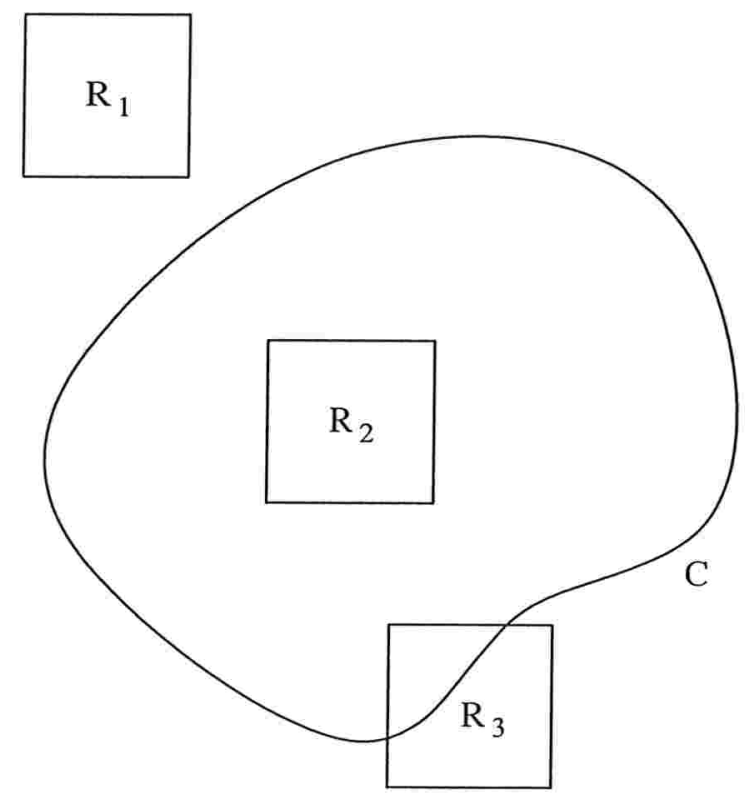

Figura 3.3: Testes de coerência de três regiões com relação a uma curva fechada

Para determinar se uma região $R$ é coerente com relação a uma curva fechada $C$, basta verificar se existe algum ponto de $C$ contido no interior de $R$. Se houver, $R$ não é coerente com relação a $C$. Caso contrário, $R$ é coerente com relação a $C$. Sendo a região de teste retangular e paralela aos eixos coordenados, testar se um ponto da curva está em seu interior gasta tempo $\mathrm{O}(1)$, pois tal teste de pertinência resume-se a comparar as coordenadas das extremidades de $R$ com as coordenadas do ponto. Se a curva tem $p$ pontos, um teste de coerência consumirá tempo $\mathrm{O}(p)$.

Utilizando o conceito de coerência, se encontrarmos uma região $R$ coerente com relação 
a uma curva fechada $C$, sabemos que os pontos de $R$ estão todos fora ou todos dentro de $C$. Então basta escolhermos um ponto qualquer de $R$ e fazermos o teste interior/exterior com relação a $C$. Se o teste indicar que o ponto pertence à região fechada delimitada pela curva, podemos pintar todos os pontos de $R$ com a cor interior. Se o ponto estiver no exterior da região delimitada pela curva, podemos pintar todos os pontos de $R$ com a cor exterior.

Em [CorP92] foi apresentado um algoritmo recursivo para o preenchimento de regiões baseado em coerência com quadtrees. Nesse algoritmo uma região não coerente com o objeto é dividida recursivamente em quatro partes (quadrantes). Parte-se da imagem toda e cada nó da folha pode chegar a um pixel, computando sempre regiões quadradas ou retangulares. Veja exemplo na Figura 3.4.

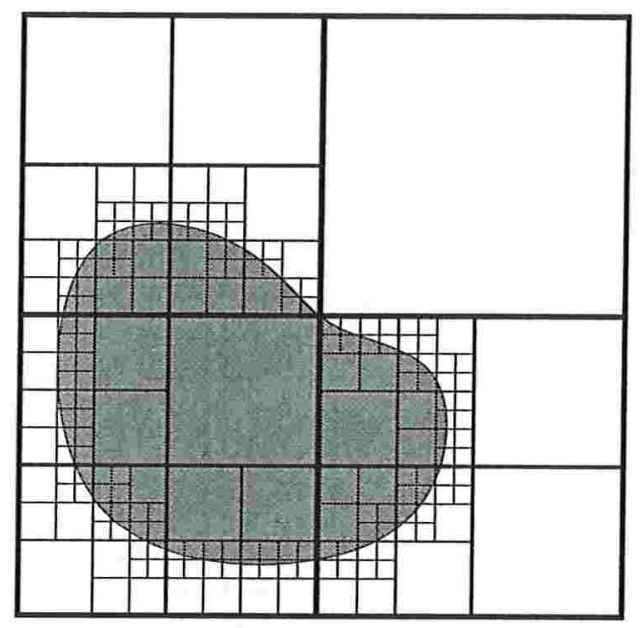

Figura 3.4: Divisão recursiva de uma imagem

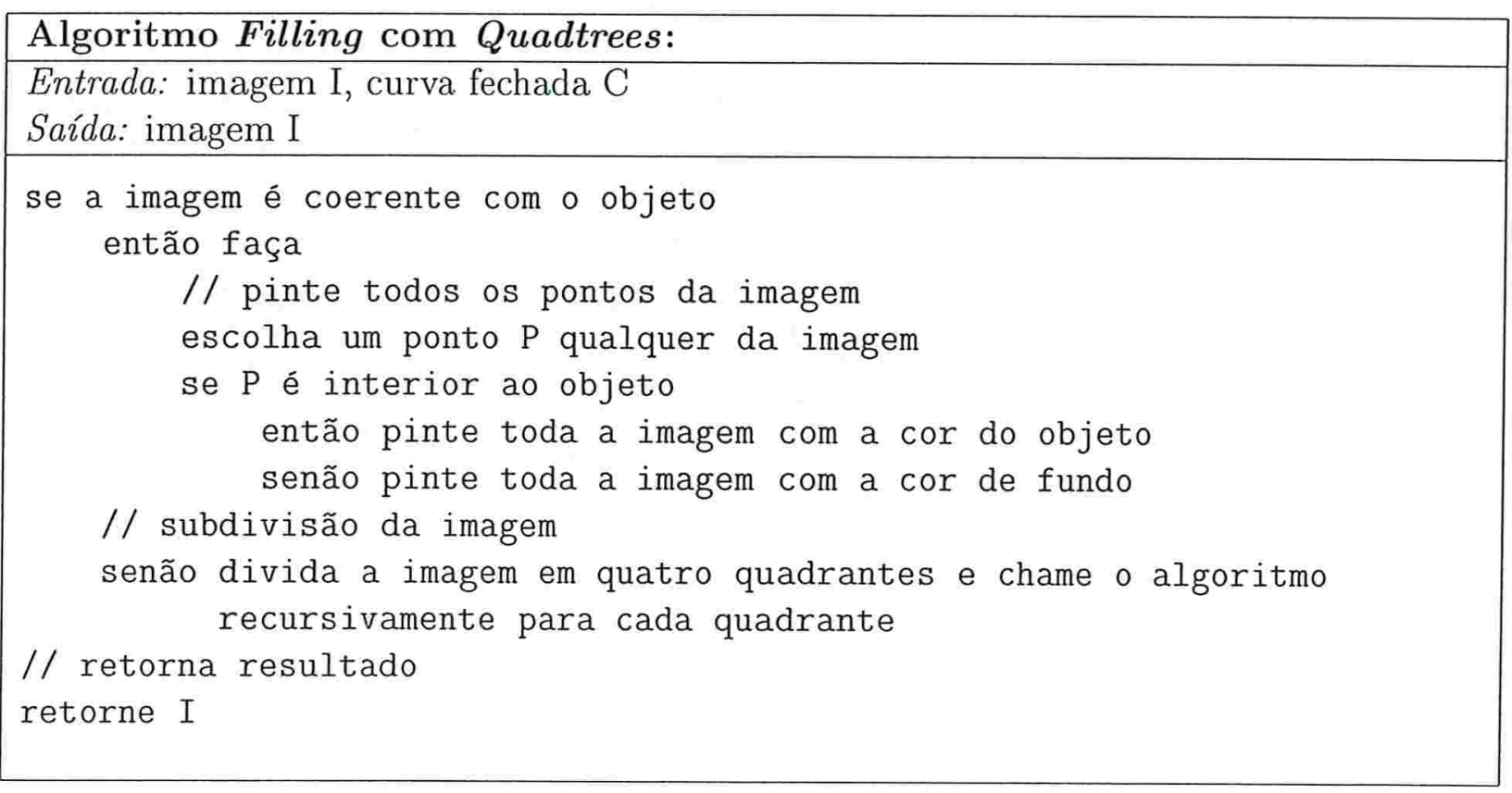


Note que a chamada inicial do algoritmo definido acima deve ser feita passando como parâmetro a imagem inteira. Cada chamada recursiva do algoritmo então será feita para uma parte da imagem.

Em [HunS79] foi provado que a quadtree que representa as chamadas recursivas ao algoritmo tem $\mathrm{O}(r+p)$ nós, onde $p$ é o perímetro da curva e $r$ é a resolução da imagem. Então o algoritmo será chamado $\mathrm{O}(r+p)$ vezes, fazendo um teste de coerência (de custo $\mathrm{O}(p))$ em cada vez. Além disso, apenas $\mathrm{O}(r+p)$ testes interior serão feitos (nas folhas da árvore), cada um gastando também $\mathrm{O}(p)$. Há também $\mathrm{O}\left(r^{2}\right)$ atribuições de cor. No total temos um tempo de execução $\mathrm{O}\left((r+p) \cdot p+(r+p) \cdot p+r^{2}\right)$, ou $\mathrm{O}\left(r \cdot p+p^{2}+r^{2}\right)$.

\subsection{Coerência Maximal}

A coerência com quadtrees reduz consideravelmente a complexidade de tempo do preenchimento. Porém é fácil notar que as regiões consideradas na subdivisão não são maximais, como mostra a Figura 3.5.

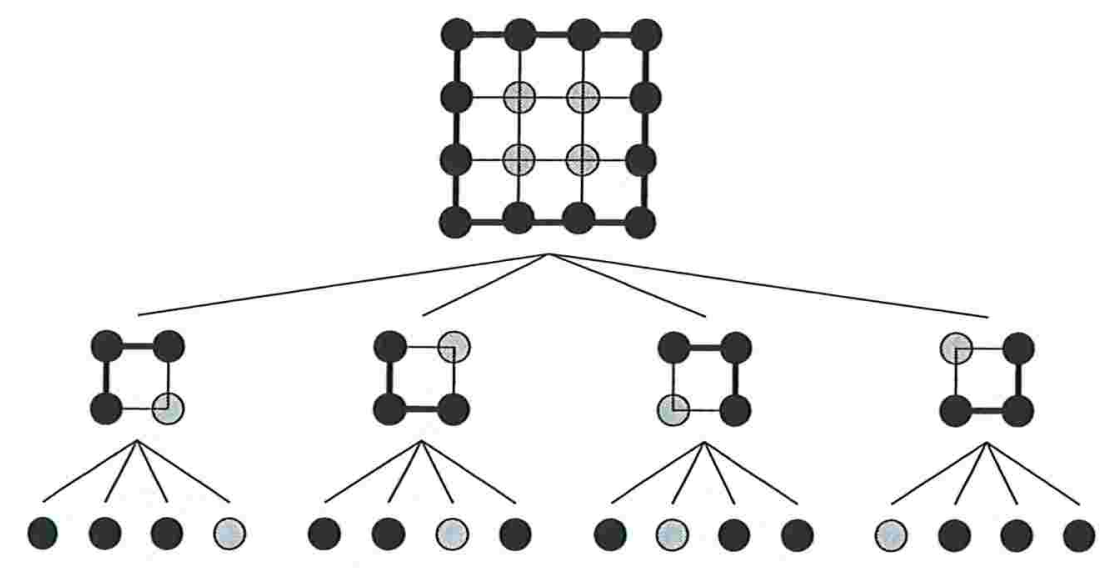

Figura 3.5: Subdivisão de uma imagem em regiões não maximais

A coerência maximal encontra as maiores regiões coerentes existentes na imagem. O funcionamento é simples: primeiro cada ponto da curva é marcado na imagem. Então, para cada ponto $P$ da curva, o preenchimento é iniciado a partir de cada vizinho 8-conexo de $P$ interior à curva ainda não preenchido (veja a Figura 3.6). A propagação pode ser feita utilizcindo-se uma fila, processo semelhante a uma busca em largura em um grafo. 


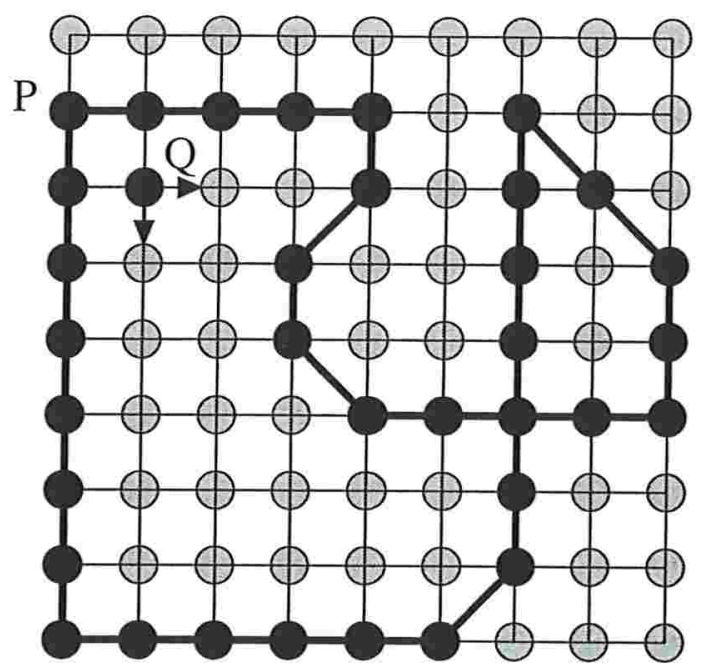

Figura 3.6: Propagação da cor interior a partir do ponto $Q$ vizinho de $P$

O processo de propagação da cor interior é conhecido como FloodFill (veja [Fol96]) e deve ser feito apenas entre vizinhos 4-conexos, para garantir que a propagação não atravesse a curva 8-conexa.

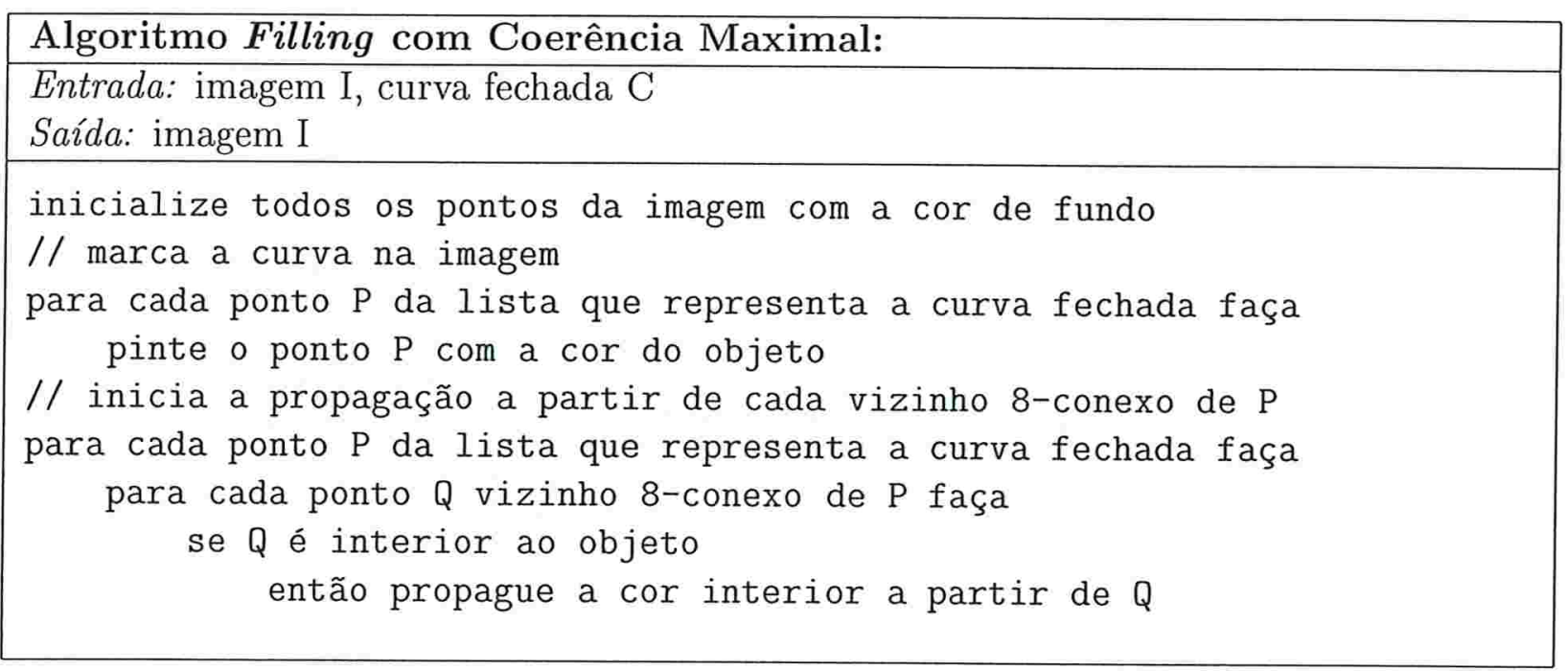

Esse algoritmo faz $\mathrm{O}(p)$ testes interior/exterior, pois para cada ponto da curva no máximo oito testes interior/exterior são feitos. A propagação da cor interior é feita para $\mathrm{O}\left(r^{2}\right)$ pontos, onde a propagação para cada ponto consome tempo constante, pois envolve apenas uma remoção do primeiro elemento de uma fila e no máximo quatro inserções nessa fila. No total teremos então tempo $\mathrm{O}\left(p \cdot p+r^{2}+r^{2}\right)$, ou $\mathrm{O}\left(p^{2}+r^{2}\right)$. 


\subsection{Comparação Teórica entre os Algoritmos de Pre- enchimento Seqüenciais}

$\mathrm{Na}$ Tabela 3.1 estão listadas as complexidades do número de testes e do tempo de execução para os três algoritmos apresentados, onde $r$ é a resolução da imagem e $p$ é o perímetro da curva.

\begin{tabular}{|l|c|c|}
\hline Algoritmo & Testes Interior/Exterior & Tempo de Execução \\
\hline Quadrático & $\mathrm{O}\left(r^{2}\right)$ & $\mathrm{O}\left(r^{2} \cdot p\right)$ \\
Coerência com Quadtrees & $\mathrm{O}(r+p)$ & $\mathrm{O}\left(p^{2}+r \cdot p+r^{2}\right)$ \\
Coerência Maximal & $\mathrm{O}(p)$ & $\mathrm{O}\left(p^{2}+r^{2}\right)$ \\
\hline
\end{tabular}

Tabela 3.1: Comparação teórica entre os algoritmos de preenchimento seqüenciais

Podemos observar que em uma análise assintótica, o algoritmo de coerência maximal é teoricamente mais rápido do que o preenchimento utilizando quadtrees e que este é teoricamente mais rápido do que o algoritmo de preenchimento quadrático, apesar de a primeira diferença ser menor do que a segunda. Mas deve-se notar que na prática o preenchimento com quadtrees pode ser mais rápido do que o utilizando coerência maximal para certas classes de curvas, como observado em [Sil98]. 


\section{Capítulo 4}

\section{Traçado de Linhas (Stroking)}

A operação de traçado de linhas destina-se a modelar a forma produzida quando uma caneta é movida sobre um papel ao longo de uma trajetória. A caneta é substituída por uma brush e o papel pelo reticulado de pixels que forma a imagem. O caminho percorrido pela brush pode ser definido por uma curva discreta. A brush pode ser definida por uma região limitada por uma curva discreta fechada.

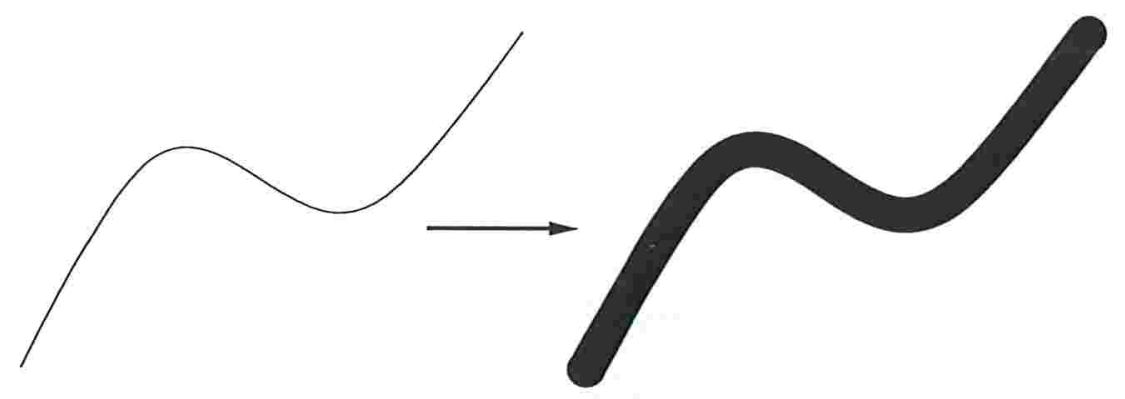

Figura 4.1: Traçado de uma linha

O stroking pode ser definido como uma dilatação (ou soma de Minkowski) de uma brush sobre uma curva. A Figura 4.2 mostra a soma de Minkowski que gera a Figura 4.1.

Como no caso do preenchimento de regiões, usualmente utiliza-se scan-conversion no traçado de linhas. Duas abordagens podem ser utilizadas: a primeira consiste em colocar a brush sobre cada ponto do caminho e marcar os pixels afetados [Whi83, BleSM88] e a segunda consiste em transformar o problema em um problema de preenchimento de regiões. Porém, se a complexidade geométrica dos objetos cresce, as equações tornam-se muito complexas, como descrito em [GhoM84]. Alternativamente, caminhos e brushes são usualmente aproximados, em uma fase de pré-processamento, por polígonos, como no sistema METAFONT de Knuth [Knu86]. 


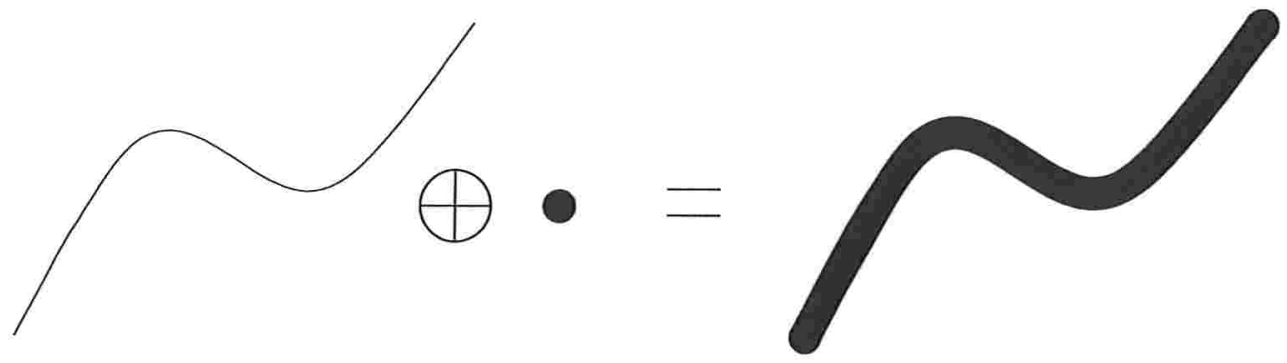

Figura 4.2: Soma de Minkowski que define a Figura 4.1

Os algoritmos descritos em [FabSF98] para a operação de stroking utilizam o paradigma de teste interior/exterior, assim como os vistos para a operação de preenchimento. Da mesma forma com o que ocorre para o preenchimento, nessa abordagem a quantidade de pré-processamento diminui significativamente.

Mas como essa abordagem em geral produz algoritmos mais lentos, veremos dois algoritmos para redução da complexidade de tempo, além de uma versão quadrática.

O teste interior/exterior de um ponto $P$ para uma região definida por uma dilatação de uma brush $B$ sobre uma curva discreta $C$ pode ser feito da forma ilustrada pela Figura 4.3: posiciona-se a brush sobre cada ponto da curva e testa-se se a brush contém $P$. O teste para cada ponto da curva é idêntico ao teste interior/exterior feito na operação de preenchimento e consome tempo de execução $\mathrm{O}\left(p_{B}\right)$, onde $p_{B}$ é o perímetro da curva que define a brush. Um teste interior/exterior então consome tempo de execução $\mathrm{O}\left(p_{B} \cdot p\right)$.

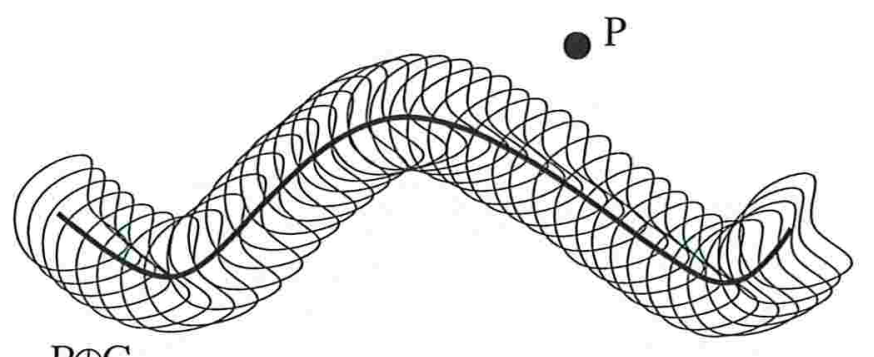

$\mathrm{B} \oplus \mathrm{C}$

Figura 4.3: Teste interior/exterior utilizado na operação de stroking

Uma versão alternativa (mais fácil de implementar), que gasta o mesmo tempo de execução, consiste em calcular o inverso de $B(-B)$, posicionar $-B$ sobre $P$ e testar se cada ponto da curva está no interior de $-B$. Pode-se ainda utilizar a bounding box da brush para diminuir o número de testes sobre $-B$, como mostra a Figura 4.4. 


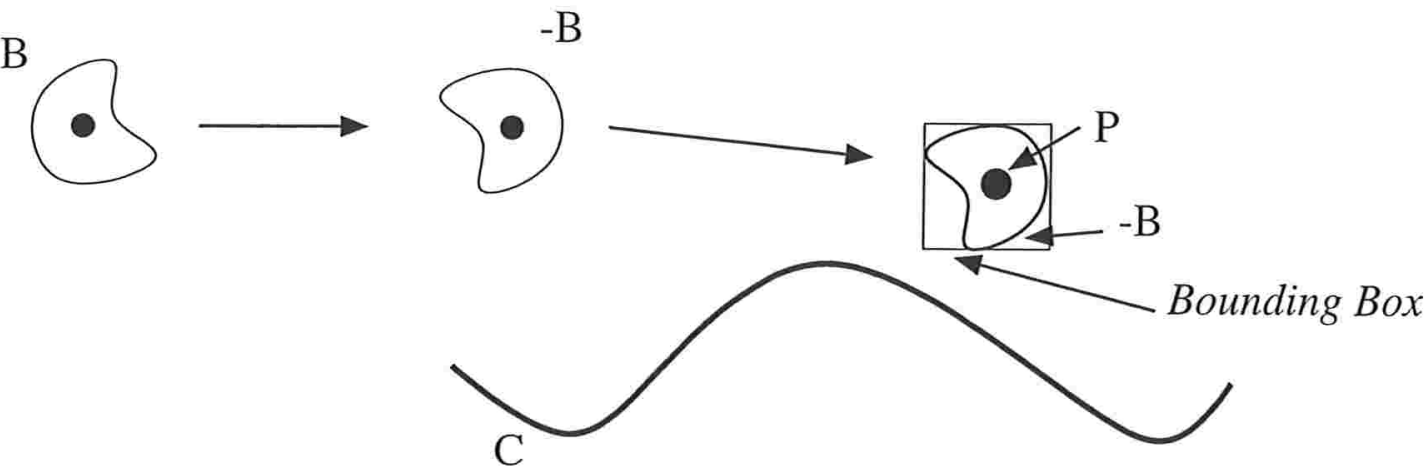

Figura 4.4: Versão mais simples do teste interior/exterior para stroking

\subsection{Versão Quadrática}

Essa primeira versão simplesmente testa cada ponto da imagem contra a curva dilatada pela brush.

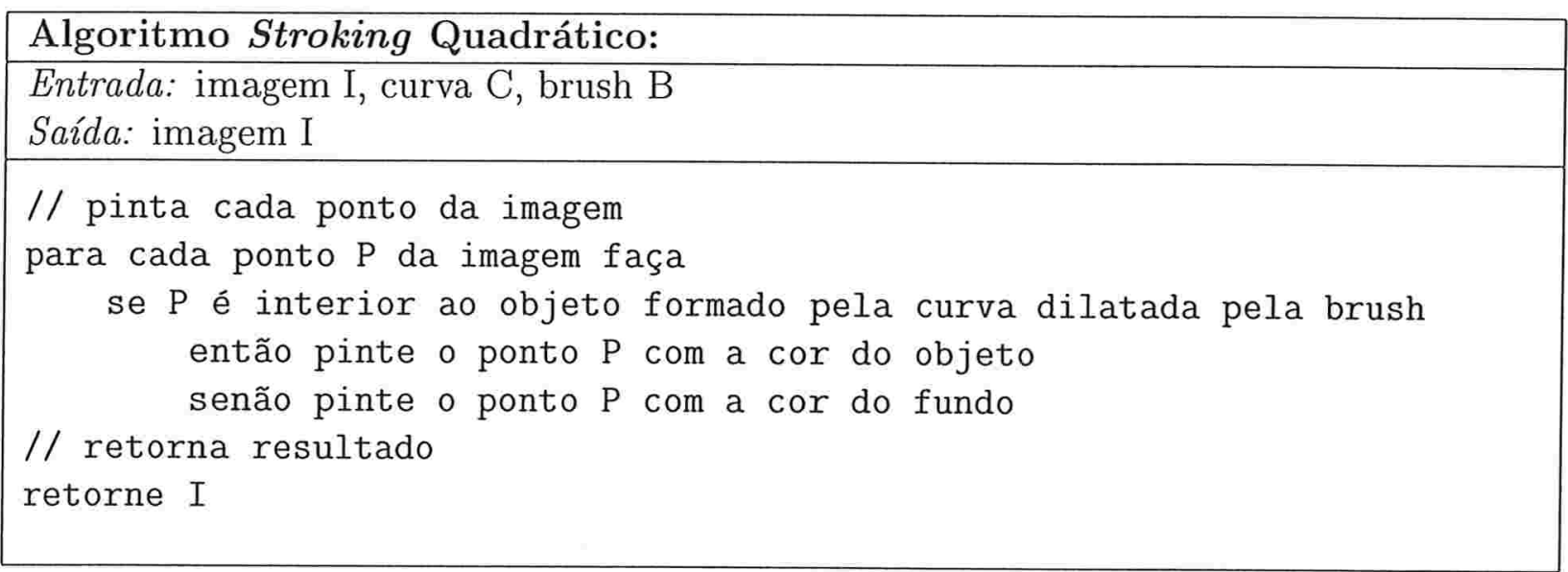

Essa versão do algoritmo faz $\mathrm{O}\left(r^{2}\right)$ testes interior/exterior e $\mathrm{O}\left(r^{2}\right)$ atribuições de cor aos pontos da imagem. O tempo total gasto é $\mathrm{O}\left(r^{2} \cdot\left(p_{B} \cdot p\right)+r^{2}\right)=\mathrm{O}\left(r^{2} \cdot p_{B} \cdot p\right)$.

\subsection{Coerência com Quadtrees}

Nesse algoritmo utilizamos o mesmo conceito de coerência visto anteriormente. Porém nesse caso a coerência será testada com relação à região de stroking, ao invés de testar a coerência com relação a uma curva fechada. 


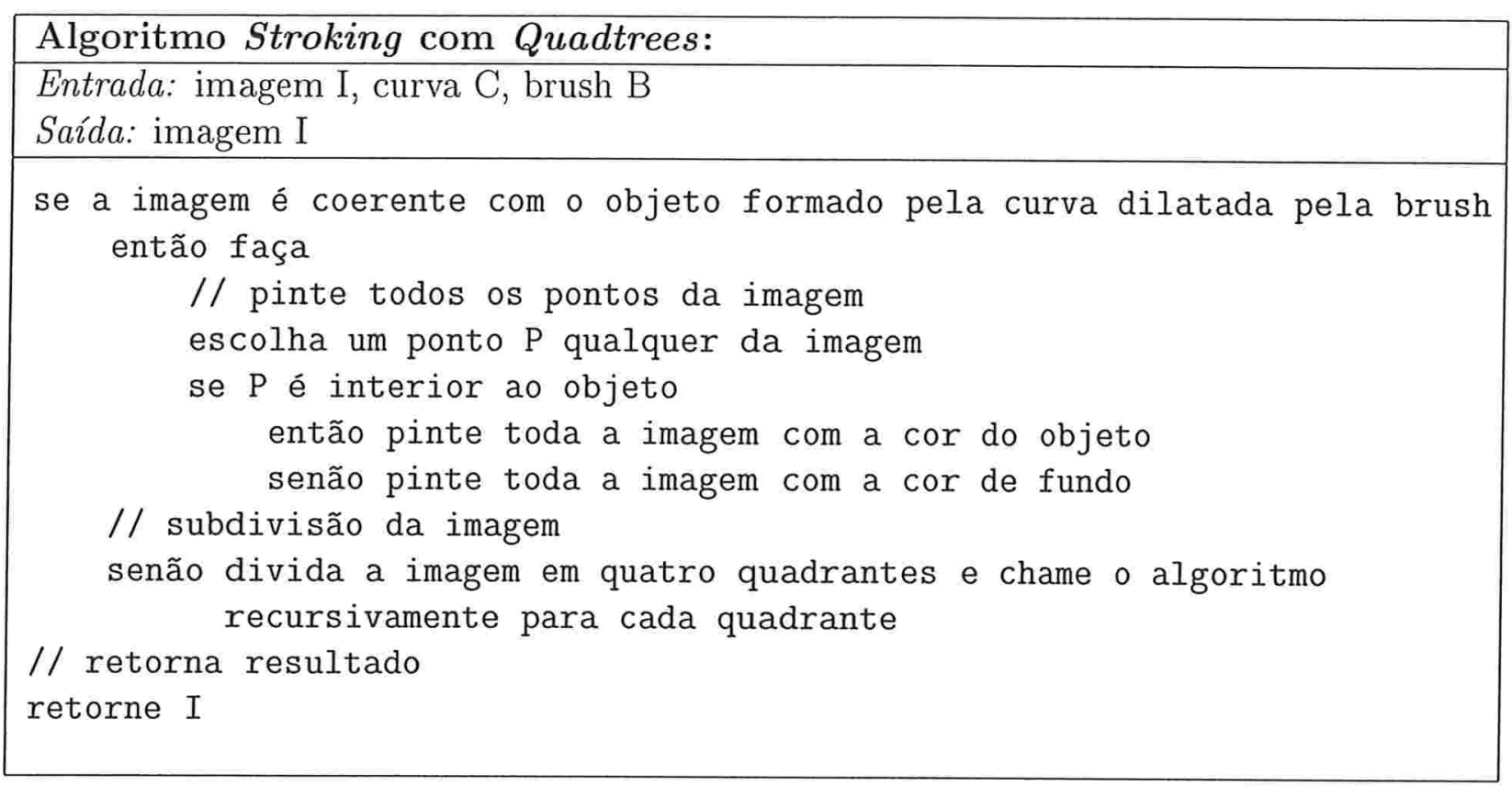

Note que a chamada inicial do algoritmo definido acima deve ser feita passando como parâmetro a imagem inteira. Cada chamada recursiva do algoritmo então será feita para uma parte da imagem.

O algoritmo é semelhante ao algoritmo de preenchimento com quadtrees. A chamada inicial é feita a partir da imagem inteira. Esse algoritmo faz $\mathrm{O}(b \cdot(r+p))$ testes interior/exterior [FabSF98], onde $r$ é a resolução da imagem, $p$ é o perímetro da curva e $b$ é o tamanho da bounding box da brush. O tempo total gasto é $\mathrm{O}\left(b \cdot(r+p) \cdot\left(p_{B} \cdot p\right)+r^{2}\right)=$ $\mathrm{O}\left(b \cdot r \cdot p_{B} \cdot p+b \cdot p_{B} \cdot p^{2}+r^{2}\right)$.

\subsection{Pi-Coerência}

Esse algoritmo procura minimizar o número de testes interior/exterior utilizando o fato de que quando a brush já foi testada para um determinado ponto da curva, não é necessário testar novamente todo os pontos da brush em um ponto da curva adjacente. Para descobrir quais pontos devem ser analisados quando a posição da brush é alterada, podemos utilizar uma bounding box.

Na Figura 4.5 o teste já foi feito para o ponto inicial da curva. Para o próximo ponto, basta verificar a região ainda não coberta, que corresponde a uma linha e uma coluna da bounding box da brush. 


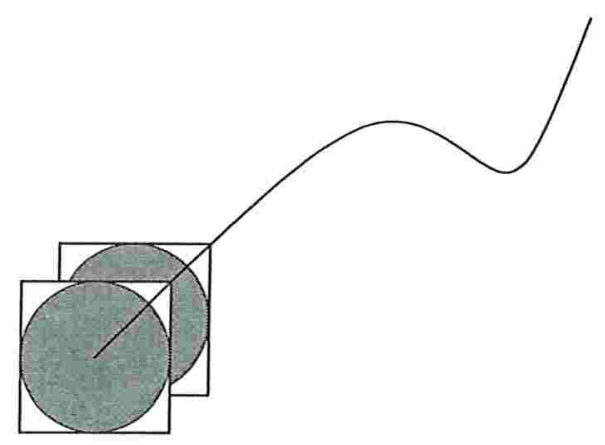

Figura 4.5: Apenas mais alguns teste precisam ser feitos quando a brush anda sobre a curva

Oito direções devem ser consideradas no deslocamento da brush, como mostra a Figura 4.6, pois as curvas consideradas são 8-conexas.
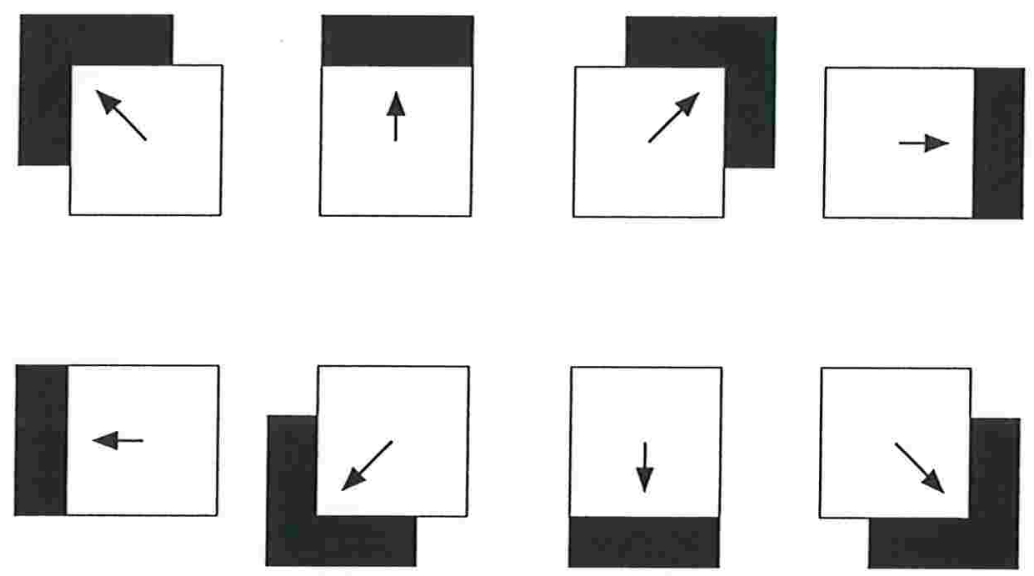

Figura 4.6: Oito direções a serem consideradas no deslocamento da brush

O algoritmo consiste em determinar quais pontos da bounding box da brush devem ser testados (fase de cobertura) e então testá-los (refinamento). 


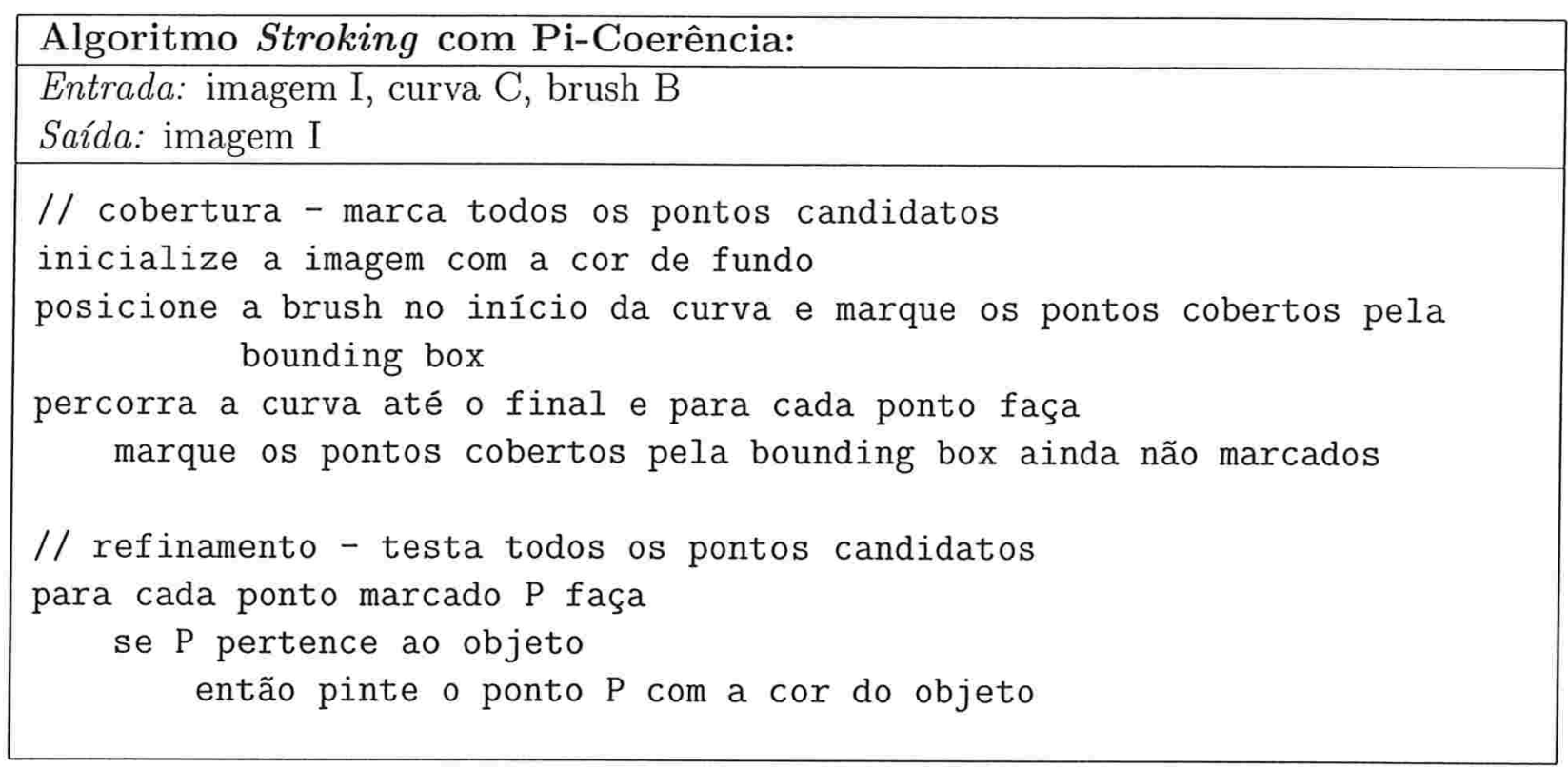

Em [FabSF98] provou-se que esse algoritmo faz $\mathrm{O}((c+p) \cdot c)$ testes interior/exterior, onde $c$ é a maior dimensão da bounding box da brush e $p$ é o perímetro da curva.

O tempo de processamento gasto é $\mathrm{O}\left((c+p) \cdot c \cdot\left(p_{B} \cdot p\right)+r^{2}\right)=\mathrm{O}\left(c^{2} \cdot p_{B} \cdot p+c \cdot p_{B} \cdot p^{2}+r^{2}\right)$.

\subsection{Comparação Teórica entre os Algoritmos de Stro- king Seqüenciais}

Na Tabela 4.1 estão listadas as complexidades do número de testes e do tempo de execução para os três algoritmos apresentados, onde $r$ é a resolução da imagem, $p$ é o perímetro da curva, $p_{B}$ é o perímetro da brush, $b$ é o tamanho da bounding box da brush e $c$ é a maior dimensão da bounding box da brush.

\begin{tabular}{|l|c|c|}
\hline Algoritmo & Testes Interior/Exterior & Tempo de Execução \\
\hline Quadrático & $\mathrm{O}\left(r^{2}\right)$ & $\mathrm{O}\left(r^{2} \cdot p_{B} \cdot p\right)$ \\
Coerência com Quadtrees & $\mathrm{O}(b \cdot r+b \cdot p)$ & $\mathrm{O}\left(b \cdot r \cdot p_{B} \cdot p+b \cdot p_{B} \cdot p^{2}+r^{2}\right)$ \\
Pi-Coerência & $\mathrm{O}\left(c^{2}+c \cdot p\right)$ & $\mathrm{O}\left(c^{2} \cdot p_{B} \cdot p+c \cdot p_{B} \cdot p^{2}+r^{2}\right)$ \\
\hline
\end{tabular}

Tabela 4.1: Comparação teórica entre os algoritmos de stroking seqüenciais

Podemos observar que em uma análise assintótica, sendo $b \ll r$ e $c \ll r$, o algoritmo de pi-coerência é teoricamente mais rápido do que o stroking utilizando quadtrees e que este é teoricamente mais rápido do que o algoritmo quadrático, apesar de a primeira diferença 
ser menor do que a segunda. Assim como observamos no capítulo anterior, o algoritmo de stroking com quadtrees pode ser mais rápido do que o stroking com pi-coerência em certos casos, como por exemplo para brushes muito grandes com relação ao comprimento da curva. Para mais detalhes sobre esse e outros exemplos veja[Sil98]. 


\section{Capítulo 5}

\section{Paralelismo}

Antes de apresentarmos as versões paralelas dos algoritmos descritos, veremos uma breve definição de alguns conceitos básicos utilizados em computação paralela.

\subsection{Conceitos Básicos de Computação Paralela}

Um computador paralelo é um computador com uma coleção de processadores interligados, com capacidade de comunicação entre si, que podem ser usados para resolver um mesmo problema em conjunto, diminuindo o tempo global de processamento. Por esse motivo são muito utilizados para resolver problemas que requerem muita computação, como é o caso dos algoritmos de preenchimento e stroking descritos anteriormente.

\subsubsection{Memória Compartilhada x Memória Distribuída}

Um computador paralelo pode ter uma memória global, acessível a todos os processadores (memória compartilhada) ou cada processador pode ter a sua própria memória, inacessível diretamente para os outros processadores (memória distribuída). Veja esquema na Figura 5.1. A troca de informações entre os processadores no caso de computadores com memória distribuída é muito mais lenta do que no caso de memória compartilhada, pois os dados devem ser enviados de um processador a outro através da rede que liga os processadores. 

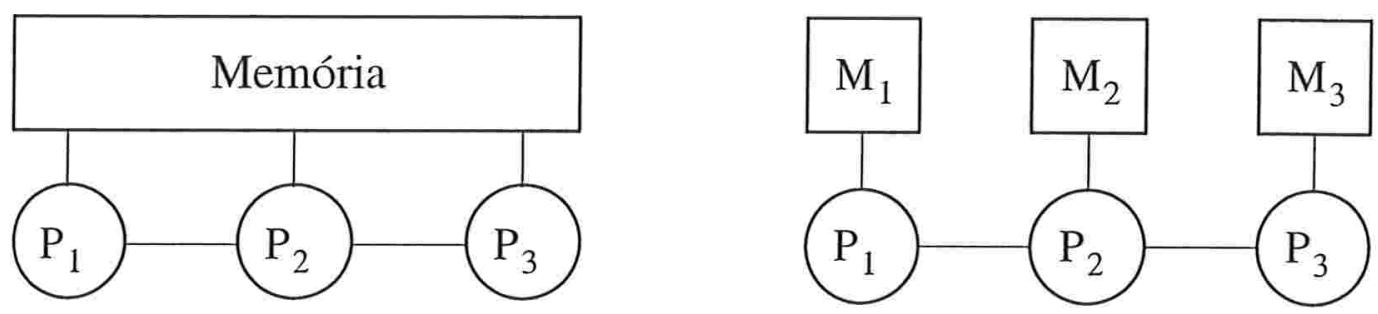

Figura 5.1: Memória Compartilhada X Memória Distribuída

A principal desvantagem de computadores com memória compartilhada é que a complexidade do hardware cresce com o número de processadores. Por esse motivo, em geral as máquinas de memória distribuída costumam ser mais baratas e possibilitam a presença de mais processadores do que as de memória compartilhada.

Por outro lado, algoritmos utilizando memória compartilhada em geral são muito mais fáceis de se implementar do que utilizando memória distribuída, pois a implementação é mais natural, uma vez que não é necessário se preocupar com a troca de informações entre os processadores. Esse fato poderá ser comprovado nos algoritmos apresentados nos próximos capítulos.

\subsubsection{Tipos de Máquinas Paralelas}

Uma classificação muito comum para máquinas paralelas foi proposta por Flynn [Fly72], que relaciona o fluxo de dados com o fluxo de instruções de cada processador:

- SIMD: Single Instruction stream, Multiple Data stream. Fluxo de instruções único (há sincronia na execução dos comandos), múltiplos fluxos de dados entre os processadores e a memória.

- SPMD: Single Program, Multiple Data stream. Programa único para todos os processadores, múltiplos fluxos de dados.

- MISD: Multiple Instruction stream, Single Data stream. Fluxos de instruções independentes para cada processador, fluxo de dados único.

- MIMD: Multiple Instruction stream, Multiple Data stream. Fluxos de instruções independentes para cada processador, múltiplos fluxos de dados entre os processadores e a memória.

As máquinas utilizadas em nossa implementação e testes, tanto no caso de memória compartilhada como no caso de memória distribuída são do tipo MIMD, que é o tipo mais comum de máquina paralela disponível no mercado atualmente. 


\subsubsection{Topologias nas Conexões entre os Processadores}

Os processadores podem estar ligados entre si de diversas formas [CosT95, KGGK94]: em anel, hipercubo, grade, vetor linear, toroidal, árvore binária, entre outras, conforme mostra a Figura 5.2. Cada uma dessas topologias se adapta melhor a um tipo de algoritmo.
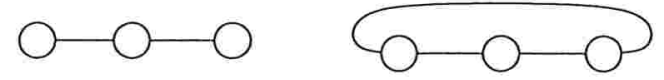

Vetor

Anel<smiles>C1OC2OC3OCC3C2O1</smiles>

Grade 2D

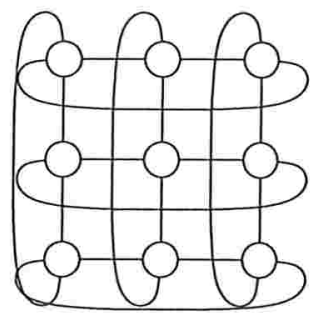

Toroidal

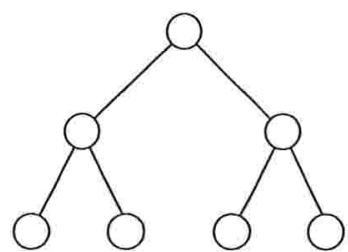

Árvore Binária

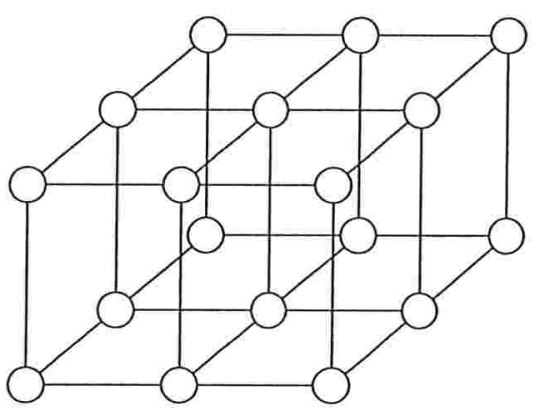

Grade 3D

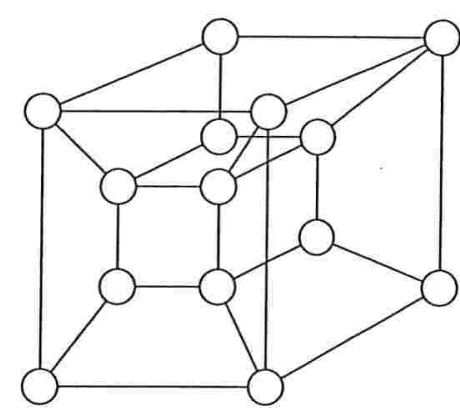

Hipercubo

Figura 5.2: Alguns exemplos de topologias existentes

\subsection{Balanceamento de Carga}

Para evitar que alguns processadores tenham mais trabalho a ser feito do que outros, deve-se fazer um balanceamento de carga entre os processadores. Se esse cuidado não for tomado, corre-se o risco de ter em algum momento um ou mais processadores sem trabalho a fazer enquanto os outros estão fazendo cálculos, o que a princípio aumenta o tempo de total de execução. 
O balanceamento pode ser:

- Estático: Antes de se iniciar o processamento, divide-se o trabalho a ser feito entre os processadores tentando prever o tempo que será gasto com cada tarefa. É mais simples de se implementar mas em alguns casos, quando é difícil prever o comportamento do algoritmo no que se refere ao tempo de execução, não produz um resultado satisfatório.

- Dinâmico: Durante a execução do programa pode-se delegar tarefas de um processador para outro, conforme se torne necessário. A implementação é mais complicada e introduz mais tempo de execução e comunicação entre os processadores ao algoritmo, mas é necessária quando é muito difícil ou até inviável fazer um balanceamento estático que funcione bem.

\subsection{Partição do Problema}

O problema pode ser particionado de duas formas: particionando os objetos considerados na entrada ou particionando a imagem. Devido à semelhança com o ray tracing nesse ponto, estudou-se a classificação proposta por Green [Green91] para algoritmos de ray tracing e alguns trabalhos publicados sobre ray tracing paralelo [San94, NotG97, KimK96, KNKNS88].

- Partição dos objetos: se há mais de um objeto presente na composição de uma mesma imagem, pode-se atribuir o cálculo de um ou mais objetos a cada processador. Dessa forma, pode-se diminuir a quantidade de memória gasta por cada processador. Como cada processador utilizará apenas os dados referentes ao conjunto de dados dos objetos atribuídos a ele, a partição dos objetos é uma boa opção para computadores de memória distribuída. Essa forma de particionar o problema só pode ser utilizada quando realmente houverem vários objetos na mesma imagem. Isso pode ser descoberto durante a execução do programa contando-se o número de objetos definidos.

- Partição da imagem: cada parte da imagem é atribuída a um processador. Então cada objeto será testado apenas para aquela área. Tem-se a desvantagem de ter que manter uma cópia de cada objeto para cada processador no caso de memória distribuída, o que não ocorre no caso de memória compartilhada. Este será o modelo adotado em todos os algoritmos apresentados aqui, visto que é o que apresenta melhores resultados na prática sem resultar em complicações no balanceamento de carga, além de que no nosso caso a memória requerida pelos objetos (curvas discretas) é usualmente pequena quando comparada com o tamanho da imagem resultante, por exemplo. 


\subsection{Análise da Performance}

Um fato conhecido em computação paralela (e.g. [HwangB84]) é que nem sempre o algoritmo seqüencial mais rápido é o mais rápido quando paralelizado. Por isso iremos analisar as paralelizações propostas para todos os algoritmos apresentados.

Para podermos analisar a performance de um algoritmo paralelo, podemos utilizar tanto ferramentas teóricas quanto práticas, que veremos a seguir:

\subsubsection{Análise Teórica}

A análise teórica de um algoritmo paralelo é semelhante à análise teórica de um algoritmo seqüencial, introduzindo-se uma variável a mais: o número de processadores utilizados. Mas se já temos uma análise teórica de um algoritmo seqüencial, podemos analisar a versão paralela calculando apenas o tempo gasto introduzido com a paralelização sobre a versão seqüencial.

Quando um algoritmo é executado em paralelo, é gasto algum tempo extra de execução em detalhes que se tornam necessários como divisão de tarefas, comunicação entre os processadores, combinação de resultados entre outros. Esse tempo gasto a mais na execução do algoritmo é comumente chamado de overhead. Podemos utilizar o overhead para fazermos uma análise teórica do comportamento dos algoritmos com relação ao número de processadores utilizados.

\subsubsection{Análise Prática}

Em complemento à análise teórica, é muito comum fazermos uma avaliação dos algoritmos paralelos na prática, medindo-se o tempo gasto na execução para diversos números de processadores. A partir dos tempos de execução obtidos, utilizaremos uma das ferramentas mais comuns da computação paralela: o speed-up.

Seja $t_{1}$ o tempo de execução da melhor implementação conhecida do algoritmo seqüencial e $t_{p}$ o tempo de execução do algoritmo paralelo sendo analisado, utilizando $p$ processadores. Então definimos o speed-up como:

$$
S_{p}=\frac{t_{1}}{t_{p}}
$$




\subsection{O Projeto PixelFlow}

A maioria dos computadores paralelos atuais possui um número pequeno de processadores complexos. Porém, a máquina PixelFlow [EylesMP97, MolEP92], idealizada pelo grupo de Computação Gráfica da Universidade da Carolina do Norte, apresenta um número grande de processadores, criados especificamente para a execução de um algoritmo de computação gráfica, o ray-tracing.

O PixelFlow utiliza uma técnica de composição de imagens para renderização de múltiplos objetos, utilizando uma arquitetura que possibilita uma performance que varia linearmente com o número de processadores utilizados, possibilitando o uso de um número muito grande de processadores.

Da mesma forma, podemos prever a construção de uma máquina paralela dedicada à execução de algoritmos de preenchimento ou stroking. Isso nos levou a considerar a execução dos algoritmos paralelos descritos neste texto para um número variável de processadores, de um até o limite de um processador por pixel gerado, utilizando tanto técnicas de composição de imagens quanto divisão da área da imagem entre os processadores. 


\section{Capítulo 6}

\section{Preenchimento de Regiões em Paralelo}

Nesta seção serão estudadas algumas formas de paralelizar os algoritmos vistos para preenchimento de regiões. Serão apresentadas propostas para máquinas com memória compartilhada e distribuída. Por uma questão de simplicidade, os algoritmos trabalharão apenas com um único objeto. Mas a generalização para um número arbitrário de objetos é direta, uma vez que a tarefa de construir uma imagem contendo vários objetos pode ser decomposta na renderização de cada objeto em seqüência.

\subsection{Versão Quadrática}

A paralelização desse algoritmo é trivial. Como a computação de cada ponto da imagem é independente dos demais, podemos dividir a imagem igualmente entre os processadores. Isso pode ser feito em faixas horizontais ou verticais, independentemente do número de processadores. Veja exemplo na Figura 6.1.

\subsubsection{Memória Compartilhada}

A implementação utilizando memória compartilhada é muito simples. Basta cada processador produzir a sua parte da imagem sem se preocupar com os demais, pois as áreas atribuídas a cada processador são disjuntas. Além disso, se os dados de entrada já estão disponíveis no programa, eles podem facilmente ser acessados por todos os processadores diretamente no local de origem. O mesmo ocorre com a saída, que é comum a todos os 


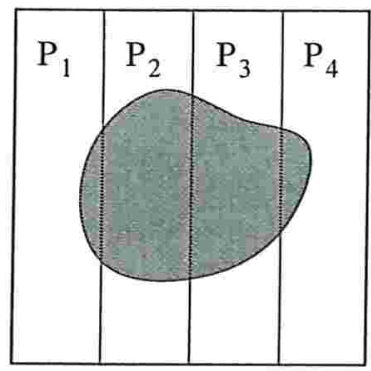

Figura 6.1: Divisão de uma imagem entre quatro processadores

processadores.

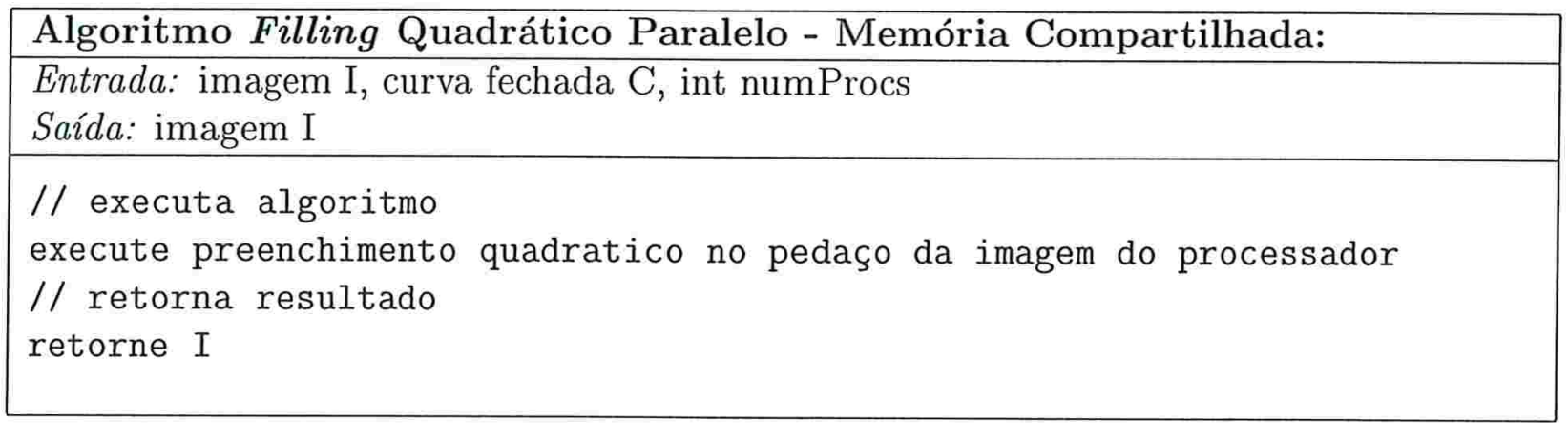

\subsubsection{Memória Distribuída}

Em uma implementação utilizando memória distribuída cada processador deverá ter uma cópia da curva. Portanto deve-se inicialmente enviar uma cópia dela a cada processador. Além disso, no final do algoritmo deve-se juntar todos os pedaços da imagem de cada processador, compondo uma imagem única.

Um processador será responsável pela leitura da entrada, distribuição da curva aos demais, coleta e junção dos resultados e envio da saída pelo programa. Esse processador é chamado de processador mestre. No nosso caso o processador mestre também auxilia os outros processadores, tomando uma parte do trabalho para si. 


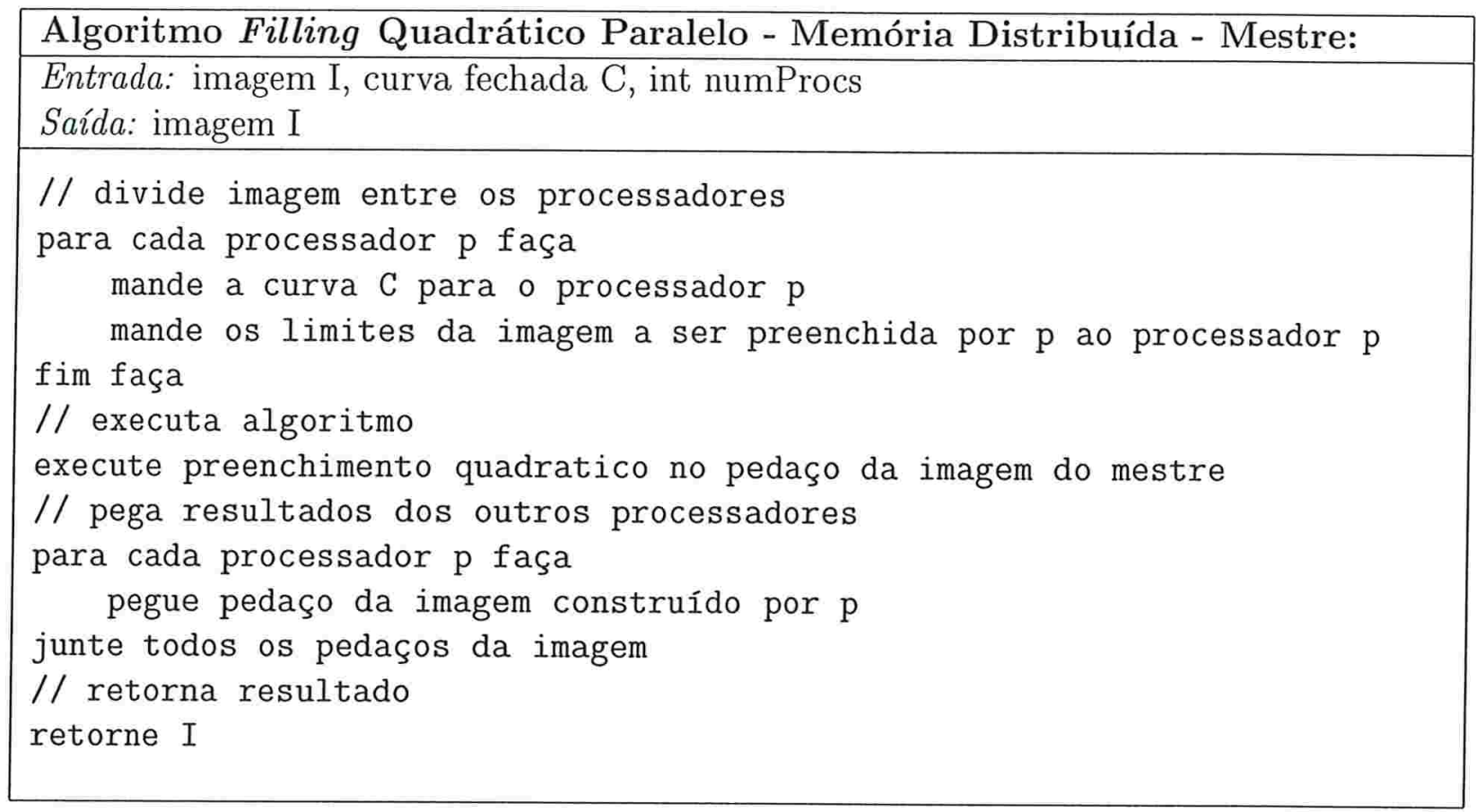

\begin{tabular}{|l|}
\hline Algoritmo Filling Quadrático Paralelo - Memória Distribuída - Outros: \\
\hline Entrada: (nada) \\
Saída: (nada) \\
\hline // pega dados do processador mestre \\
pegue a curva discreta C do processador mestre \\
pegue limites da imagem a construir \\
// executa algoritmo \\
execute preenchimento quadrático no pedaço da imagem do processador \\
// manda resultados ao processador mestre \\
mande pedaço da imagem ao processador mestre
\end{tabular}




\subsection{Coerência com Quadtrees}

A paralelização desse algoritmo é semelhante à da versão quadrática, dividindo-se a imagem igualmente entre os processadores. Porém, como diferentes trechos da imagem levam tempos diferentes para acabar, deve-se introduzir um balanceamento dinâmico, transferindo trabalho de um processador a outro conforme vão terminando, como mostra a Figura 6.2. Isso evita que um processador termine o trabalho muito antes dos demais, garantindo um balanceamento de carga semelhante a todos os processadores.

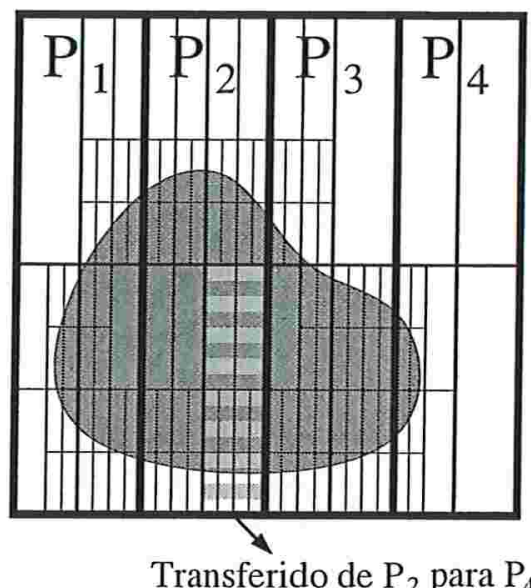

Figura 6.2: Divisão de uma imagem entre quatro processadores com transferência de trabalho

Para possibilitar a transferência de trabalho de um processador a outro, deve-se substituir a recursão do algoritmo feita através de chamadas à função por uma pilha híbrida, que possibilite a remoção do elemento da base, além do acesso convencional ao topo. Cada elemento da pilha contém as coordenadas da imagem a ser preenchida. Cada passo do algoritmo retira o elemento do topo da pilha e, em caso de ser necessária uma subdivisão da imagem, quatro novos elementos são inseridos no topo da pilha, correspondentes às quatro chamadas recursivas do algoritmo. Dessa forma, a base da pilha sempre conterá a maior região ainda não processada da imagem.

Quando um processador termina seu trabalho, deve consultar todos os outros para saber a quantidade de trabalho que cada um pode transferir a ele. Se a maior quantidade de trabalho for muito pequena, pode-se decidir por não pegar mais trabalho de nenhum.

Para transferir trabalho de um processador a outro, basta retirar um elemento da base da pilha de um e colocar no topo da pilha do outro. 


\subsubsection{Memória Compartilhada}

Como a memória é compartilhada, a consulta a outros processadores pode ser feita acessando-se diretamente a pilha dos outros processadores, bastando para isso implementar uma exclusão mútua na pilha de cada processador, a fim de evitar acesso concorrente.

Nesse caso, como na versão quadrática, os pedaços de imagens atribuídos a cada processador são disjuntos. Mas o processo de transferência de trabalho requer uma comunicação entre os processadores de modo que, quando cada processador termina seu trabalho, deve consultar todos os outros em busca de mais trabalho.

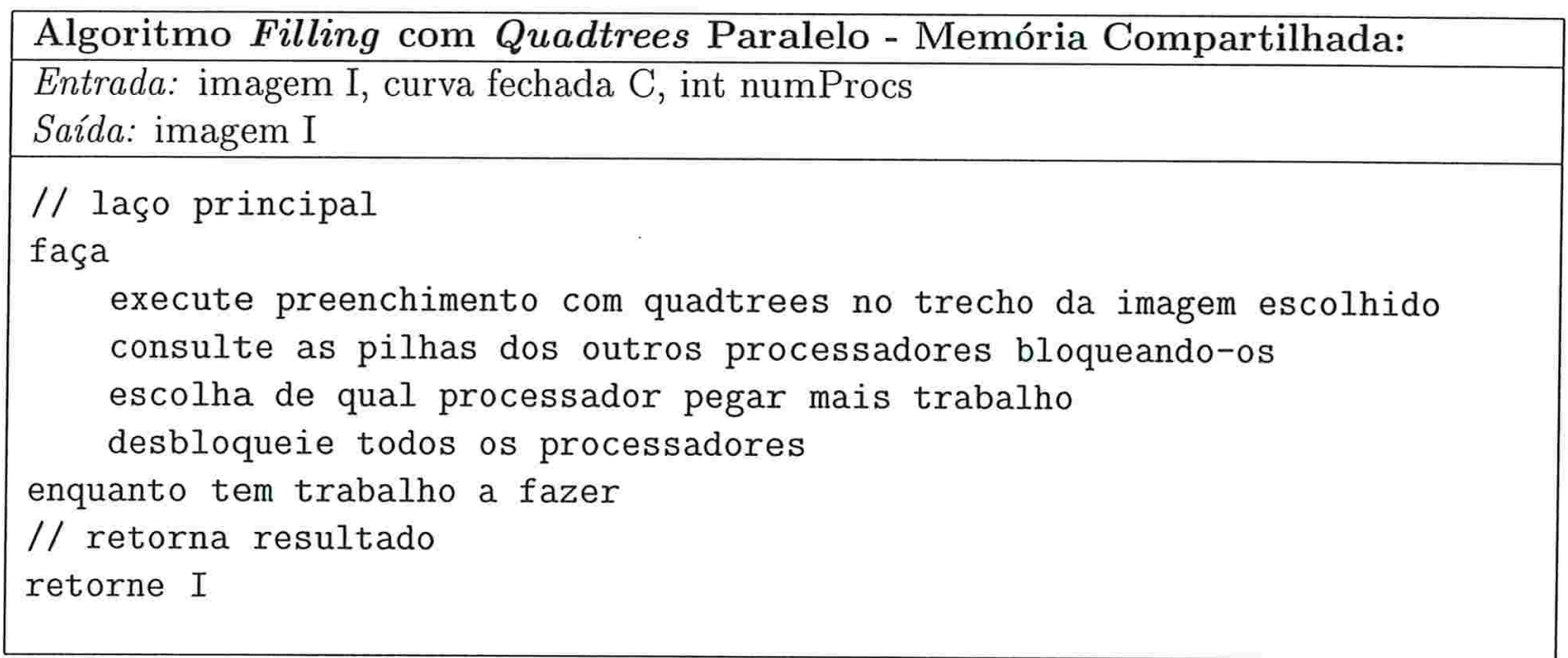

\subsubsection{Memória Distribuída}

A comunicação deve ser feita utilizando-se mensagens assíncronas, a fim de não prejudicar o trabalho de nenhum processador. Então um processador que quer contatar os outros pode esperar a resposta, mas os outros, que ainda estão trabalhando, podem checar se há mensagens pendentes apenas quando há a possibilidade de transferir dados. Se não há nenhum pedido, podem continuar trabalhando.

Quando um processador transfere trabalho para outro, deve limpar a área da imagem correspondente para que o processador mestre possa juntar as imagens de ambos utilizando uma combinação "ou". 

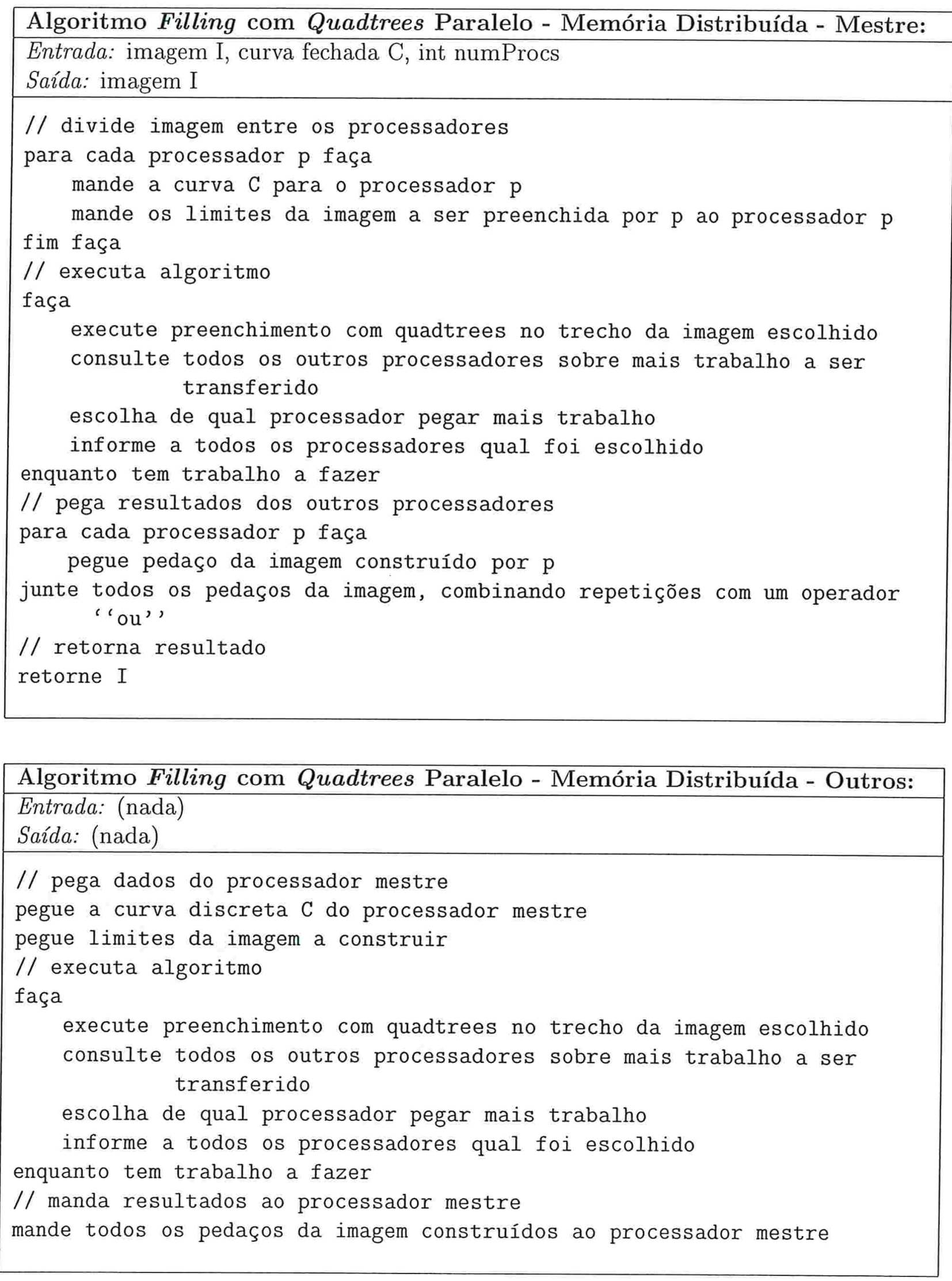


\subsection{Coerência Maximal}

Uma paralelização possível para esse algoritmo consiste em dividir a imagem igualmente entre os processadores e então executar o algoritmo normalmente, limitando a propagação da cor interior à região atribuída ao processador. Porém essa paralelização não mantém a característica original do algoritmo, que é a de propagar a cor interior o máximo possível. Mas veremos que só é vantajoso manter essa característica do algoritmo no caso de memória compartilhada.

\subsubsection{Memória Compartilhada}

A fim de possibilitar a máxima propagação da cor do objeto, pode-se dividir a curva igualmente entre os processadores e deixá-los fazer a propagação simultaneamente, como mostra a Figura 6.3, tomando o cuidado de não preencher áreas já preenchidas por outros processadores nem propagar áreas já preenchidas. No caso de memória compartilhada isso é simples, pois a área da memória correspondente à imagem construída é comum a todos os processadores.

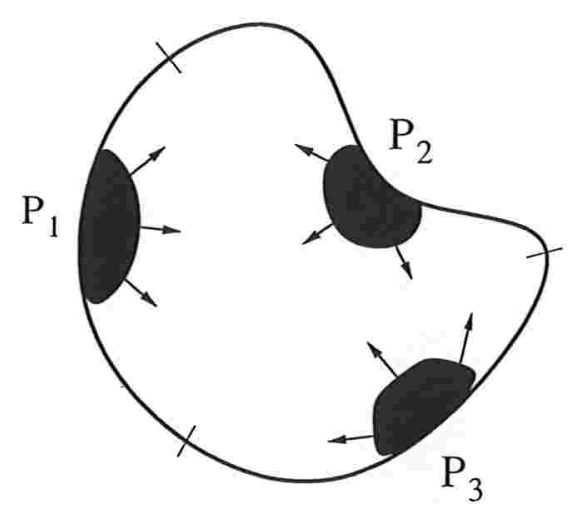

Figura 6.3: Preenchimento de uma região em paralelo utilizando memória compartilhada 


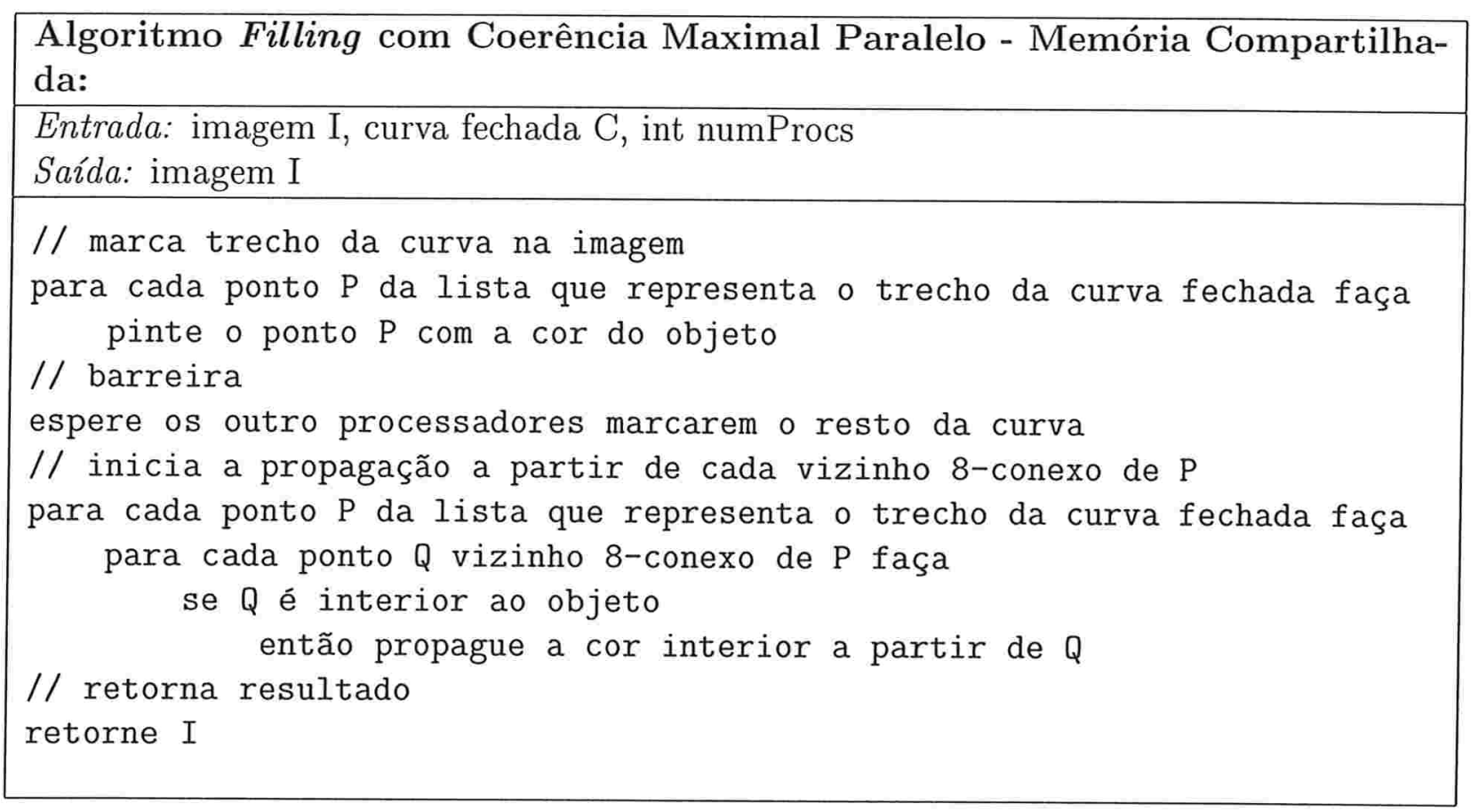

\subsubsection{Memória Distribuída}

A imagem deve ser dividida igualmente entre os processadores. Mas como o algoritmo trabalha no interior da curva, propagando a cor do objeto, deve-se impedir que uma região que não contém a curva seja atribuída a um processador. Isso pode ser feito calculando os limites da curva em um eixo e dividindo o trecho desse eixo ocupado pela curva igualmente entre os processadores, como mostra a Figura 6.4. Como é difícil mudar os limites de uma propagação deve-se utilizar balanceamento estático. As áreas não atribuídas a nenhum processador devem ser preenchidas com a cor de fundo.

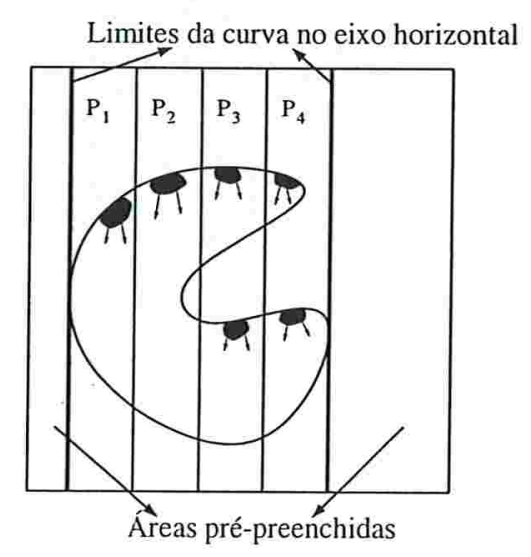

Figura 6.4: Divisão da imagem entre quatro processadores 
A divisão da imagem só pode ser feita em faixas verticais se o tamanho da faixa ocupada pela curva no eixo horizontal for maior ou igual ao número de processadores. Caso contrário faixas horizontais devem ser utilizadas.

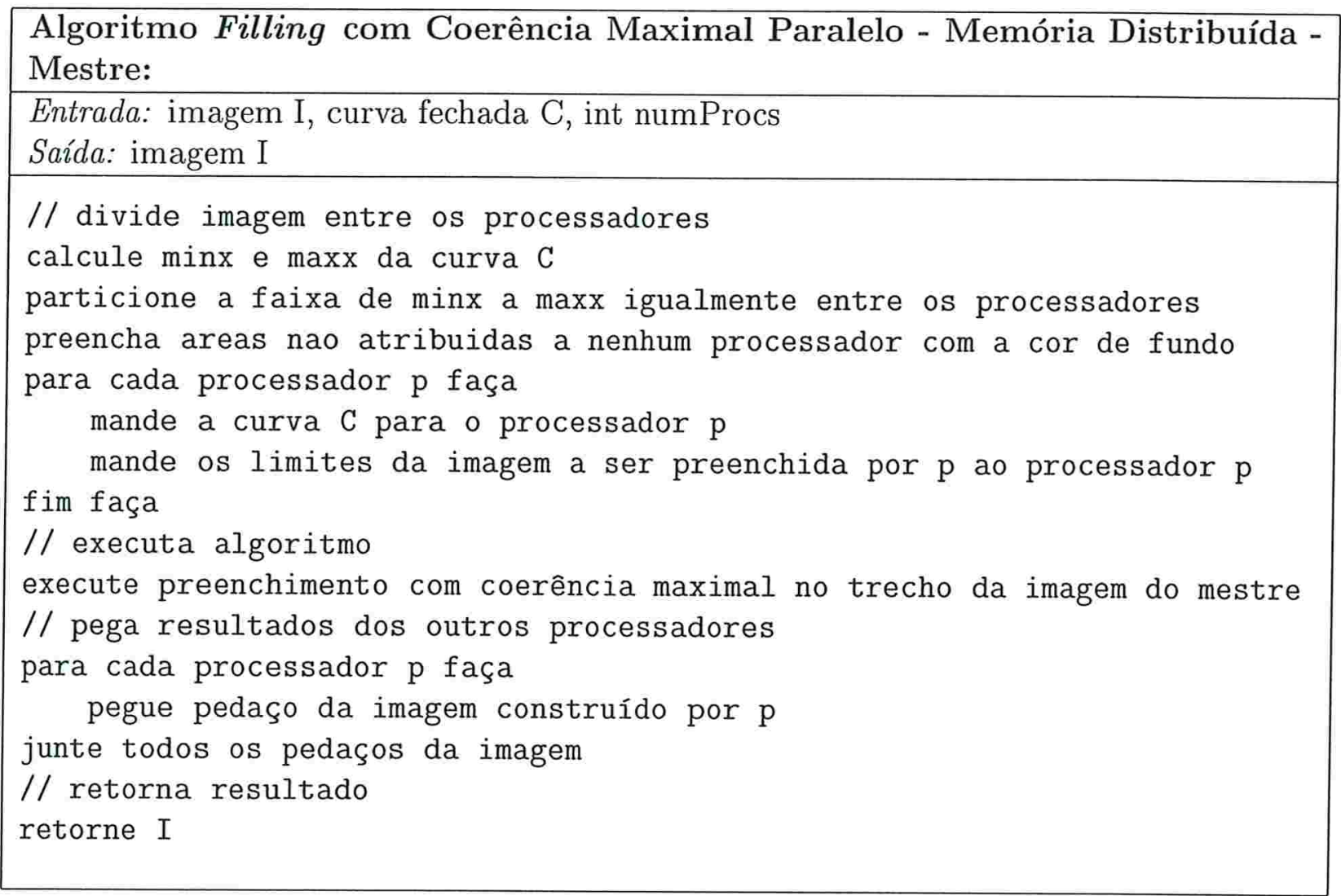

\begin{tabular}{l} 
Algoritmo Filling com Coerência Maximal Paralelo - Memória Distribuída - \\
Outros: \\
\hline Entrada: (nada) \\
Saída: (nada) \\
// pega dados do processador mestre \\
pegue a curva discreta C do processador mestre \\
pegue limites da imagem a construir \\
// executa algoritmo \\
execute preenchimento com coerência maximal no trecho da imagem do \\
$\quad$ processador \\
// manda resultados ao processador mestre \\
mande todos o pedaço da imagem construido ao processador mestre
\end{tabular}




\subsection{Comparação Teórica entre os Algoritmos de Pre- enchimento Paralelos}

A seguir faremos uma análise teórica dos overheads introduzidos em cada algoritmo paralelo. Essa análise será útil para compararmos os algoritmos paralelos entre si, juntamente com os resultados práticos apresentados mais adiante.

\subsubsection{Memória Compartilhada}

Uma vez que os dados estão disponíveis para um dos processadores, eles estão disponíveis para todos os outros em uma máquina com memória compartilhada. Isso quer dizer que não há overhead resultante do envio e recebimento de dados referentes à entrada e saída entre os processadores.

Porém, no algoritmo que utiliza coerência com quadtrees há um overhead resultante da comunicação e transferência de trabalhos entre os processadores. Em cada uma das $\mathrm{O}(r+p)$ subdivisões da imagem, no máximo $n$ processadores podem se comunicar com os outros $n-1$ processadores em busca de mais trabalho, resultando em um overhead $\mathrm{O}\left((r+p) \cdot n^{2}\right)$.

\subsubsection{Memória Distribuída}

O envio da curva aos processadores causa um overhead linearmente dependente do número de processadores e do perímetro da curva $(\mathrm{O}(n \cdot p))$.

O algoritmo de coerência com quadtrees introduz um overhead igual ao do algoritmo utilizando memória compartilhada $\left(\mathrm{O}\left(n^{2} \cdot(r+p)\right)\right)$.

No algoritmo de coerência maximal há um overhead resultante da limitação da propagação da cor do objeto, quadraticamente dependente da resolução da imagem $\left(\mathrm{O}\left(r^{2}\right)\right)$.

O envio dos pedaços da imagem construída ao processador mestre causa um overhead quadraticamente dependente da resolução da imagem, ou $\mathrm{O}\left(r^{2}\right)$. 


\subsubsection{Tabela Comparativa}

\begin{tabular}{|c|c|c|}
\hline Algoritmo & $\begin{array}{c}\text { Overhead } \\
\text { Memória Compartilhada }\end{array}$ & $\begin{array}{c}\text { Overhead } \\
\text { Memória Distribuída }\end{array}$ \\
\hline $\begin{array}{l}\text { Quadrático } \\
\text { Coerência com Quadtrees } \\
\text { Coerência Maximal }\end{array}$ & $\begin{array}{c}0 \\
\mathrm{O}\left(n^{2} \cdot p+n^{2} \cdot r\right) \\
0\end{array}$ & $\begin{array}{c}\mathrm{O}\left(n \cdot p+r^{2}\right) \\
\mathrm{O}\left(n^{2} \cdot p+n^{2} \cdot r+r^{2}\right) \\
\mathrm{O}\left(n \cdot p+r^{2}\right)\end{array}$ \\
\hline
\end{tabular}

Tabela 6.1: Comparação teórica entre os algoritmos de preenchimento paralelos

\subsubsection{Fixando a curva e o tamanho da imagem}

Se fixarmos o perímetro da curva $(p)$ e a resolução da imagem $(r)$ e variarmos apenas o número de processadores utilizados $(n)$, teremos as seguintes complexidades para os overheads dos algoritmos:

\begin{tabular}{|c|c|c|}
\hline Algoritmo & $\begin{array}{c}\text { Overhead } \\
\text { Memória Compartilhada }\end{array}$ & $\begin{array}{c}\text { Overhead } \\
\text { Memória Distribuída }\end{array}$ \\
\hline Quadrático & 0 & $\mathrm{O}(n)$ \\
\hline Coerência com Quadtrees & $\mathrm{O}\left(n^{2}\right)$ & $\mathrm{O}\left(n^{2}\right)$ \\
\hline Coerência Maximal & 0 & $\mathrm{O}(n)$ \\
\hline
\end{tabular}

Tabela 6.2: Comparação teórica entre os algoritmos de preenchimento paralelos fixando a curva e o tamanho da imagem 


\subsection{Resultados Práticos}

Os algoritmos apresentados foram implementados e testados para duas imagens teste. A primeira (Figuras 6.5 e 6.6) mostra um exemplo de uma curva de moderada complexidade, com algumas cúspides (pontos onde as derivadas paramétricas são nulas) e auto-interseções, composta por 47 curvas de Bézier, com graus variando de 2 a 10, totalizando 211 pontos de controle. A curva discreta resultante tem 9.425 pontos. Essas imagens foram selecionadas para compor a contra-capa dos proceedings de [FabAF00].

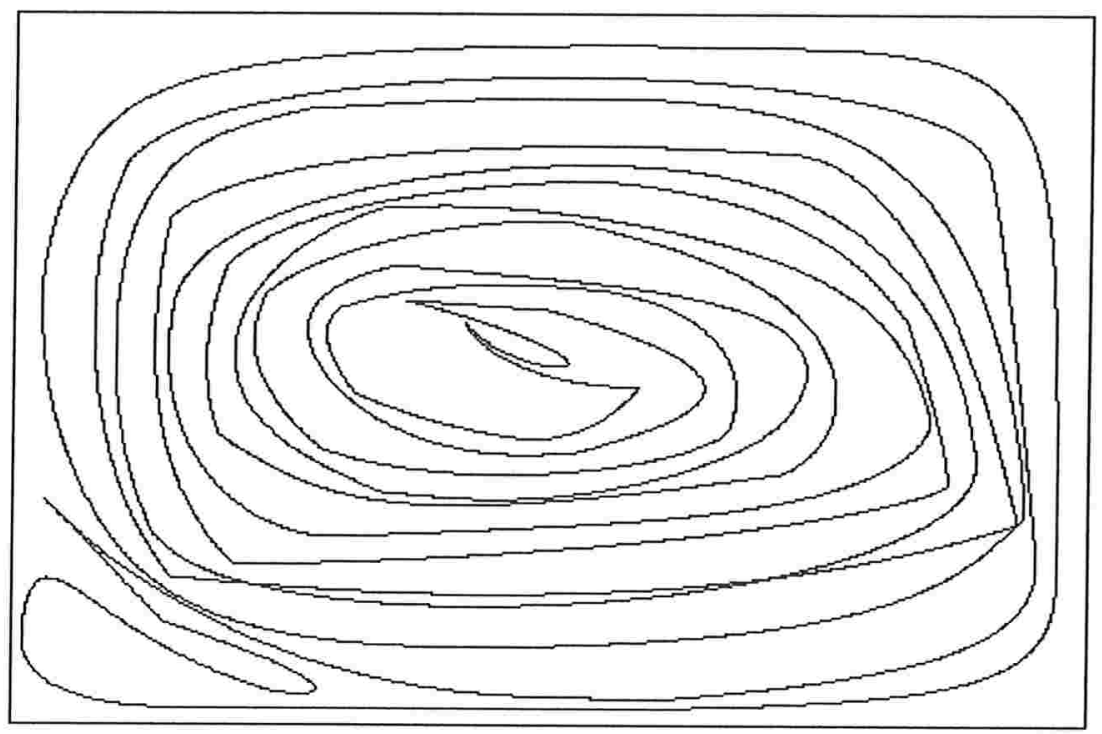

Figura 6.5: Curva da Imagem Teste 1

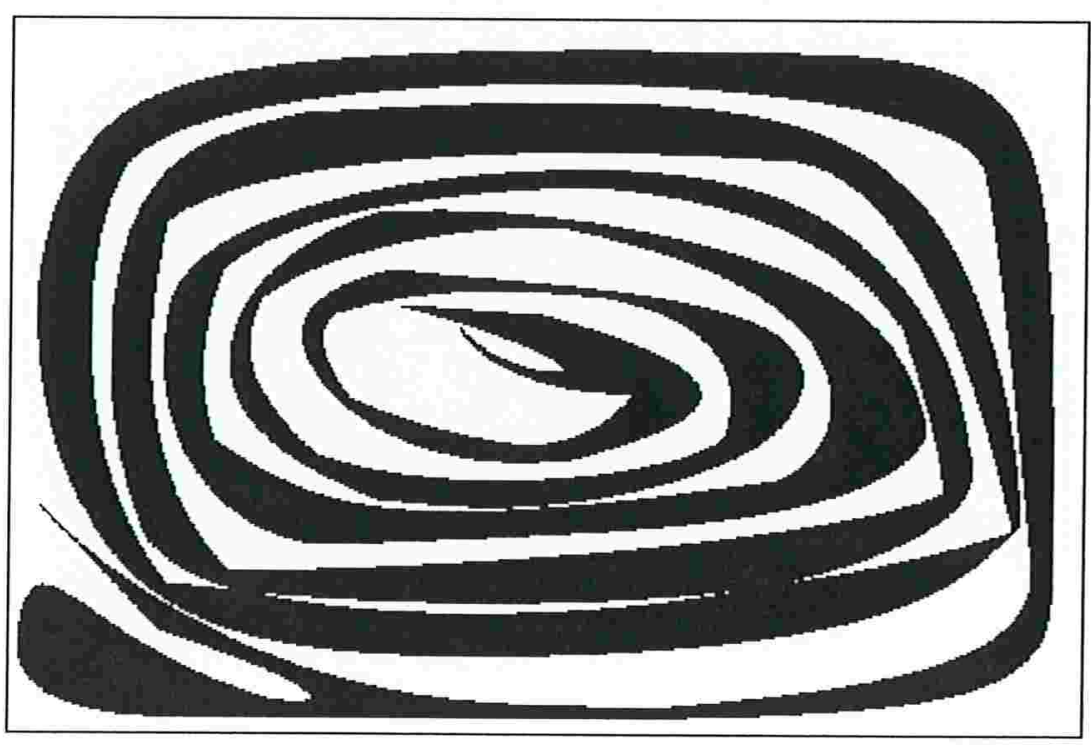

Figura 6.6: Imagem Teste 1 
A segunda imagem teste (Figuras 6.7 e 6.8) explora um exemplo de uma curva composta por 41 curvas de Bézier, com graus variando de 3 a 6, totalizando 159 pontos de controle. Há um alto grau de complexidade, havendo várias auto-interseções, cúspides e pontos com múltiplas interseções, o que demonstra a robustez do algoritmo. A curva discreta resultante tem 5.495 pontos.

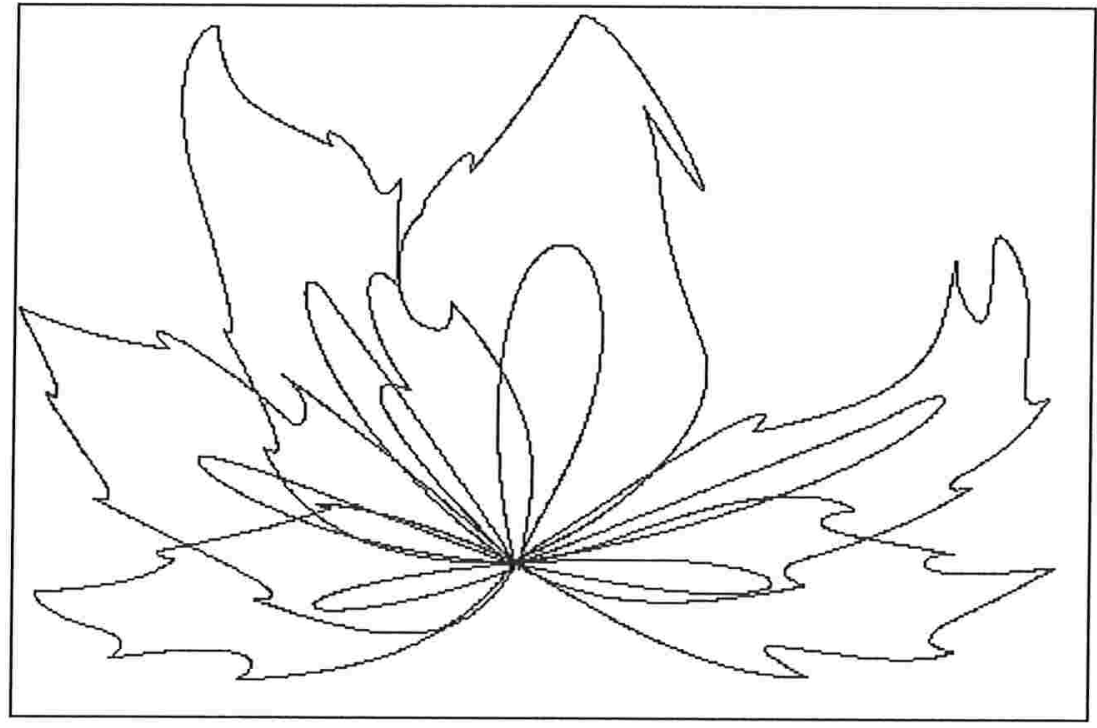

Figura 6.7: Curva da Imagem Teste 2

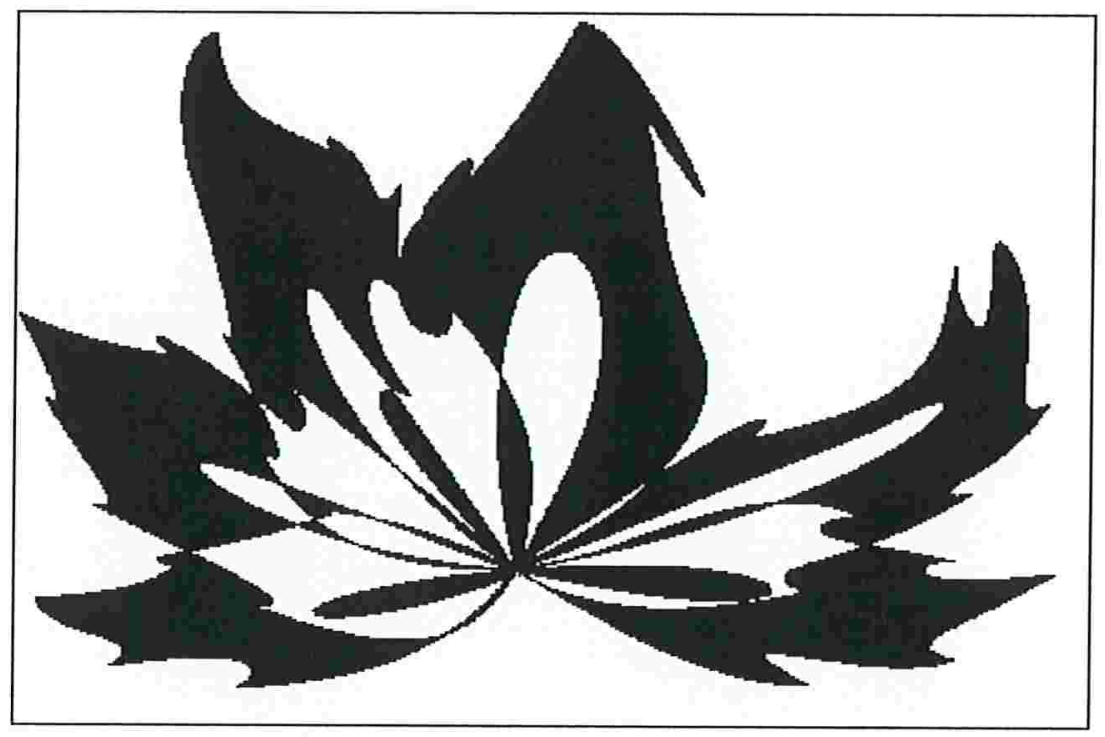

Figura 6.8: Imagem Teste 2 


\subsubsection{Memória Compartilhada}

Os algoritmos que utilizam memória compartilhada foram executados em uma máquina SUN com 6 processadores. Para a execução em paralelo foram utilizadas threads do tipo pthreads (POSIX threads), onde cada thread foi inicializada como sendo um Light Weight Process, ou seja, um processo escalonado pelo sistema operacional, mas ainda pertencente ao mesmo processo que a gerou. Isso possibilita a execução de cada thread em um processador diferente e o acesso concorrente à memória de forma simples. Os algoritmos seqüenciais também foram executados na mesma máquina, utilizando apenas um processador, a fim de possibilitar uma comparação realista entre os algoritmos paralelos e os seqüenciais.

Os tempos gastos na execução para as duas imagens teste estão apresentados na Figura 6.9 .
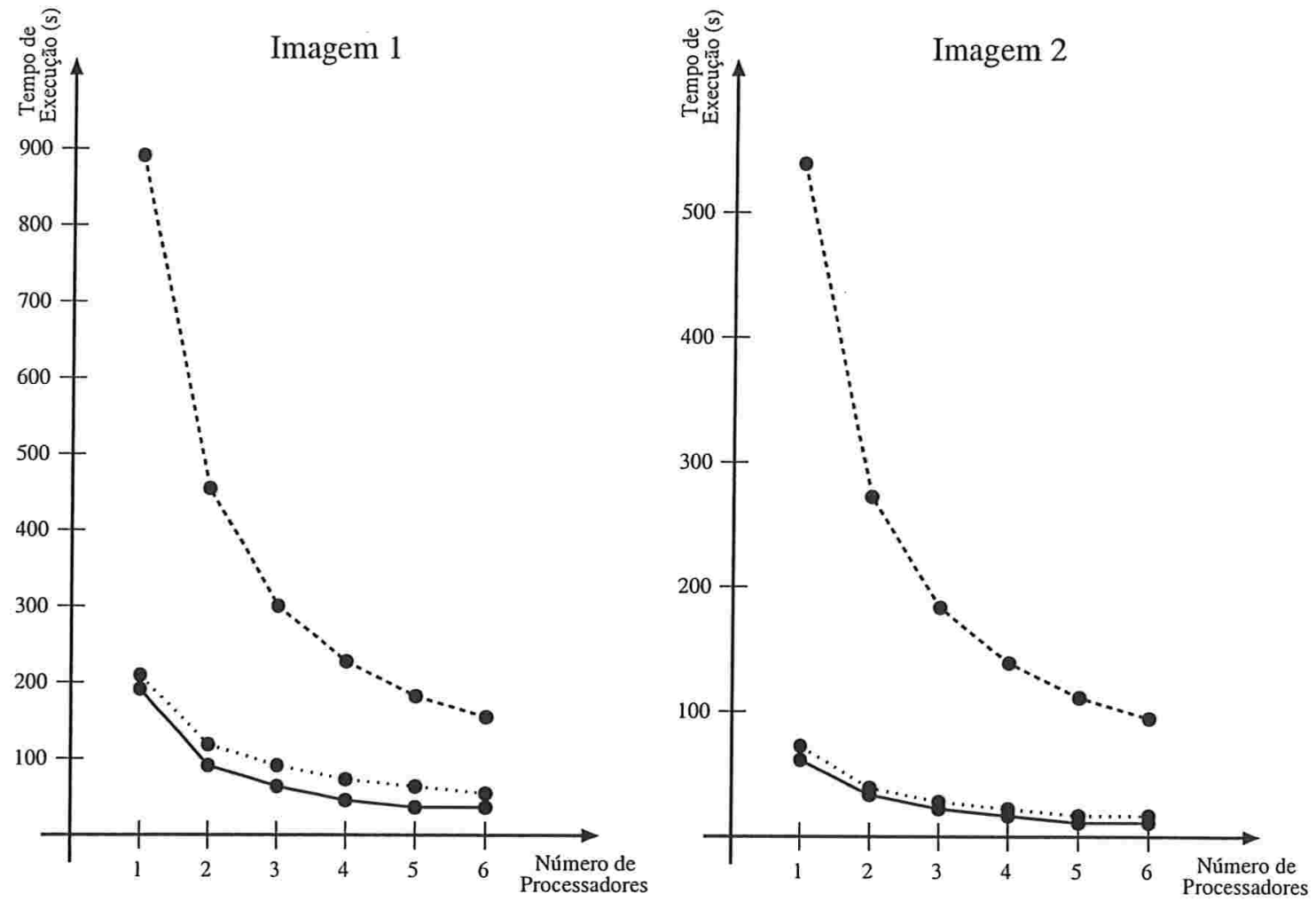

$$
\begin{aligned}
& \text { … Quadrático } \\
& \text { … Coerência com Quadtrees } \\
& \text { - Coerência Maximal }
\end{aligned}
$$

Figura 6.9: Tempos de execução para os algoritmos paralelos de preenchimento utilizando memória compartilhada 


\subsubsection{Memória Distribuída}

Os algoritmos que utilizam memória distribuída foram executados em uma máquina Parsytec PowerXplorer com 8 processadores com memória exclusiva para cada um. Os algoritmos seqüenciais foram executados na mesma máquina, utilizando apenas um processador. Os tempos gastos na execução para as duas imagens teste estão apresentados na Figura 6.10.
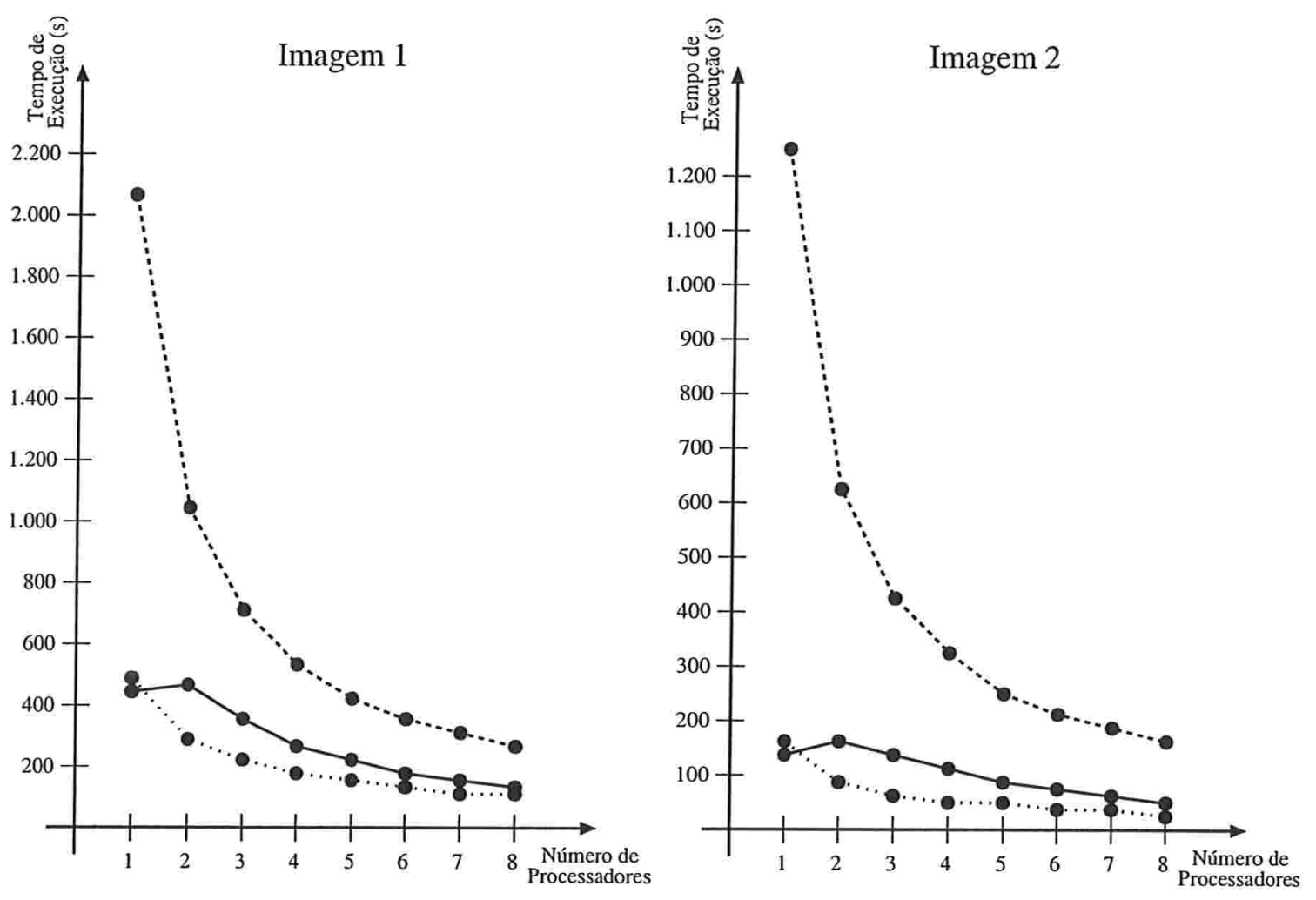

$$
\begin{aligned}
& \text { … Quadrático } \\
& \text { … Coerência com Quadtrees } \\
& \text { - Coerência Maximal }
\end{aligned}
$$

Figura 6.10: Tempo de execução para os algoritmos paralelos de preenchimento utilizando memória distribuída 


\subsection{Análise dos Dados}

Com base nos tempos de execução obtidos para as duas imagens de teste através dos algoritmos de preenchimento seqüenciais e paralelos, foram gerados os gráficos dos speed-ups (Figuras 6.11 e 6.12).

Para fazer uma análise comparativa entre os algoritmos, deve-se considerar o fato de que em cada caso a curva e o tamanho da imagem são mantidos. Isso implica que as variáveis $p$ (perímetro da curva) e $r$ (resolução da imagem) foram mantidas constantes. Então faremos uma análise considerando apenas a variação do número de processadores $(n)$.

\subsubsection{Memória Compartilhada}
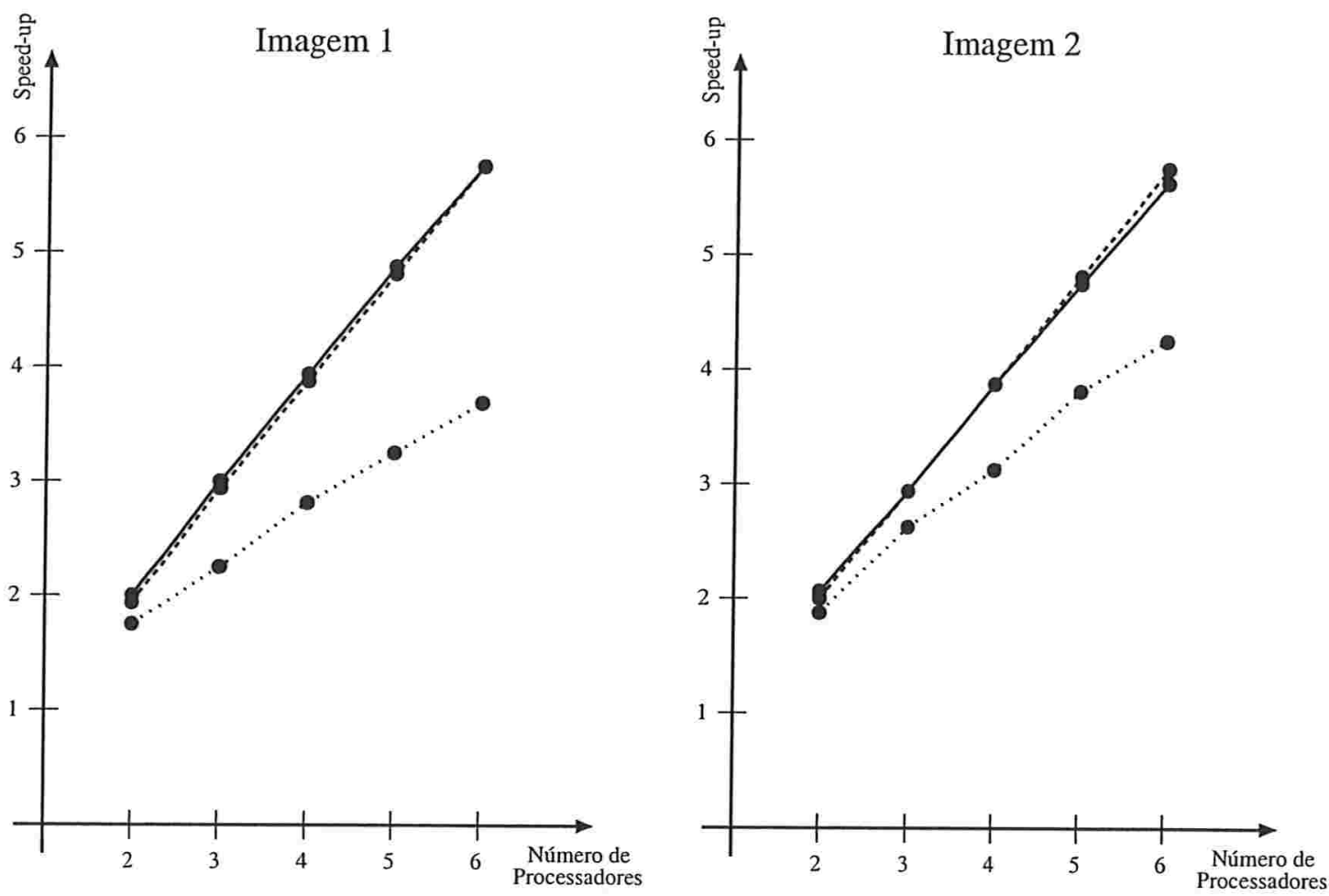

$$
\begin{aligned}
& \text {... Quadrático } \\
& \text {... Coerência com Quadtrees } \\
& \text { - Coerência Maximal }
\end{aligned}
$$

Figura 6.11: Speed-ups para os algoritmos paralelos de preenchimento utilizando memória compartilhada

Analisando os gráficos dos tempos de execução, podemos facilmente perceber que, para um número baixo de processadores, os tempos de execução dos algoritmos que utilizam 
coerência com quadtrees e coerência maximal são semelhantes. Também percebemos que, apesar de o algoritmo quadrático apresentar tempos de execução muito maiores do que os outros dois, essa diferença tende a diminuir conforme o número de processadores utilizados aumenta.

Por outro lado, analisando os gráficos dos speed-ups, podemos notar que o algoritmo quadrático e o que utiliza coerência maximal têm speed-ups semelhantes, com speed-up $(n)$ muito próximo de $n$, devido ao fato de não introduzirem nenhum overhead na execução em paralelo. Esse speed-up alto e aproximadamente linear indica que a execução do algoritmo para um número grande de processadores será muito eficiente, do mesmo modo que ocorre para um número baixo de processadores. Já o algoritmo que utiliza coerência com quadtrees apresenta um speed-up menor, devido ao alto overhead apresentado na execução em paralelo.

As duas análises combinadas levam à conclusão de que o algoritmo de preenchimento que utiliza coerência maximal é o mais na execução seqüencial e também na execução em paralelo, tanto para um número baixo quanto para números maiores de processadores, devido ao baixo tempo de execução obtido e ao alto speed-up apresentado.

\subsubsection{Memória Distribuída}

Uma análise dos gráficos dos tempos de execução mostra que, para um número baixo de processadores, o algoritmo que utiliza coerência com quadtrees é mais rápido do que o que utiliza coerência maximal, apesar de ocorrer o inverso na execução seqüencial. O algoritmo quadrático apresenta tempos de execução muito maiores do que os outros dois, sendo que essa diferença tende a diminuir conforme o número de processadores utilizados aumenta.

Analisando os gráficos dos speed-ups, podemos notar que o algoritmo quadrático é o único que apresenta speed-up $(n)$ próximo de $n$. O algoritmo que utiliza coerência maximal tem o pior speed-up, apesar de apresentar overhead com complexidade igual ao do algoritmo quadrático. Isso ocorre porque, apesar da complexidade do teste da limitação da propagação da cor interior ter complexidade igual à do preenchimento, o tempo gasto no teste da limitação é muito maior, o que faz com que a constante da análise assintótica da complexidade seja maior.

A combinação das análises leva à conclusão de que na execução seqüencial o algoritmo de coerência maximal é o mais rápido, na execução em paralelo utilizando um número baixo de processadores o algoritmo de coerência com quadtrees é o mais rápido e na execução em paralelo utilizando um número alto de processadores o algoritmo quadrático é teoricamente o mais rápido, devido ao alto speed-up apresentado. 

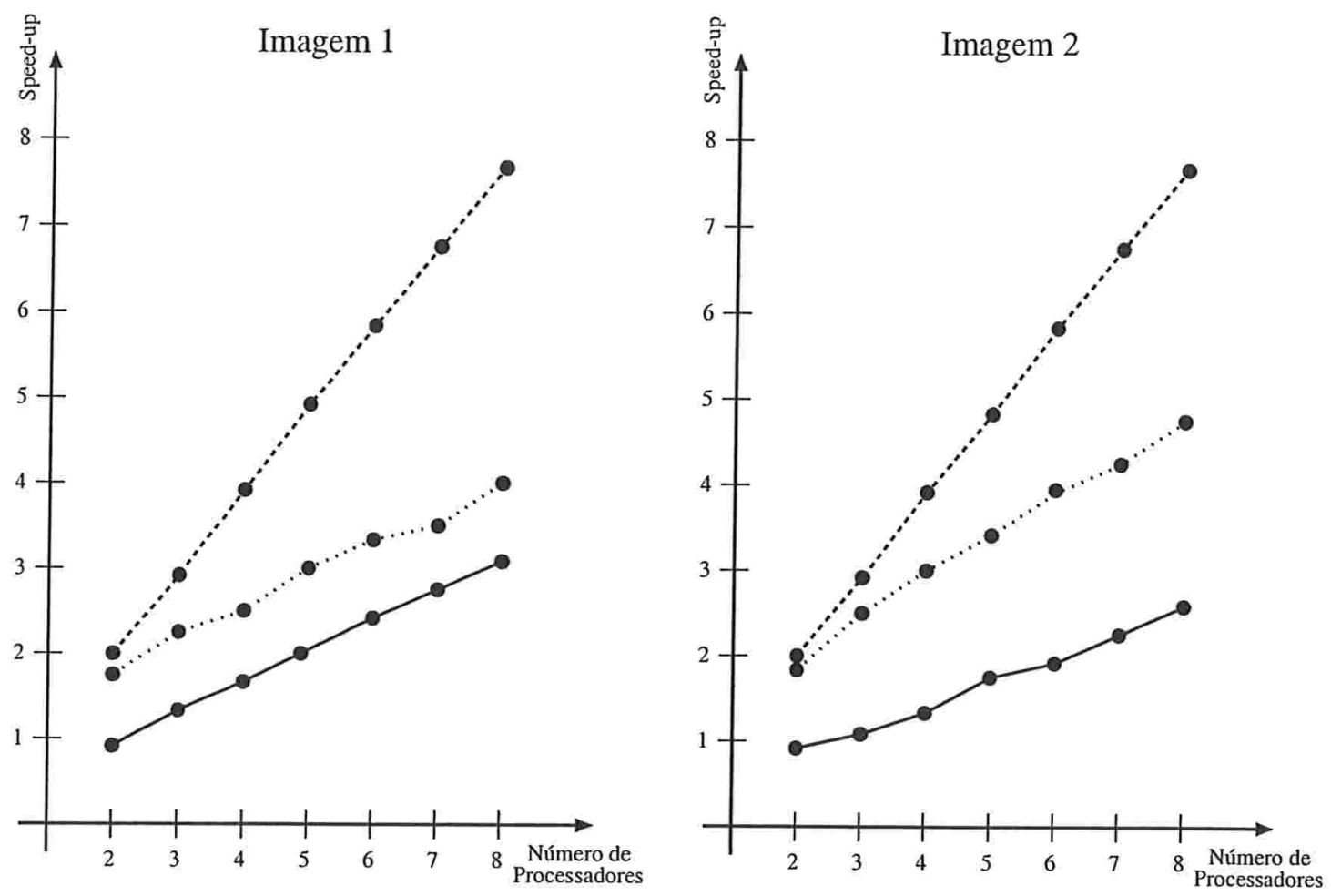

-.. Quadrático

.... Coerência com Quadtrees

- Coerência Maximal

Figura 6.12: Speed-ups para os algoritmos paralelos de preenchimento utilizando memória distribuída

\subsubsection{Tabela Comparativa}

\begin{tabular}{|c|c|c|}
\hline Número de & Algoritmo mais rápido & Algoritmo mais rápido \\
Processadores & Memória Compartilhada & Memória Distribuída \\
\hline Seqüencial & Coerência Maximal & Coerência Maximal \\
Baixo & Coerência Maximal & Coerência com Quadtrees \\
Alto & Coerência Maximal & Quadrático \\
\hline
\end{tabular}

Tabela 6.3: Comparação prática entre os algoritmos de preenchimento paralelos 


\section{Capítulo 7}

\section{Traçado de Linhas em Paralelo}

Nesta seção serão estudadas algumas formas de paralelizar os algoritmos vistos para o traçado de linhas. Alguns detalhes que já foram mencionados no capítulo anterior serão omitidos aqui, devido à semelhança da paralelização e execução entre os algoritmos paralelos de preenchimento e stroking.

\subsection{Versão Quadrática}

Como o que ocorre com o preenchimento de regiões, a paralelização desse algoritmo é trivial. Como a computação de cada ponto da imagem é independente dos demais, podemos dividir a imagem igualmente entre os processadores. Veja exemplo na Figura 7.1.

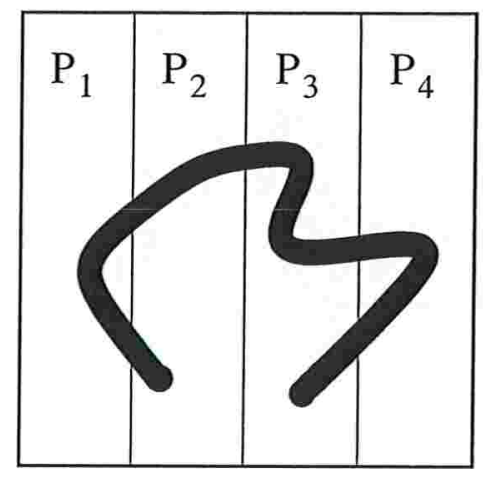

Figura 7.1: Divisão de uma imagem entre quatro processadores 


\subsubsection{Memória Compartilhada}

Cada processador deve produzir a sua parte da imagem, sem se preocupar com os demais, pois as áreas atribuídas a cada processador são disjuntas.

\begin{tabular}{|l|}
\hline Algoritmo Stroking Quadrático Paralelo - Memória Compartilhada: \\
\hline Entrada: imagem I, curva C, brush B, int numProcs \\
Saída: imagem I \\
\hline // executa algoritmo \\
execute stroking quadratico no pedaço da imagem do processador \\
// retorna resultado \\
retorne I \\
\hline
\end{tabular}

\subsubsection{Memória Distribuída}

Inicialmente o processador mestre deve enviar uma cópia da curva e da brush a cada processador. Então cada um executará o algoritmo no seu trecho da imagem e retornará o resultado ao processador mestre.

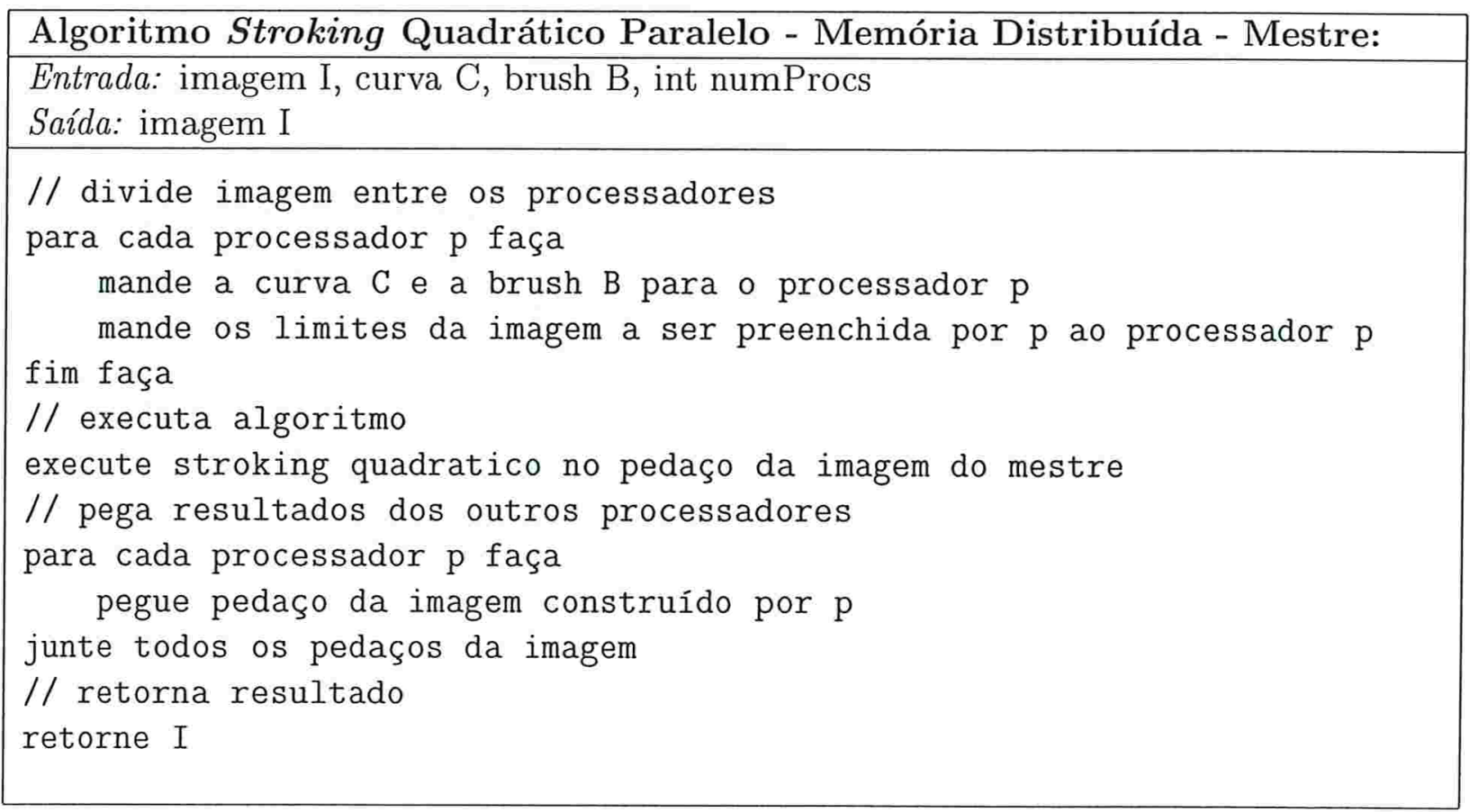




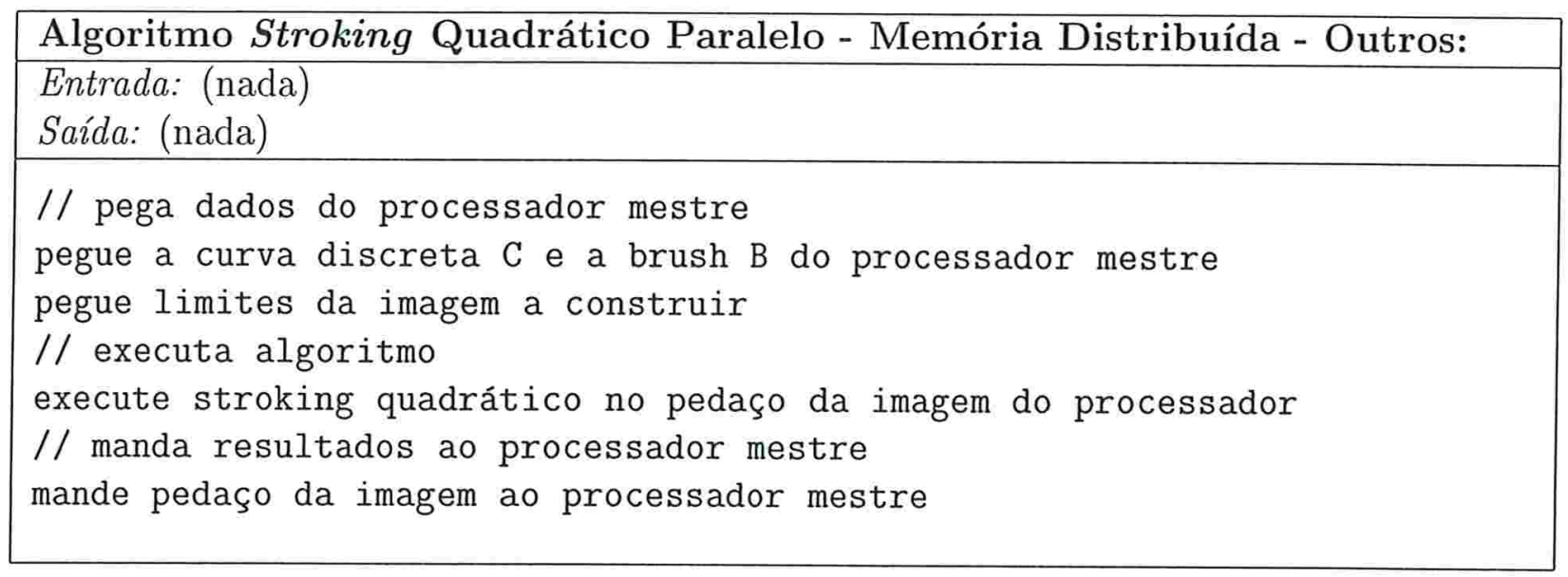

\subsection{Coerência com Quadtrees}

A paralelização desse algoritmo é idêntica à paralelização do algoritmo de preenchimento utilizando coerência com quadtrees. Deve-se utilizar um balanceamento dinâmico, transferindo trabalho de um processador a outro quando algum acabar antes dos outros (Figura 7.2) e deve-se utilizar uma pilha híbrida para implementar a recursão do algoritmo.

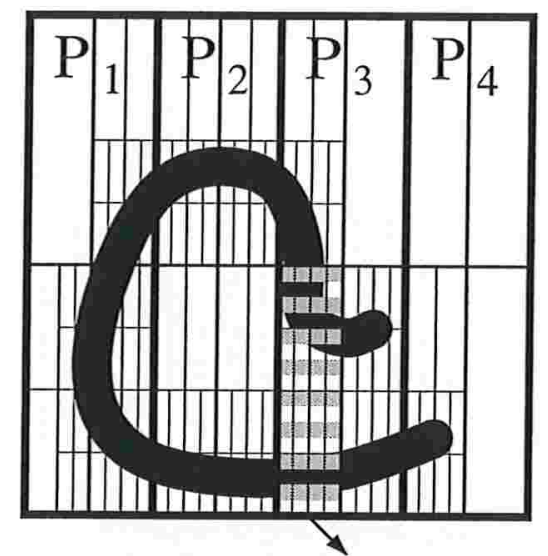

Transferido de $\mathrm{P}_{3}$ para $\mathrm{P}_{4}$

Figura 7.2: Divisão de uma imagem entre quatro processadores com transferência de trabalho 


\subsubsection{Memória Compartilhada}

Os pedaços de imagens atribuídos a cada processador são disjuntos. A transferência de trabalho é feita de modo que, quando um processador termina seu trabalho, consulta a pilha dos outros processadores e retira um elemento da base da pilha de algum, utilizando exclusão mútua para evitar acesso concorrente.

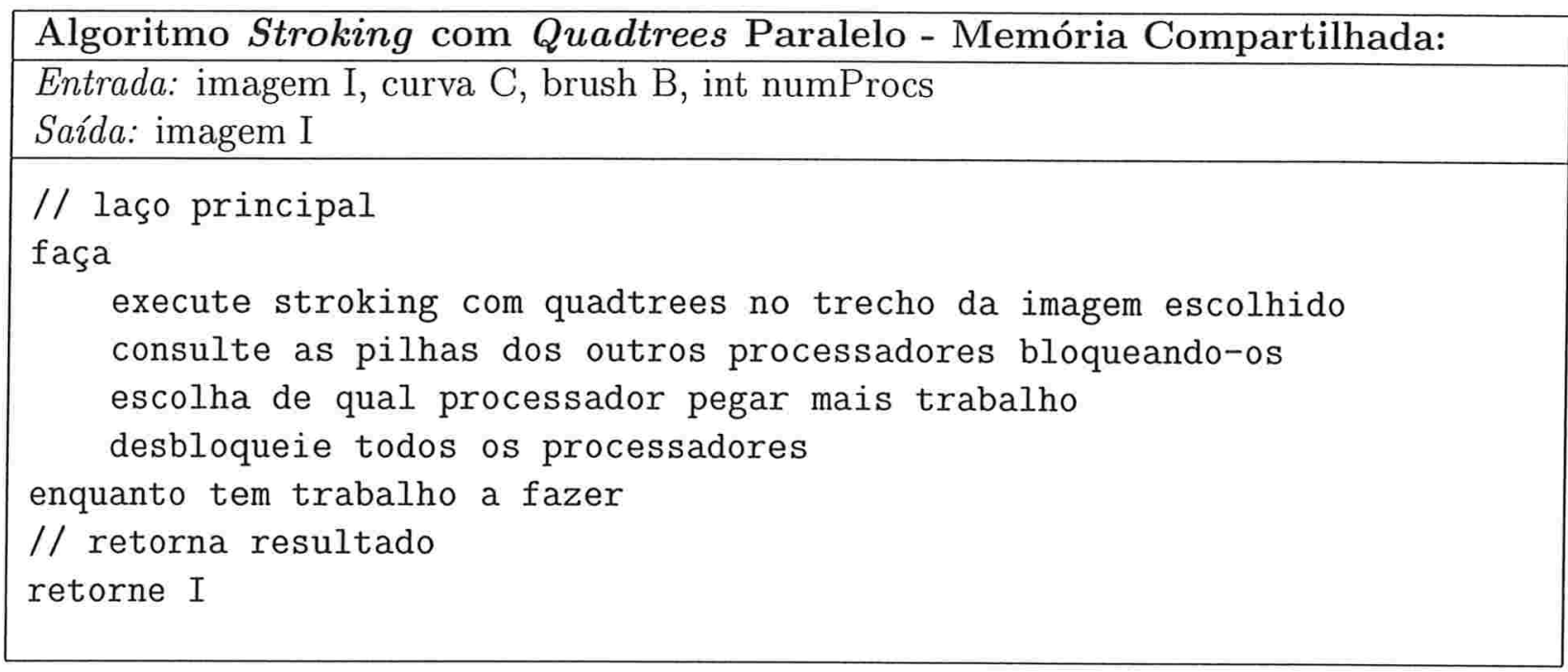

\subsubsection{Memória Distribuída}

A comunicação deve ser feita utilizando-se mensagens assíncronas, a fim de não prejudicar o trabalho de nenhum processador. Então um processador que quer contatar os outros pode esperar a resposta, mas os outros, que ainda estão trabalhando, podem checar se há mensagens pendentes apenas quando há a possibilidade de transferir dados. Se não há nenhum pedido, podem continuar trabalhando.

Quando um processador transfere trabalho para outro, deve limpar a área da imagem correspondente para que o processador mestre possa juntar as imagens de ambos utilizando uma combinação "ou". 

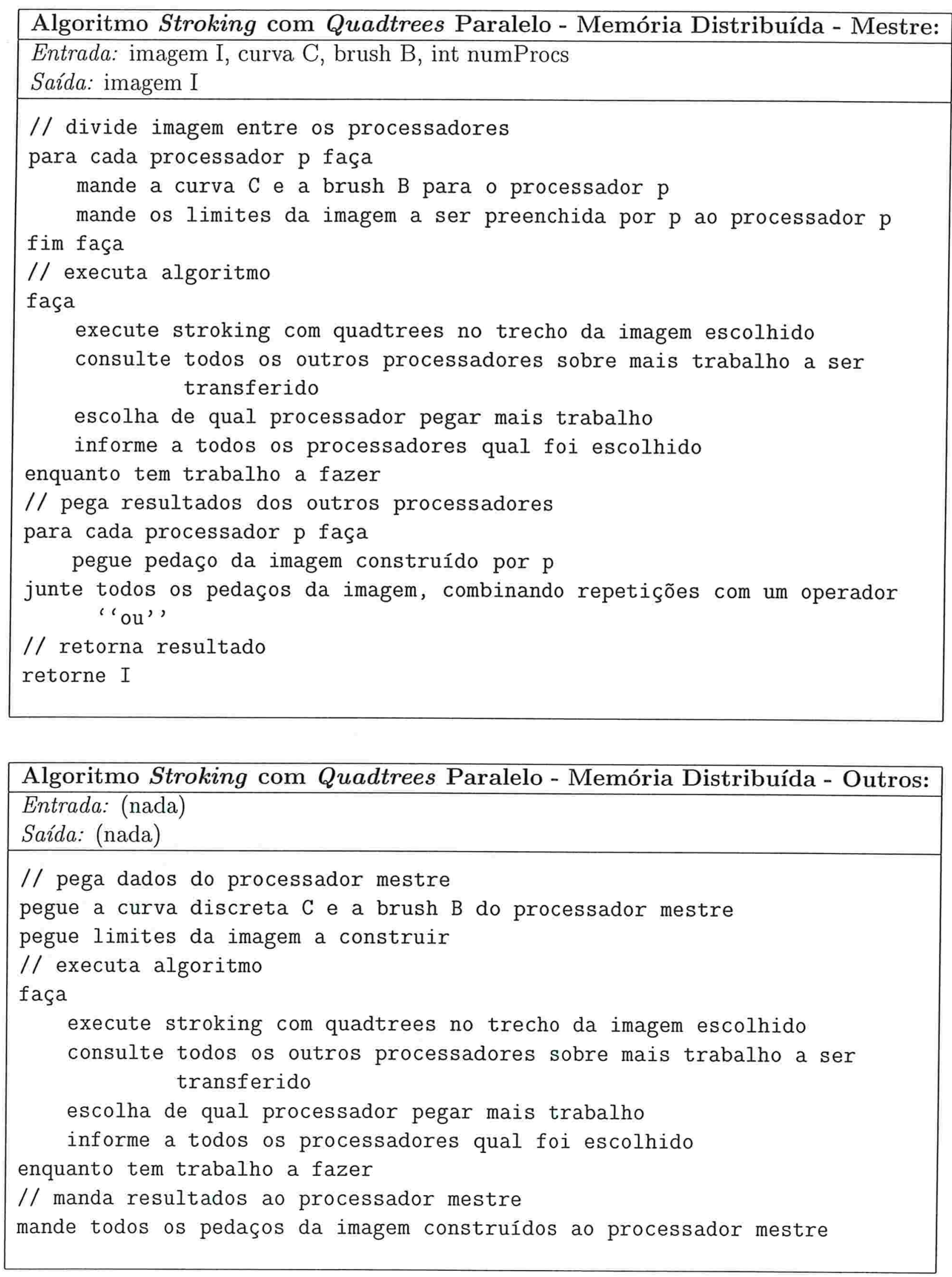


\subsection{Pi-Coerência}

Como o algoritmo de pi-coerência é baseado no deslocamento da brush sobre a curva, deve-se dividir a curva igualmente entre os processadores, como mostrado na Figura 7.3. Cada processador executará ambos os passos do algoritmo (cobertura e refinamento) apenas no trecho da curva correspondente. Para simplificar o algoritmo eles podem ser executados simultaneamente, ou seja, cada ponto da cobertura é testado (refinado) imediatamente. Deve-se notar que o procedimento inicial do algoritmo, que corresponde a marcar todos os pontos da bounding box da brush no ponto inicial, deve ser repetido para cada trecho da curva.

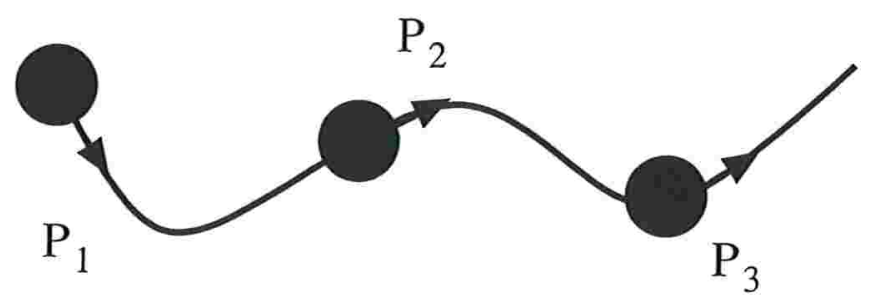

Figura 7.3: Traçado de uma linha em paralelo

\subsubsection{Memória Compartilhada}

A paralelização desse algoritmo utilizando memória compartilhada é trivial. Basta cada processador produzir a sua parte da curva independentemente dos outros. Eventuais sobreposições de curvas provenientes de processadores diferentes poderão ocorrer, mas isso não prejudica o funcionamento do algoritmo, nem requer a utilização de exclusão mútua, uma vez que a atribuição de cor à imagem é uma operação atômica.

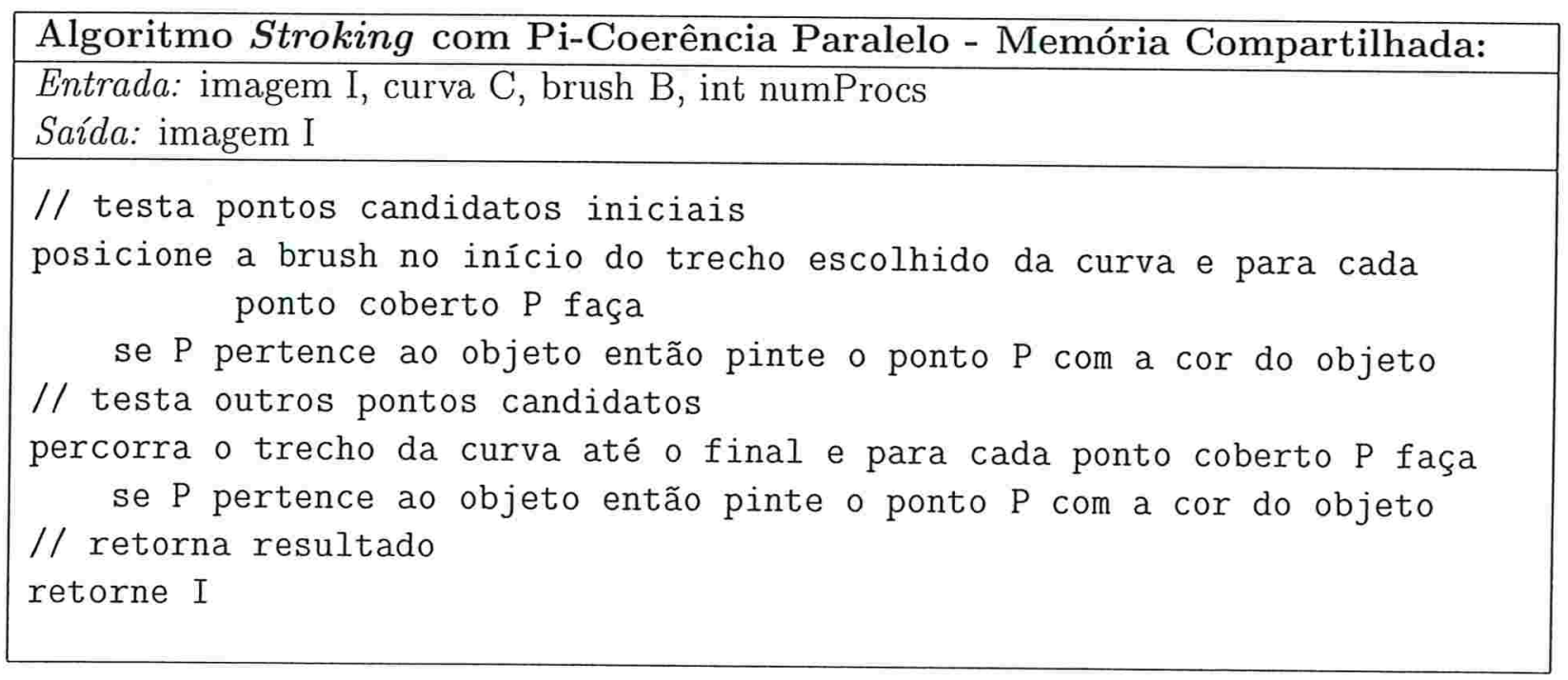




\subsubsection{Memória Distribuída}

Nesse caso cada processador produz a sua própria imagem, contendo apenas o trecho da curva correspondente e todas são combinadas no final, formando uma imagem única.

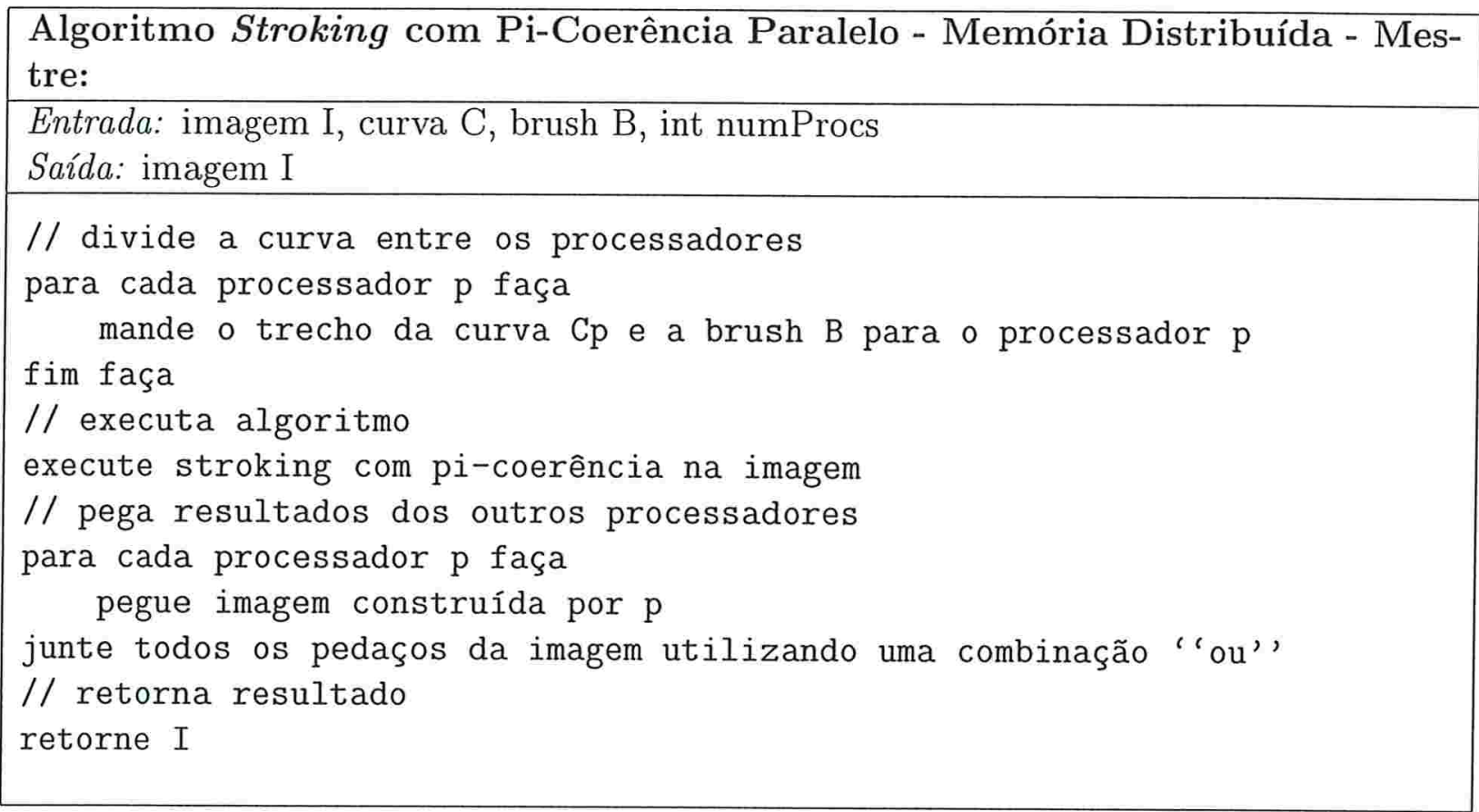

\begin{tabular}{|l|}
\hline Algoritmo Stroking com Pi-Coerência Paralelo - Memória Distribuída - Ou- \\
tros: \\
\hline Entrada: (nada) \\
Saída: (nada) \\
\hline // pega dados do processador mestre \\
pegue o trecho de curva discreta Cp do processador mestre \\
// executa algoritmo \\
execute stroking com pi-coerência na imagem \\
// manda resultados ao processador mestre \\
mande pedaço da imagem ao processador mestre
\end{tabular}




\subsection{Comparação Teórica entre os Algoritmos de Stro- king Paralelos}

A seguir faremos uma análise teórica dos overheads introduzidos em cada algoritmo de stroking paralelo.

\subsubsection{Memória Compartilhada}

Uma vez que os dados estão disponíveis para um dos processadores, eles estão disponíveis para todos os outros em uma máquina com memória compartilhada. Isso quer dizer que não há overhead resultante do envio e recebimento de dados referentes à entrada e saída entre os processadores.

No algoritmo que utiliza coerência com quadtrees há um overhead resultante da comunicação e transferência de trabalhos entre os processadores. Em cada uma das $\mathrm{O}(b \cdot(r+p))$ subdivisões da imagem, no máximo $n$ processadores podem se comunicar com os outros $n-1$ processadores em busca de mais trabalho, resultando em um overhead $\mathrm{O}\left(b \cdot(r+p) \cdot n^{2}\right)$.

\subsubsection{Memória Distribuída}

O envio da curva aos processadores causa um overhead linearmente dependente do número de processadores, do perímetro da curva e do perímetro da brush $\left(\mathrm{O}\left(n \cdot\left(p+p_{B}\right)\right)\right)$. No caso do algoritmo que utiliza pi-coerência a curva é dividida entre os processadores. Portanto nesse caso o overhead abaixa para $\mathrm{O}\left(p+n \cdot p_{B}\right)$.

O algoritmo de coerência com quadtrees introduz um overhead igual ao do algoritmo utilizando memória compartilhada $\left(\mathrm{O}\left(n^{2} \cdot b \cdot(r+p)\right)\right)$.

O envio dos pedaços da imagem construída ao processador mestre causa um overhead quadraticamente dependente da resolução da imagem, ou $\mathrm{O}\left(r^{2}\right)$. No caso do algoritmo que utiliza pi-coerência cada processador envia a imagem inteira. Portanto o overhead sobe para $\mathrm{O}\left(n \cdot r^{2}\right)$. 


\subsubsection{Tabela Comparativa}

\begin{tabular}{|c|c|c|}
\hline Algoritmo & $\begin{array}{l}\text { Overhead } \\
\text { Memória Compartilhada }\end{array}$ & $\begin{array}{c}\text { Overhead } \\
\text { Memória Distribuída }\end{array}$ \\
\hline Quadrático & 0 & $\mathrm{O}\left(n \cdot p+n \cdot p_{B}+r^{2}\right)$ \\
\hline Coerência com Quadtrees & $\mathrm{O}\left(n^{2} \cdot p \cdot b+n^{2} \cdot r \cdot b\right)$ & $\begin{array}{l}\mathrm{O}\left(n^{2} \cdot p \cdot b+n^{2} \cdot r \cdot b\right. \\
\left.\quad+n \cdot p_{B}+r^{2}\right)\end{array}$ \\
\hline Pi-Coerência & 0 & $\mathrm{O}\left(p+n \cdot p_{B}+n \cdot r^{2}\right)$ \\
\hline
\end{tabular}

Tabela 7.1: Comparação teórica entre os algoritmos de stroking paralelos

\subsubsection{Fixando a curva, a brush e o tamanho da imagem}

Se fixarmos os perímetros da curva $(p)$ e da brush $\left(p_{B}\right)$ e a resolução da imagem $(r)$ e variarmos apenas o número de processadores utilizados $(n)$, teremos as seguintes complexidades para os overheads dos algoritmos:

\begin{tabular}{|c|c|c|}
\hline Algoritmo & $\begin{array}{c}\text { Overhead } \\
\text { Memória Compartilhada }\end{array}$ & $\begin{array}{c}\text { Overhead } \\
\text { Memória Distribuída }\end{array}$ \\
\hline Quadrático & 0 & $\mathrm{O}(n)$ \\
\hline Coerência com Quadtrees & $\mathrm{O}\left(n^{2}\right)$ & $\mathrm{O}\left(n^{2}\right)$ \\
\hline Pi-Coerência & 0 & $\mathrm{O}(n)$ \\
\hline
\end{tabular}

Tabela 7.2: Comparação teórica entre os algoritmos de stroking paralelos fixando a curva, a brush e o tamanho da imagem 


\subsection{Resultados Práticos}

Foram utilizadas duas imagens teste para os algoritmos apresentados para stroking paralelo. A primeira é uma curva em forma de espiral (Figura 7.4), composta de 15 curvas de Bézier, com graus variando de 2 a 8, totalizando 68 pontos de controle e 3.276 pontos no total, dilatada por uma brush (Figura 7.5) composta de uma curva de Bézier fechada de grau 5 (6 pontos de controle), em forma de gota e 41 pontos no total. A imagem final está na Figura 7.6.

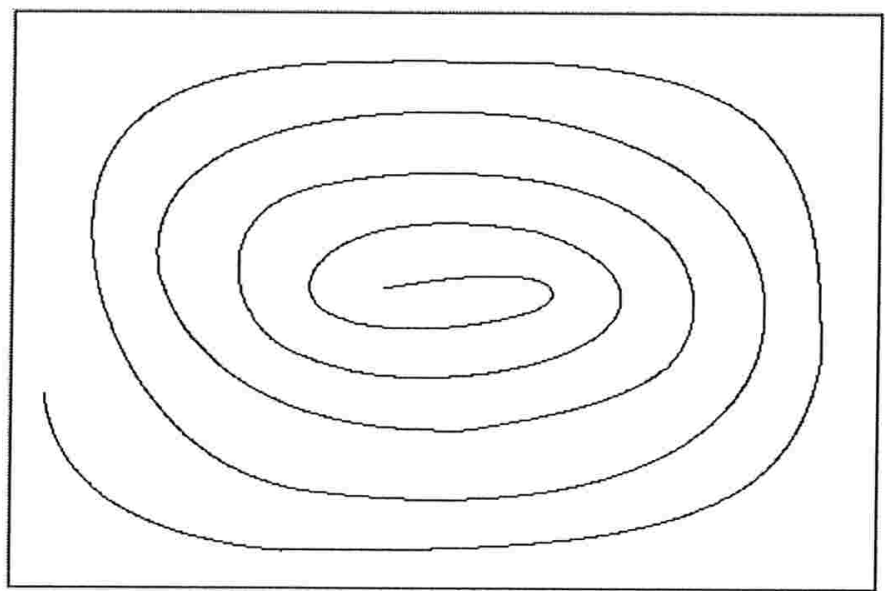

Figura 7.4: Curva da Imagem Teste 3

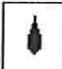

Figura 7.5: Brush da Imagem Teste 3

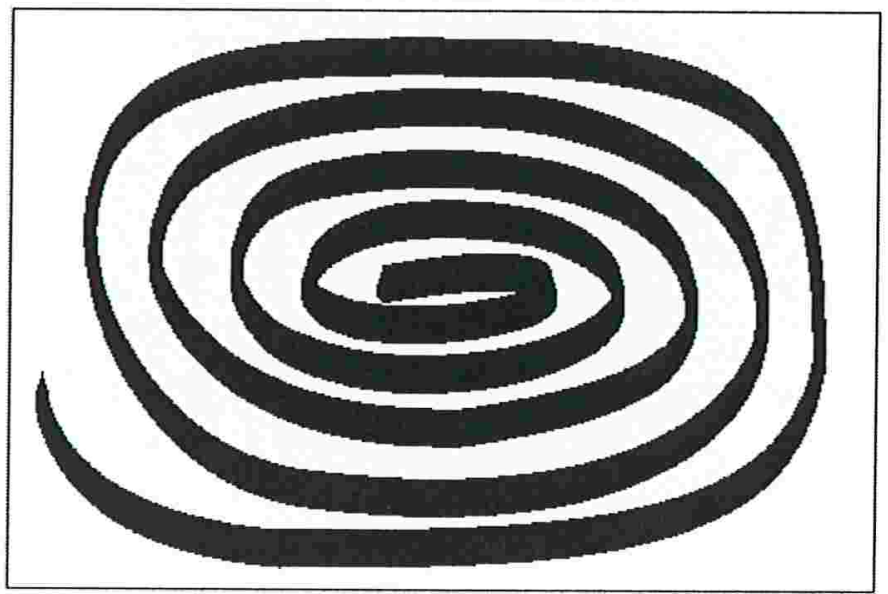

Figura 7.6: Imagem Teste 3 
Capítulo 7. Traçado de Linhas em Paralelo

69

A segunda imagem é uma curva em forma de texto (Figura 7.7), composta de 42 curva de Bézier, com graus variando de 1 a 5 , totalizando 181 pontos de controle e 4.324 pontos no total, dilatada por uma brush (Figura 7.8) composta de uma curva de Bézier fechada de grau 6 (7 pontos de controle), de forma aproximadamente circular e 15 pontos no total. A imagem final está na Figura 7.9.

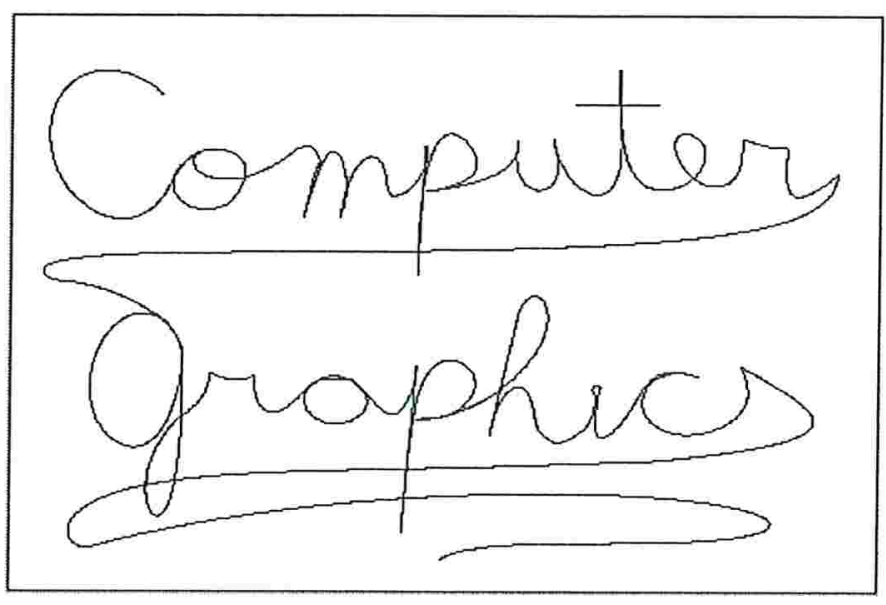

Figura 7.7: Curva da Imagem Teste 4

Figura 7.8: Brush da Imagem Teste 4

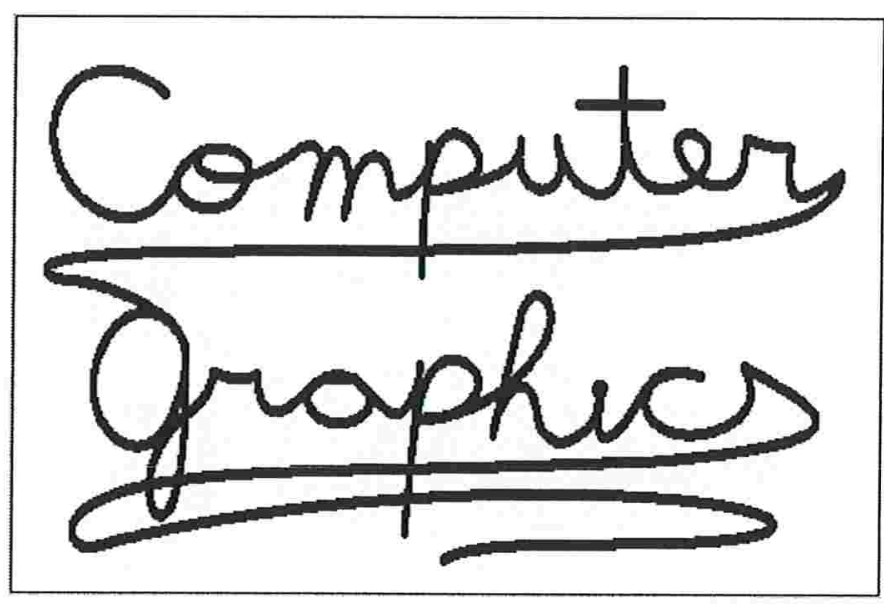

Figura 7.9: Imagem Teste 4 


\subsubsection{Memória Compartilhada}

Os algoritmos de stroking que utilizam memória compartilhada foram executados da mesma forma que os algoritmos de preenchimento, em uma máquina SUN com 6 processadores. Os tempos gastos na execução para as duas imagens teste estão apresentados na Figura 7.10.
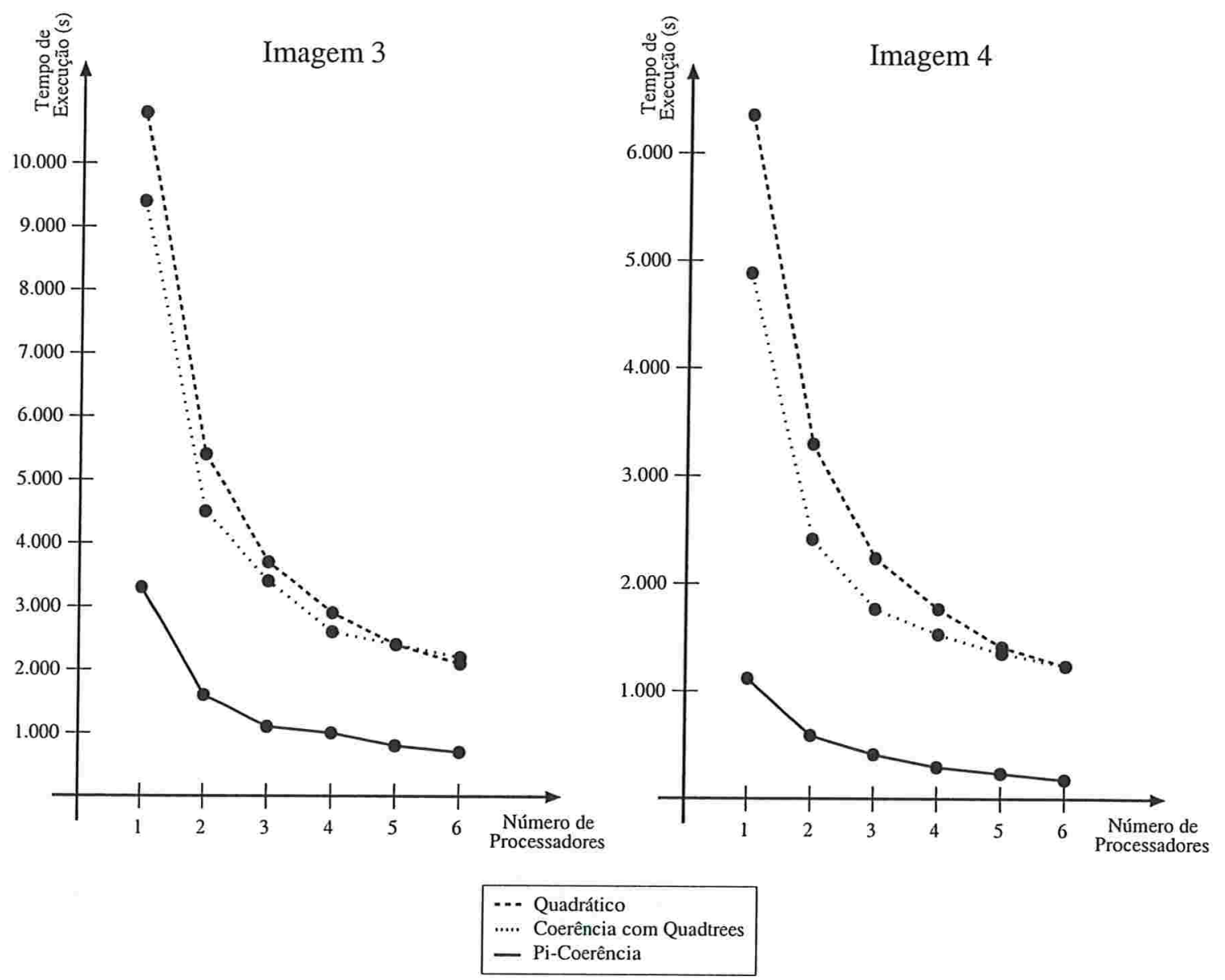

Figura 7.10: Tempo de execução para os algoritmos paralelos de stroking utilizando memória compartilhada 


\subsubsection{Memória Distribuída}

Os algoritmos de stroking que utilizam memória distribuída foram executados da mesma forma que os algoritmos de preenchimento, em uma máquina Parsytec PowerXplorer com 8 processadores. Os tempos gastos na execução para as duas imagens teste estão apresentados na Figura 7.11.
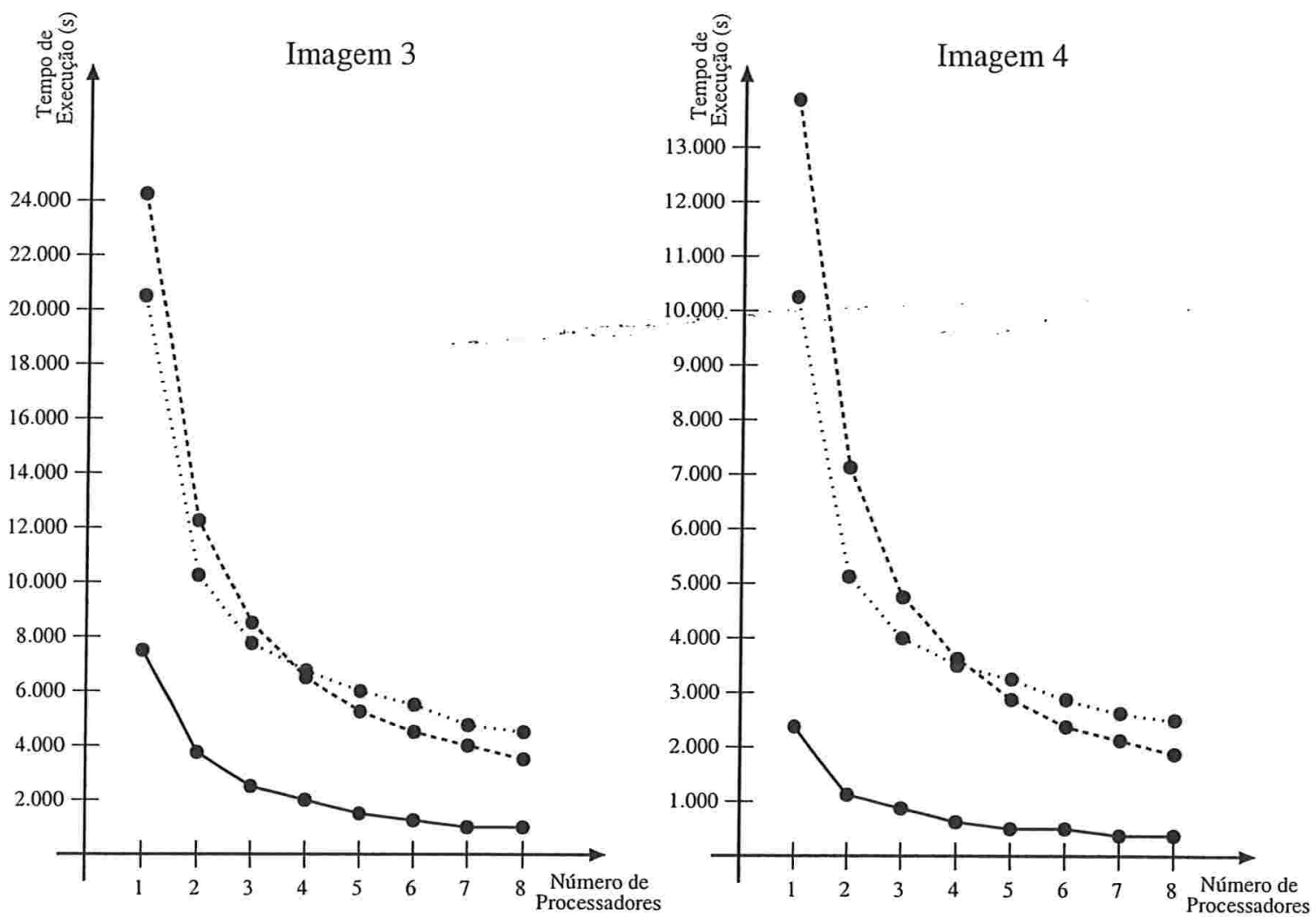

\section{-..- Quadrático}

.... Coerência com Quadtrees

- Pi-Coerência

Figura 7.11: Tempo de execução para os algoritmos paralelos de stroking utilizando memória distribuída 


\subsection{Análise dos Dados}

Com base nos tempos obtidos na execução dos algoritmos seqüenciais e paralelos foram gerados os gráficos dos speed-ups (Figuras 7.12 e 7.13).

\subsubsection{Memória Compartilhada}
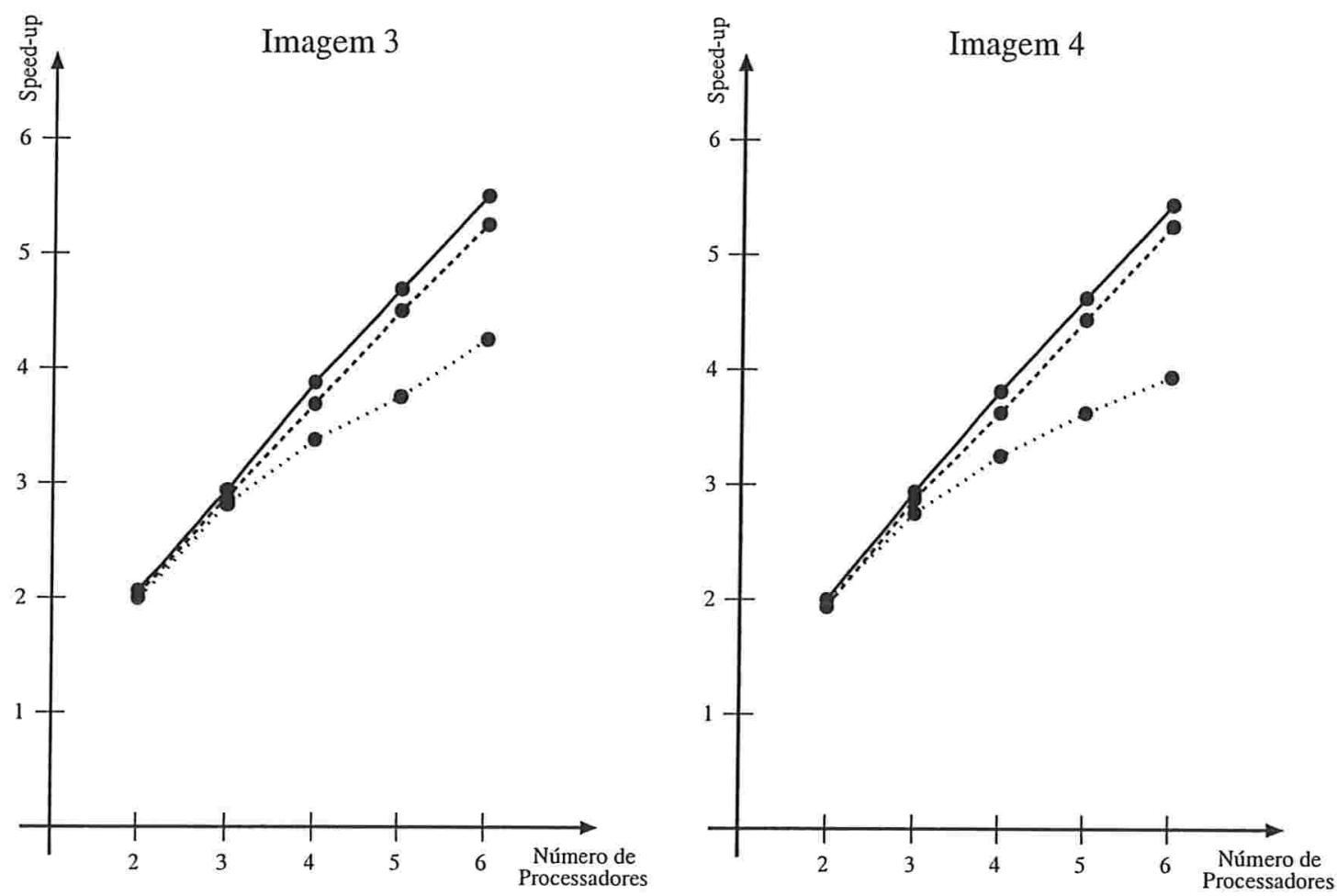

-.. Quadrático

… Coerência com Quadtrees

- Pi-Coerência

Figura 7.12: Speed-ups para os algoritmos paralelos de stroking utilizando memória compartilhada

Os gráficos dos tempos de execução mostram que o algoritmo que utiliza pi-coerência é o mais rápido de todos para todos os número de processadores testados. O algoritmo quadrático é mais lento para um número baixo de processadores mas há uma tendência indicando que para um número maior de processadores ele é mais rápido do que o algoritmo que utiliza coerência com quadtrees.

O gráfico dos speed-ups mostra que os speed-ups dos algoritmos quadrático e do que utiliza pi-coerência são semelhantes (devido aos overheads semelhantes), enquanto que o 
algoritmo que utiliza coerência com quadtrees apresenta speed-up consideravelmente menor.

Combinando as duas informações podemos chegar à conclusão de que o algoritmo que utiliza pi-coerência é o mais rápido tanto para números baixos quanto para números maiores de processadores, devido ao baixo tempo de execução obtido nos testes e ao alto speed-up apresentado.

\subsubsection{Memória Distribuída}
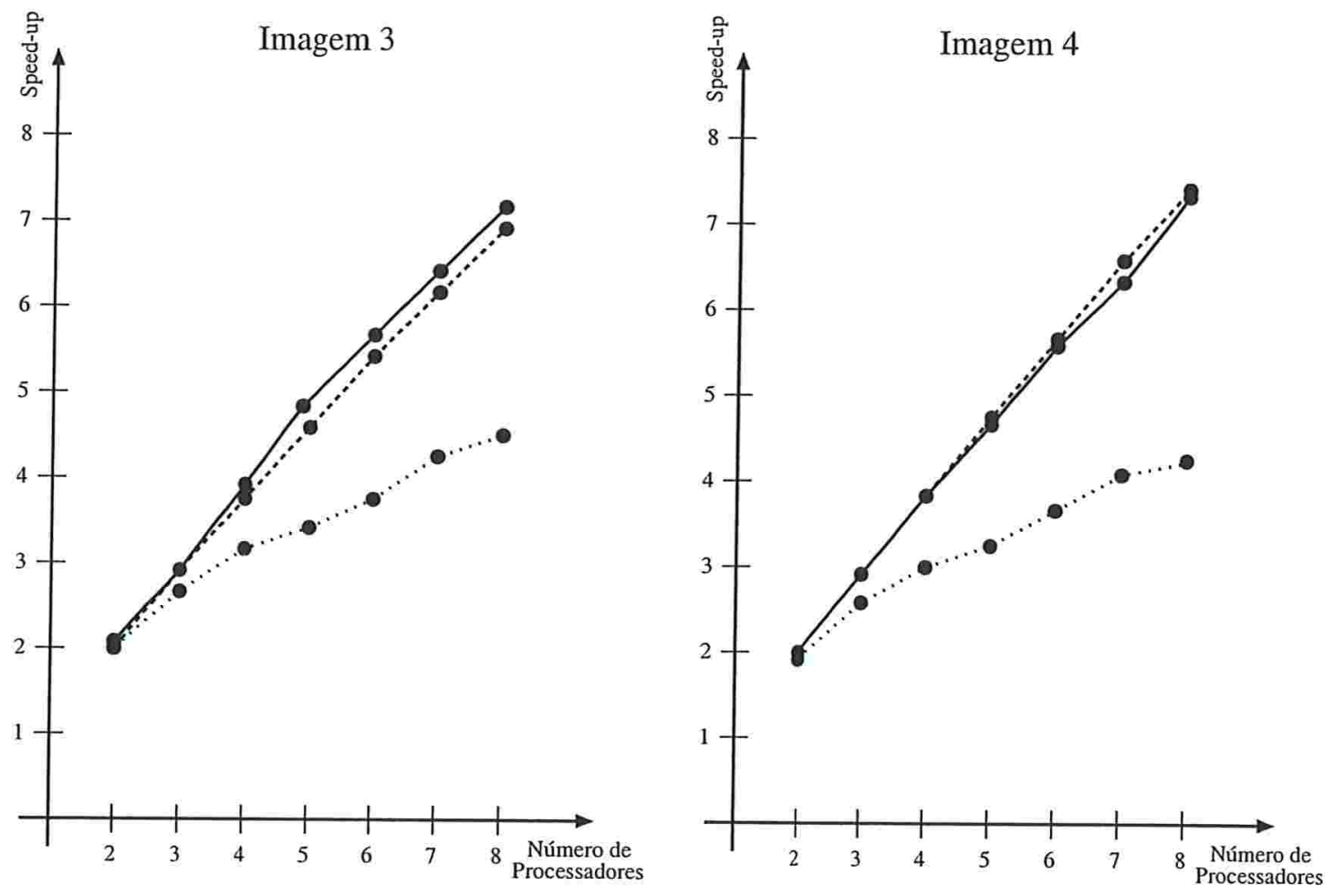

$$
\begin{aligned}
& \text {-..- Quadrático } \\
& \text { … } \text { Coerência com Quadtrees } \\
& \text { - Pi-Coerência }
\end{aligned}
$$

Figura 7.13: Speed-ups para os algoritmos paralelos de stroking utilizando memória distribuída

A análise dos gráficos dos tempos de execução mostra que o algoritmo que utiliza picoerência é o mais rápido de todos para todos os número de processadores testados. O algoritmo quadrático é mais lento para um número baixo de processadores mas para um número maior de processadores ele é mais rápido do que o algoritmo que utiliza coerência com quadtrees.

O gráfico dos speed-ups mostra que os speed-ups dos algoritmos quadrático e do que 
utiliza pi-coerência são semelhantes (devido aos overheads semelhantes), enquanto que o algoritmo que utiliza coerência com quadtrees apresenta um speed-up consideravelmente menor.

Combinando as duas informações podemos chegar à conclusão de que o algoritmo que utiliza pi-coerência é o mais rápido tanto para números baixos quanto para números maiores de processadores, devido ao baixo tempo de execução obtido nos testes e ao alto speed-up apresentado.

\subsubsection{Tabela Comparativa}

\begin{tabular}{|c|c|c|}
\hline $\begin{array}{c}\text { Número de } \\
\text { Processadores }\end{array}$ & $\begin{array}{c}\text { Algoritmo mais rápido } \\
\text { Memória Compartilhada }\end{array}$ & $\begin{array}{c}\text { Algoritmo mais rápido } \\
\text { Memória Distribuída }\end{array}$ \\
\hline Seqüencial & Pi-Coerência & Pi-Coerência \\
Baixo & Pi-Coerência & Pi-Coerência \\
Alto & Pi-Coerência & Pi-Coerência \\
\hline
\end{tabular}

Tabela 7.3: Comparação prática entre os algoritmos de stroking paralelos 


\section{Capítulo 8}

\section{Conclusões}

Neste texto foram propostos algoritmos paralelos para duas operações básicas em computação gráfica: preenchimento de regiões (filling) e traçado de linhas (stroking). Como base foram apresentadas três versões para cada operação: uma implementação trivial, com número de testes quadrático com relação à resolução da imagem, uma utilizando coerência com quadtrees [CorP92] e uma utilizando uma forma alternativa de coerência [FabSF97, FabSF98].

Foram propostas paralelizações tanto para máquinas de memória compartilhada quanto para máquinas de memória distribuída. Os algoritmos propostos foram implementados e executados para algumas imagens de teste a fim de se obterem dados reais para os tempos de execução, tanto para os algoritmos seqüenciais quanto para os algoritmos paralelos utilizando diferentes números de processadores.

Além da análise prática foram feitas também análises teóricas. Para os algoritmos seqüenciais foram feitas análises detalhadas das complexidades dos algoritmos. Para os algoritmos paralelos foram feitas análises das complexidades dos overheads, que são os tempos de execução introduzidos com a paralelização dos algoritmos.

Juntando as análises práticas e teóricas, foi feita uma previsão comparativa do tempo de execução dos algoritmos paralelos para números variáveis de processadores, não apenas para os verificados. 
As análises levaram a concluir que os seguintes algoritmos são os melhores em cada caso:

\begin{tabular}{|c|c|c|c|c|}
\hline $\begin{array}{c}\text { Número } \\
\text { de }\end{array}$ & $\begin{array}{c}\text { Filling } \\
\text { Memória } \\
\text { Processadores }\end{array}$ & $\begin{array}{c}\text { Filling } \\
\text { Memória } \\
\text { Compartilhada }\end{array}$ & $\begin{array}{c}\text { Stroking } \\
\text { Memória } \\
\text { Compartibuída }\end{array}$ & $\begin{array}{c}\text { Stroking } \\
\text { Memória } \\
\text { Distribuída }\end{array}$ \\
\hline Seqüencial & Coerência Maximal & Coerência Maximal & Pi-Coerência & Pi-Coerência \\
Baixo & Coerência Maximal & Coer. c/ Quadtrees & Pi-Coerência & Pi-Coerência \\
Alto & Coerência Maximal & Quadrático & Pi-Coerência & Pi-Coerência \\
\hline
\end{tabular}

Tabela 8.1: Comparação final entre todos os algoritmos descritos

Deve-se considerar a previsão para números muito grandes de processadores apenas ilustrativa. Apesar da análise teórica indicar os melhores algoritmos em cada caso, para garantir a execução eficiente deve ser feito um estudo mais específico dos algoritmos, dando maior peso aos processos de entrada e saída de dados e de comunicação entre os processadores. Mas com algumas pequenas modificações os algoritmos indicados certamente serão muito eficientes.

Como trabalhos futuros seguindo o que foi apresentado neste texto, podemos citar: em primeiro lugar, um sistema completo de renderização de curvas, como a linguagem PostScript, deve incluir a possibilidade de serem utilizadas técnicas de suavização da imagem (antialiasing), como o que foi apresentado por Fabris e Forrest em [FabF97a, FabF97b].

Em segundo lugar, pode-se investigar a possibilidade de generalização dos algoritmos para dimensões maiores, resultando em algoritmos genéricos eficientes e rápidos para análises multi-dimensionais.

Finalmente pode-se ainda estudar possíveis alterações em alguns algoritmos a fim de transformá-los em algoritmos sistólicos, mais indicados para execução com números muito grandes de processadores e implementação em chip. 


\section{Referências Bibliográficas}

[BleSM88] T. W. Bleser, J. L. Silvert e J. P. McGee. Charcoal sketching: returning control to the artist. ACM Transactions on Graphics, 7(1), 76-81, Janeiro de 1988.

[Bro96] F. P. Brooks. Springing into Fifth Decade of Computer Graphics - Where we've been and Where we're going! Em Computer Graphics, vol. 29 pág. 513, Agosto de 1996.

[CorJ87] M. E. A. Corthout e H. B. M. Jonkers. The transformational development of a new Point Containment algorithm. Philips Journal of Research, 41(2), 83-174, 1987.

[CorJ88] M. E. A. Corthout e H. B. M. Jonkers. A new Point Containment algorithm for B-Regions in the discrete plane. Em Theoretical Foundations of Computer Graphics and CAD, 279-306. Springer-Verlag, 1988.

[CorP89] M. E. A. Corthout e E. J. D. Pol. A Point Containment algorithm for regions in the discrete plane outlined by Rational Bézier curves. Em Proceedings of RIDT 89 Conference, 169-179, Lausanne, Switzerland, Outubro de 1989. Cambridge University Press.

[CorP92] M. E. A. Corthout e E. J. F. Pol. Point Containment and the Pharos Chip. Joint Ph.D Thesis, Leiden University, The Netherlands, 1992.

[CosT95] M. Cosnard e D. Trystram. Parallel algorithms and architetures. International Thompson Computer Press, 1995.

[EylesMP97] J. Eyles, S. Molnar, J. Poulton, T. Greer, A. Lastra e N. England. PixelFlow: The Realization. Proceedings of the Siggraph/Eurographics Workshop on Graphics Hardware. Los Angeles, CA. Agosto 3-4, 1997, 57-68.

[FabAF00] A. E. Fabris, M. M. O. Assis A. R. Forrest. Parallelization of Filling Algorithms on Distributed Memory Machines using the Point Containment Paradigm. Em SIBGRAPI 2000 Conference Proceedings, 235-242. IEEE Computer Society Press, 2000. 
[FabAF01] A. E. Fabris, M. M. O. Assis A. R. Forrest. An Efficient Parallel Algorithm for Stroking Discrete Polynomial Curves. A ser submetido.

[FabF97a] A. E. Fabris e A. R. Forrest. Antialiasing of Curves by Discrete Pre-Filtering. Computer Graphics. 31(3):317-326, Agosto de 1997.

[FabF97b] A. E. Fabris e A. R. Forrest. High Quality Rendering of Two-Dimensional Continuous Curves. Em SIBGRAPI 97 Conference Proceedings, pages 10-17. IEEE Computer Society Press, 1997.

[FabSF97] A. E. Fabris, L. Silva e A. R. Forrest. An efficient filling algorithm for nonsimple closed curves using the Point Containment paradigm. Em SIBGRAPI 97 Conference Proceedings, 2-9. IEEE Computer Society Press, 1997.

[FabSF98] A. E. Fabris, L. Silva e A. R. Forrest. Stroking discrete polynomial Bézier curves via Point Containment paradigm. Em SIBGRAPI 98 Conference Proceedings, 118-126. IEEE Computer Society Press, 1998.

[Far90] G. E. Farin. Curves and Sufaces for Computer Aided Geometric Design. Second Edition. Academic Press, 1990

[Fly72] M. J. Flynn. Some computer organizations and their effectivenes. IEEE Transactions on Computers. V. C-21, N. 9, 1972.

[Fol96] J. D. Foley et. al. Computer Graphics: Principles and Practice (second edition in C). Addison-Wesley Publishing Company, Reading, 1996.

[For85] A. R. Forrest. Computational Geometry in Practice. Em R. A. Earnshaw, editor, Fundamental Algorithms for Computer Graphics, 107-197. Springer-Verlag, 1985 .

[For88] A. R. Forrest. Geometric Computing environments: some tentative thoughts. Em Theoretical Foundations of Computer Graphics and CAD, 185-197. Springer-Verlag, 1988.

[Fra86] W. R. Franklin. Problems with raster graphics algorithms. Em L. R. A. Kessener, F. J. Peters e M. L. P. van Lierop, editors, Data Structures for Raster Graphics, 1-7. Springer-Verlag, 1986.

[GhoM84] P. K. Gosh e S. P. Mudur. The brush-trajectory approach to figure specification. ACM Transactions on Graphics, 3(2), 1-24, Abril de 1984.

[Green91] S. A. Green. Parallel processing for computer graphics. Cambridge, MIT Press, 1991.

[HunS79] G. M. Hunter e K. Steiglitz. Operations on images using quadtrees. IEEE Transactions on Pattern Analysis and Machine Intelligence, 145-153, 1979. 
[HwangB84] K. Hwang e F. Briggs. Computer Architecture and Parallel Processing. McGrawHill, 1984.

[KimK96] H. J. Kim e C. M. Kyung. A new parallel ray-tracing system based on object decomposition. The Visual Computer. Vol. 12. 244-253. Springer-Verlag, 1996.

[Kla91] R. V. Klassen. Drawing Antialiased Cubic Spline Curves. ACM Transactions on Graphics. 10(1):92-108, Janeiro de 1991.

[KNKNS88] H. Kobayashi, S. Nishimura, H. Kubota, T. Nagamura e Y. Shigei. Load balancing strategies for a parallel ray-tracing system based on a constant subdivision. The Visual Computer. Vol. 4. 197-209. Springer-Verlag, 1998.

[Knu86] D. E. Knuth. The METAFONT book. Addison-Wesley, Reading, MA, 1986.

[KGGK94] V. Kumar, A. Grama, A. Gupta e G. Karypis. Introduction to parallel computing: design and analysis of algorithms. The Benjamin/Cummings Publishing Company, Inc, 1994.

[Lien87] S.-L. Lien, M. Shantz e V. R. Pratt. Adaptive Forward Differencing for Rendering Curves and Surfaces. Computer Graphics. 21(3):111-118, July 1987.

[MolEP92] S. Molnar, J. Eyles e J. Poulton. PixelFlow: High-Speed Rendering Using Image Composition. Computer Graphics 26(2):231-240, Julho de 1992.

[NewS79] R. V. Newman e W. Sproull. Principles of Interactive Computer Graphics. Springer-Verlag, New York, second edition, 1979

[NotG97] I. Notkim e C. Gotsman. Parallel Progressive Ray-Tracing. Computer Graphics Forum. Vol. 16, N. 1, 43-55. 1997.

[San94] E. T. Santos Avaliação do Algoritmo de "Ray Tracing"em Multicomputadores. Dissertação de Mestrado. Escola Politécnica da USP. 1994.

[Sil98] L. Silva. Algoritmos Geométricos Discretos: Complexidade e Aplicações. Dissertação de Mestrado. Instituto de Matemática e Estatística da USP. 1998.

[Whi83] T. Whitted. Anti-aliased line drawing using brush extrusion. ACM Computer Graphics (SIGGRAPH'83 Proceedings), 31(2), 151-156, 1983. 